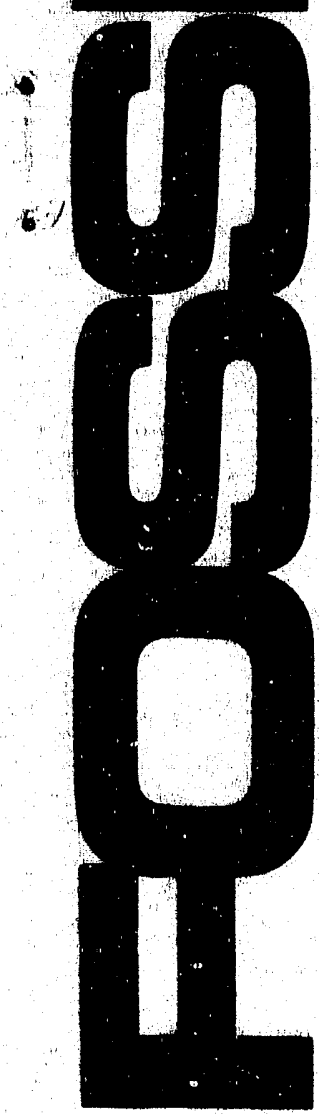

Low Cost Hydrogen/Novel Membrane Technology for Hydrogen Separation From Synthesis Gas

Final Report

R.W. Baker

C-M. Bell

P. Chow

J. Lonie

J.M. Mohr

K-V. Peinemana

1. Pinnau

J.G. Wijmans

D.E. Gottschlich

DL. Roberts

October 1990

Work Performed Under Contract No.: DE-AC21-85MC22130

For

U.S. Depertment of Energy

Office of Fossil Energy

Morgantown Energy Tectunology Center

Morgantown, West Virginia

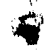

By

Membrane Technology and Research, Inc.

Menlo Park, California

and

SRI International

Menlo Park, California 


\section{DISCLAIMER}

This repon wes prepered es en cocount of wort sponsored by an enancy of the United Sentes Government. Neither the United States Governabent aor any sency thereof, nor any of their

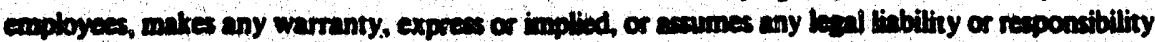

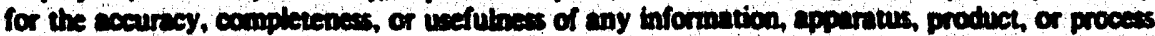
discloed, or represents that its use would not infirinse privately owned rithes. Reterence herein to any specific commercial product, process. or service by trade nane, tredemark, manufecturer, or

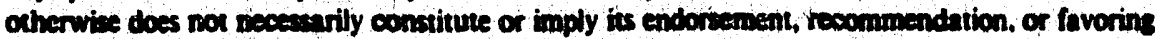
by the United Saces Covernment or any eqency thereof. The views and opinions of authors expresed berein do sot necescurily state of reflect those of the United States Government of any enency thereof.

This report has been reproduced directly from the best available copy.

$$
\therefore \cdots: \because
$$

Available to DOE and DOE contractors from the Orice of Scientific and Technical Information, P.O. Box 62, Oak Ridre, TN 37831; prices available from (615)576-8401, FTS 626-8401.

Available to the public from the National Technical Information Service, U.S. Department of Commerce, 5285 Port Royal Rd., Sprinefield, VA 22161. 


\title{
Low Cost Hydrogen/Novel Membrane Technology for Hydrogen Separation From Synthesis Gas
}

Final Report

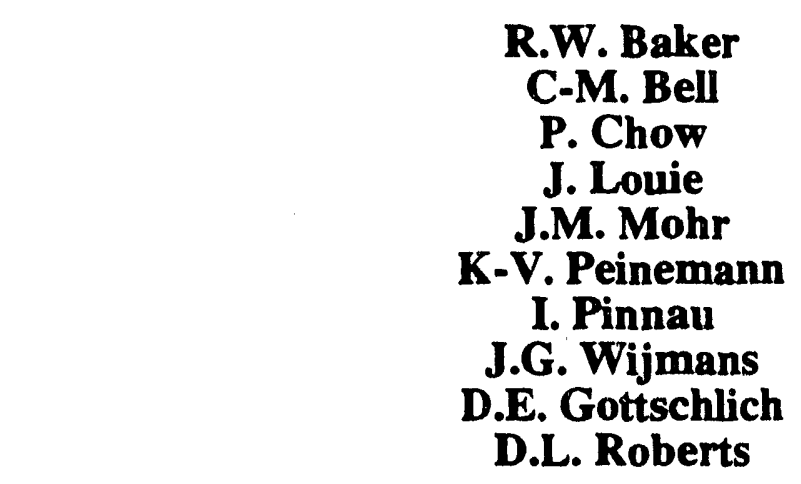

Work Performed Under Contract No.: DE-AC21-85MC22130

For

U.S. Department of Energy

Office of Fossil Energy

Morgantown Energy Technology Center

P.O. Box 880

Morgantown, West Virginia 26507-0880

\author{
By \\ Membrane Technology and Research, Inc. \\ 1360 Willow Road \\ Menlo Park, California 94025 \\ and \\ SRI International \\ 333 Ravenswood Avenue \\ Menlo Park, California 94025
}

October 1990 
I. EXECUTIVE SUMMARY ....................1

II. SIGNIFICANCE OF THE PROBLEM ................ 4

III. COAL GASIFICATION................... 4

A. Introduction and Overview ................ . 4

B. The Texaco Coal Gasification Process . . . . . . . . . . . . . 8

C. Synthesis Gas Purification by Conventional Processes . . . . . . . 11

IV. MEMBRANE GAS SEPARATION ................ 14

A. Membrane Theory ................. . 14

B. Membrane Modules and Systems. . . . . . . . . . . . . 16

V. MEMBRANE GAS SEPARATION OPPORTUNITIES IN SYNTHESIS

GAS PURIFICATION . . . . . . . . . . . . . . . . . . . . . 19

A. Final Separation . . . . . . . . . . . . . . . . . . 19

B. AGR Cost Reduction . . . . . . . . . . . . . . . . . 22

C. Shift Converter Cost Reduction . . . . . . . . . . . . . 22

VI. MEMBRANE DEVELOPMENT AND TESTING . . . . . . . . . . 23

A. Introduction and Overview . . . . . . . . . . . . . . 23

B. Selection of Permselective Polymer Materials . . . . . . . . . . . 23

C. Polyetherimide Membranes . . . . . . . . . . . . . . . . . 24

D. Polyamide Copolymer Membranes . . . . . . . . . . . . . . 36

E. Palladium Membranes . . . . . . . . . . . . . . . . . . . 39

F. Summary of Membrane Properties . . . . . . . . . . . . . . . . 46

VII. MODULE DEVELOPMENT AND TESTING . . . . . . . . . . . . 47

A. Introduction and Overview . . . . . . . . . . . . . . . 47

B. Polyetherimide Membrane Modules . . . . . . . . . . . . . . 48

C. Polyamide Copolymer Membrane Modules . . . . . . . . . . . . 50

D. Membrane Properties Used in Economic Evaluation . . . . . . . 66

VIII. MATHEMATICAL MODELING OF MEMBR.ANE GAS SEPARATION SYSTEMS ...................... 68

A. Mathematical Model . . . . . . . . . . . . . . . . 70

B. Comparison of Model and Experimental Results . . . . . . . . . 70

C. The Effect of Pressure Ratio on Membrane System Periormance . . 73

D. Effect of System Configuration on Membrane System Performance . 76

E. Example of Membrane Systcm Analysis . . . . . . . . . . . . . 78 
IX. ECONOMIC EVALUATION OF MEMBRANE GAS SEPARATION SYSTEMS FOR THE SEPARATION OF HYDROGEN FROM SYNTHESIS GAS ..................... 86

A. Introduction and Overview . . . . . . . . . . . . . . . 86

B. Procedure for Economic Evaluations . . . . . . . . . . . . . 87

C. Base Case Calculations . . . . . . . . . . . . . . . . . . . 92

D. Final Separation of Hydrogen from Nitrogen . . . . . . . . . 92

E. Acid Gas Removal Cost Reduction . . . . . . . . . . . . . . . . 100

F. Shift Reactor Cost Reduction . . . . . . . . . . . . . . 109

G. Summary of Economic Analysis . . . . . . . . . . . . 115

H. Production of Low-Purity Hydrogen . . . . . . . . . . 115

X. ALTERNATIVE SEPARATION TECHNIQUES . . . . . . . . . . 121

A. Introduction .................... . 121

B. Description of Pressure-Swing Adsorption . . . . . . . . . . . . 122

C. Economic Evaluation of Pressure-Swing Adsorption . . . . . . . . 124

REFERENCES . . . . . . . . . . . . . . . . . . . 126 


\section{List of Eigures}

Figure 1. Distribution of the $3.9 \times 10^{12} \mathrm{scf}$ of hydrogen produced

and consumed in the U.S. in 1981.. . . . . . . . . . . 5

Figure 2. Flow diagram of the Texaco coal gasification process . . . . 10

Figure 3. Approximate composition of the gas stream after each step of a coal gasification process. . . . . . . . . . . . . 12

Figure 4. Schematic diagrams of a spiral-wound and a hollow-

fiber membrane module. . . . . . . . . . . . . . . 18

Figure 5. Flow diagrams of four different membrane system

configurations ................. 20

Figure 6. Flow diagram of a coal gasifier indicating potential positions for membrane gas separation systems . . . . . . . 21

Figure 7. Cross-sectional representations of an asymmetric membrane and a multilayer composite membrane . . . . . . . 25

Figure 8. High-pressure permeability test system for pure gases and gas mixtures. . . . . . . . . . . . . . . . . 29

Figure 9. Normalized fluxes of asymmetric polyetherimide membranes with a silicone rubber sealing layer as a function of feed pressure. . . . . . . . . . . . . . . . 30

Figure 10. Selectivities of asymmetric polyetherimide membranes with a silicone rubber sealing layer as a function of feed pressure. Temperature: $25^{\circ} \mathrm{C}$. . . . . . . . . . . 31

Figure 11. Normalized fluxes of asymmetric polyetherimide membranes with a silicone rubber sealing layer as a function of feed temperature. Feed pressure: 50 psig. . . . . . . . . .

Figure 12a. Hydrogen/nitrogen selectivity of asymmetric polyetherimide membranes with a silicone rubber sealing layer as a function of feed temperature.

Figure 12b. Hydrogen/carbon dioxide selectivity of asymmetric polyetherimide membranes with a silicone rubber sealing layer as a function of feed temperature. . . . . . . . . . 34

Figure 13. Hydrogen/nitrogen selectivity of asymmetric polyetherimide membranes with a silicone rubber sealing layer as a function of feed pressure . . . . . . . . . . . . . 35

Figure 14. Cross-section of polyamide copolymer composite membrane . . . 38 
Figure 15. Normalized fluxes of polyamide copolymer composite membrane as a function of feed pressure . . . . . . . . . . . 40

Figure 16. Selectivity of polyamide copolymer composite membranes as a function of feed pressure. . . . . . . . . . . . . 41

Figure 17. Carbon monoxide/hydrogen selectivity of polyamide copolymer composite membrane as a function of feed pressure. .

Figure 18. Normalized fluxes of polyamide copolymer composite membrane as a function of temperature. . . . . . . . . . . .

Figure 19. Pure gas selectivity of polyamide copolymer composite membranes as a function of temperature . . . . . . . . . . . . 44

Figure 20. Schematic drawing of a hollow-fiber membrane module . . . . . 49

Figure 21. A schematic drawing of a spiral-wound module . . . . . . 51

Figure 22. Temperature stability test of polyamide copolymer modules. . . . 54

Figure 23. Schematic drawings of a single module and a bimodule design. . . . . . . . . . . . . . . 56

Figure 24. Effective carbon dioxide/hydrogen selectivities of bimodule and single module designs . . . . . . . . . . . . . . 57

Figure 25. Process flow diagram of gas permeation system for module testing at elevated temperature and elevated pressure . . . . . 58

Figure 26. The effect of carbon dioxide feed gas concentration on carbon dioxide/hydrogen selectivity of a polyamide copolymer composite membrane module . . . . . . . . . . . 60

Figure 27. Schematic of now pattern in (a) crossflow membrane model and (b) countercurrent membrane module . . . . . . . . . 69

Figure 28. Effect of pressure ratio on the maximum permeate mole fraction with various selectivities. . . . . . . . . . 74

Figure 29. Effect of pressure ratio on the maximum permeate mole fraction with various feed purities. . . . . . . . . . 75

Figure 30. Single-stage module configurations for gas separation . . . . . . 77

Figure 31. Series configuration (SER) for gas separation . . . . . . . . . 79

Figure 32. A two-stage cascade configurations (CAS) for gas separations . . . . . . . . . . . . . 80

Figure 33. Processing cost as a function of product purity for four membrane system configurations . . . . . . . . . . 
Figure 34. Partial feed bypass scheme ... . . . . . . . . . . . 84

Figure 35. Processing costs for the four different configurations with partial feed bypass. . . . . . . . . . . . . 85

Figure 36. Flow diagram showing procedure for calculating hydrogen cost . . . . . . . . . . . . . . . . 88

Figure 37. Base Case (non-membrane) purification system (oxygenblown gasification) . . . . . . . . . . . . . .

Figure 38. Single-stage membrane systems for final separation of hydrogen from nitrogen with an air-blown gasifier.

(a) single-stage, (b) single-stage with recycle. . . . . . . . . 95

Figure 39. Two-stage membrane systems for final separation of hydrogen from nitrogen with an air-blown gasifier.

(a) series configuration, (b) cascade configuration . . . . . . . 97

Figure 40. Effect of gasifier feed oxygen content on hydrogen cost for both the series and cascade configurations used in the membrane system separating hydrogen and nitrogen (final separation). . . . . . . . . . . . . . . . 100

Figure 41. Single-step membrane systems for reduction of AGR costs with an oxygen-blown gasifier . . . . . . . . . . . 102

Figure 42. Effect of membrane selectivity and permeability on hydrogen cost for AGR/OX-SS(PEI) . . . . . . . . . . . . . 104

Figure 43. Membrane systems for reduction of AGR costs with an oxygenblown gasifier .................. 105

Figure 44. Membrane/AGR hybrid system (AGR/AIR-HYB) for reduction of AGR costs with an air-blown gasifier. . . . . . . . . 107

Figure 45. Membrane cascade systems for reduction of AGR costs with an air-blown gasifier ................ . 108

Figure 46. Membrane systems for reduction of shift reactor costs with an oxygen-blown gasifier ............ 110

Figure 47. Single-step membrane systems for reduction of shift reactor costs with an air-blown gasifier ........... . 113

Figure 48. Membrane systems employing two membrane materials for reduction of shift reactor costs with an air-blown gasifier ................... 114

Figure 49. Air-blown gasification system for production of low-purity hydrogen with nitrogen impurities . . . . . . . . . 117 
Figure 50. Hydrogen costs for various product purities resulting from membrane and non-membrane purification systems. . . . . 118

Figure 51. Membrane systems for producing low-purity hydrogen with carbon dioxide impurities . . . . . . . . . . . . 119

Figure 52. Hydrogen costs as a function of hydrogen purity . . . . . . 120

Figure 53. Pressure history for a four-bed PSA system . . . . . . . . . 123

Figure 54. Pressure-swing acisorption purification system . . . . . . . . . . 125 


\section{List of Tables}

Table 1. Major Coal Gasification Reactions . . . . . . . . . . . . 6

Table 2. Survey of Major Coal Gasification Processes . . . . . . . . 7

Table 3. Gas Streams Produced by Coal Gasification Processes . . . : : . 8

Tabi 4. Product Gas Stream Composition with Air, $35 \% \mathrm{O}_{2}$, and $100 \% \mathrm{O}_{2}$ Used as the Gasifying Medium. . . . . . . . 11

Table 5. Capital Costs of the Purification Process for a Winkler Coal Gasification Plant Producing $\mathrm{H}_{2}{ }^{7} \ldots \ldots$. . . . . . 14

Table 6. Gas Permeabilities of Candidate Permselective Materials for $\mathrm{H}_{2} / \mathrm{N}_{2}$ Separation. . . . . . . . . . . . 23

Table 7. Gas Permeabilities of Candidate Permselective Materials for $\mathrm{H}_{2} \mathrm{~S} / \mathrm{N}_{2}$ and $\mathrm{CO}_{2} / \mathrm{N}_{2}$ Separation . . . . . . . . . 24

Table 8. Typical Composition of Casting Solution for Preparation of Asymmetric Polyetherimide Membranes . . . . . . . . . 27

Table 9. Performance of GKSS Polyetherimide Membranes for Hydrogen/Nitrogen Separation ............. 27

Table 10. Performance of Polyetherimide/Silicone Rubber Holiow Fibers for Hydrogen/Nitrogen Separation . . . . . . . . 28

Table 11. Performance of Different Polyetherimide Composite Membranes 36

Table 12. Performance of Polyamide Copolymer Composite Membranes for Carbon Dioxide/Hydrogen Separation . . . . . . . . 37

Table 13. Performance of Palladium-Silver Composite Membranes

for the Separation of Hydrogen from Carbon Dioxide . . . . . .

Table 14. Permeation Rates of the Asymmetric Polyetherimide Membrane ................... 46

Table 15. Permeation Rates of the Polyamide Copolymer Membrane . . . 47

Table 16. Performance of Polyetherimide Hollow-Fiber Membrane Module . . . . . . . . . . . . . . . . . 48

Table 17. Performance of Polyamide Copolymer Spiral-Wound Modules . . 52

Table 18. Normalized Nitrogen Permeation Rates of Two Polyamide Copolymer Membrane Modules at Varying Feed Pressures . . . 53

Table 19. Polyamide Copolymer Composite Membrane Bimodule Separation Data at $25^{\circ} \mathrm{C}$ with a $75 / 25$ Mixture of $\mathrm{CO}_{2} / \mathrm{H}_{2} \ldots \ldots$. . . . 61 
Table 20. Polyamide Copolymer Composite Membrane Bimodule Separation Data at $23^{\circ} \mathrm{C}$ with a $50 / 50$ mixture of $\mathrm{CO}_{2} / \mathrm{H}_{2} \ldots \ldots$. . . . .

Table 21. Polyamide Copolymer Composite Membrane Bimodule Separation Data at $23^{\circ} \mathrm{C}$ with a $25 / 75 \mathrm{CO}_{2} / \mathrm{H}_{2}$ Mixture . . . . . . . .

Table 22. Gas Mixture Separation Data of a Polyamide Copolymer Membrane Bimodule with a Feed Gas Mixture Containing Hydrogen Sulfide, Carbon Dioxide, and Hydrogen . . . . . . .

Table 23. Permeation Rates and Selectivities of \& Polyamide Copolymer Membrane Bimodule for a Feed Gas Mixture Containing 1.3\% Hydrogen Sulfide, 47.5\% Carbon Dioxide, and $51.2 \%$ Hydrogen . . . . . . . . . . . . . .

Table 24. Gas Mixture Separation Data of a Polyamide Copolymer Membrane Bimodule with a Feed Gas Mixture Containing Hydrogen Sulfide, Carbon Dioxide, and Hydrogen . . . . . .

Table 25. Permeation Rates and Selectivities of a Polyamide Copolymer Bimodule for a Feed Gas Mixture Containing $0.3 \%$ Hydrogen Sulfide, $46 \%$ Carbon Dioxide and $53.7 \%$ Hydrogen

Table 26. Polyetherimide Membrane Properties Used in Economic Evaluation .................... 67

Table 27. Polyamide Copolymer Membrane Properties Used in Economic Evaluation . . . . . . . . . . . . . 67

Table 28. Assumptions Used in Crossflow and Countercurrent Membrane Module Models : . . . . . . . . . . . . . 68

Table 29. List of Input Parameter/Output Parameter Combinations for the Crossflow Module Computer Model . . . . . . . 70

Table 30. Pure Gas Membrane Properties . . . . . . . . . . . . 71

Table 31. Experimental Results for Separation of a Gas Mixture With a Spiral-Wound Membrane Module . . . . . . . . 72

Table 32. Calculated Membrane Properties from Mixed Gas Experiments . 72

Table 33. Feed Conditions and Membrane Properties for Example Application .................. 81

Table 34. Purification Systems Examined for Hydrogen Purification. . . . 87

Table 35. Economic Parameters Used in Discounted Cash Flow Calculations .................. 90 
Table 36. Final Separation - Air-Blown Results . . . . . . . . . . . 94

Table 37. AGR Cost Reduction - Oxygen-Blown Results . . . . . . . 100

Table 38. AGR Cost Reduction - Air-Blown Results . . . . . . . . . 101

Table 39. Shift Reactor Cost Reduction - Oxygen-Blown Results . . . . . 111

Table 40. Shift Reactor Cost Reduction - Air-Blown Results . . . . . . . 111 


\section{EXECUTIVE SUMMARY}

Coal is an abundant, cheap resource in the United States. Usipg coal to produce hydrogen, therefore, makes good sense. However, the production of hydrogen frcin synthesis gas made by gasification of coal is expensive. To make the coal-to-hydrogen route economically attractive, improvements are being sought in each step of the process: coal gasification, water-carbon monoxide shift reaction, and hydrogen separation.

The separation of hydrogen from synthesis gas is a major cost element in the total process. Membranes could pley a role in the hydrogen separation step. separation by membranes is an attractive, new, and still lariely unexplored approach to the prablem. Membrane processes are inherently simple and efficient and of ten have lower capital and operating costs than conventional processes. In thi: report we describe the results of a program aimed at the development of membranes and membrane modules for the separation and purification of hydrogen from synthesis gas. The performance properties of the developed membranes were used in an economic evaluation of membrane gas separation systems in the coal gasification prosess.

The work performed during this four-year program began with an examination of the chemical separations required to produce hydrogen from synthesis gas, and identification of three specific separations where membranes might be applicable. We then chose appropriate membrane polymer materials for each separation and fabricated these polymers into useful membranes and modules. During the membrane development work, a range of membrane fabrication techniques and module configurations were investigated to optimize the separation properties of the membrane materials. The most promising membranes and module configurations for the three separations ware fully characterized under a variety of conditions. The parametric data thus obtained were used to develop the economic comparison of processes incorporating membranes with a base-case system without membranes. The computer calculations for the economic analysis were designed and executed by SRI International, a subcontractor on this program. Finally, we briefly investigated alternative methods of performing the three separations in the production of hydrogen from syathesis gas.

The three potential opportunities for membranes in the production of hydrogen from synthesis gas are: 1) separation of hydrogen from nitrogen as the final separation in a air-blown or oxygen-enriched air-blown gasification process, 2) separation of hydrogen from carbon dioxide and hydrogen sulfide to reduce or eliminate the conventional ethanolamine acid gas removal unit, and 3) separation of hydrogen and/or carbon dioxide from carbon monoxide prior to the shift reactor to influence the shift reaction. 
The membrane development work focussed on two polymers: polyetherimide and polyamide copolymer. Polyetherimide is glassy polymer with high thermal softening point $\left(220^{\circ} \mathrm{C}\right)$ and is unusually permeable to hydrogen. Membranes prepared from polyetherimide were selective for hydrogen over carbon dioxide, hydrogen sulfide, nitrogen and carbon monoxide. The polyamide copolymer is a rubbery polymer at room temperature and is characterized by exceptional permeabilities to acid gases such as carbon dioxide and hydrogen sulfide. Polyamide copolymer membranes are selective for the acid gares over hydrogen and thus have an inverse selectivity when compared with polyetherimide membranes.

The polyetherimide membranes were tested with pure gases and with gas mixtures at pressures up to 500 psig and temperatures up to $80^{\circ} \mathrm{C}$. No significant difference between pure gas and gas mixture permeation behavior was observed and the permeation rate vs. temperature relationship follows the Arrhenius equation, allowing extrapolation of the membrane permeation rate data to higher temperatures.

The polyamide copolymer membranes were tested with pure gases at pressures up to 500 psig and at temperatures up to $80^{\circ} \mathrm{C}$. Gas mixture testing showed that membrane performance is strongly affected by the composition of the feed gas. Carbon dioxide and hydrogen sulfide plasticize the membrane and increase the permeation rate of other gases, thereby reducing the effective membrane selectivity. The membrane permeation rate data used in the economic evaluations for the polyamide copolymer membrane are those obtained at room temperature and with a gas mixture containing hydrogen, carbon dioxide and hydrogen sulfide.

In the economic evaluations, the cost of producing hydrogen at $98 \%$ purity was calculated for a number of process configurations which include membrane separation systems at various locations. The hydrogen cost is compared to a base-case configuration representing conventional oxygen-blown gasification process. The most important conclusions from the economic evaluation are:

1. An oxygen-blown gasifier is more economical than either an air-blown or an oxygen-enriched air-blown gasifier using membranes to separate hydrogen from nitrogen.

2. In an oxygen-blown gasification process, the polyetherimide membrane has potential to reduce hydrogen costs when the membrane is used to partially remove carbon dioxide and hydrogen sulfide, thereby reducing the size of the ethanolamine acid gas removal unit. The use of a hybrid membrane/acid gas removal system results in hydrogen costs of \$4.28 Mscf hydrogen compared to \$4.62/Msef for the base case.

3. No economic advantage could be obtained by using membranes to manipulate the composition of the shift reactor feed gas, neither by venting carbon dioxide nor by bypassing the reactor with carbon dioxide and hydrogen. 
The most promising application for membranes thlis appears to be in the removal of carbon dioxide and hydrogen sulfide fror 1 the hydrogen stream produced by the shift reactor. A sensitivity analysis has shown that improving the hydrogen/carbon dioxide selectivity of the polyetherimide membrane is key to further reducing the hydrogen cost. Doubling the selectivity would reduce the

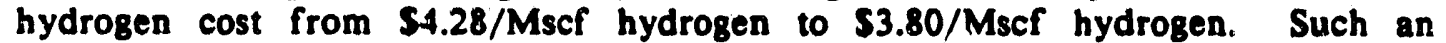
improvement in selectivity will require further membrane development work. 


\section{SIGNIFICANCE OF THE PROBLFM}

In $1981,3.9 \times 10^{12}$ scf of hydrogen wis produced and consumed in the U.S. ${ }^{1}$ The largest single use of hydrogen to date has been in amminia synthesis, which alone consumes some $37 \%$ of the total hydrogen produced. The bulk of the remaining hydrogen is used in the petroleum refining industry, encompassing hydroprocessing (36.4\%, principally hydrocracking and hydrodesulfurization), or as a refinery fuel (14.3\%). A further $9.6 \%$ share goes to methanol synthesis, and the remaining $2.7 \%$ is used in specialty merchant applications, e.g., hydrogenation of oils and fats, and the aerospace industry. Figure 1 summarizes this distribution for 1981.1

Hydrogen is produced by several methods, the choice of which is determired by such factors as the quantity and purity of hydrogen required, and the availability and cost of raw materials. Currently, most hydrogen is produced by stream reforming of methane, a process in which methane and steam are reacted to form carbon dioxide and hydrogen. Electrolysis of water is another proven reliable method, but the high cost of electricity is a limitation in this case. Other methods under development include thermochemical decomposition of water and coal gasification.

It is anticipated that the demand for hydrogen will grow by a factor of five by the year 2000, partly because of growth in present markets, particularly petroleum refining, but primarily because of the emergence of new needs. ${ }^{1}$ Industrial applications that could become large consumers of hydrogen include manufacture of synthetic fuels, hydrogen-oxygen turbines and fuel cells. The use of hydrogen as a fuel for transportation is another possibility; hydrogen is already in use in the space program, serving as the rocket propellant for the shuttle, and it could be employed as an alternative. automobile fuel by the year 2000 . As demand rises and gas and oil resources are depleted, it is likely that coal will become the primary source of hydrogen. Improvements in the efficiency of the coal gasification process could therefore have a substantial impact on the U.S. economy in the future.

\section{COAL GASIFICATION}

\section{A. Introduction and Overview}

Hydrogen is produced from coal by the water gas reaction, i.e., reacting the coal with water. Because this reaction is endothermic, heat must be supplied. This is achieved by reacting a portion of the coal in the gasifier with oxygen to produce carbon monoxide and carbon dioxide, both highly exothermic reactions. 


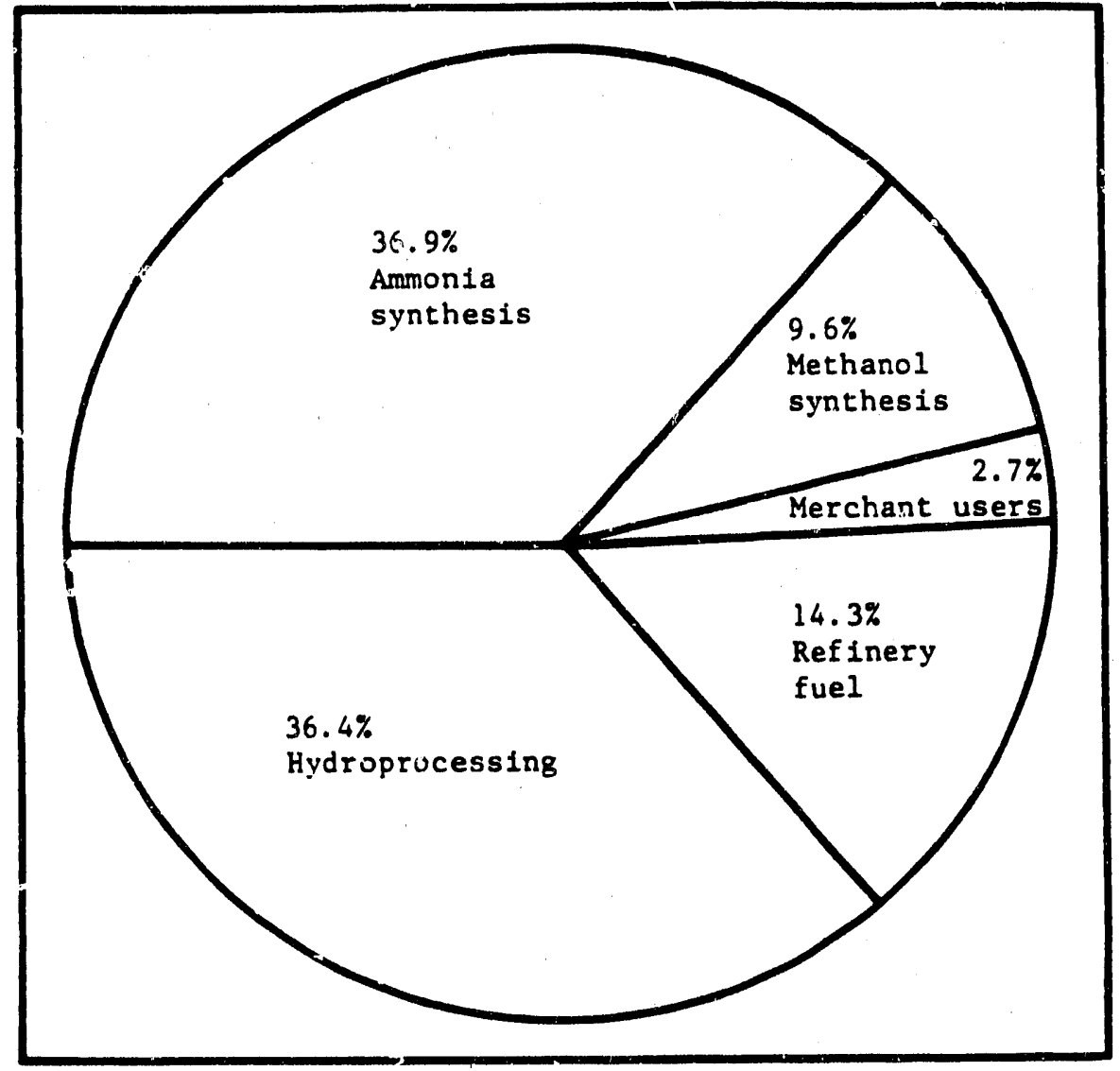

Figure 1. Distribution of the $3.9 \times 10^{12} \mathrm{sef}$ of hydrogen produced and consumed in the U.S. in 1981.1 
The process is usually performed in a large gasifying vessel where the coal is in contact with steam and either air or oxygen. The more important chemical reactions that take place in the process are shown in Table $1 .^{2}$

\section{Table 1. Maior Coal Gasification Ruactions ${ }^{2}$}

(All $\Delta \mathrm{H}^{\circ}$ at $298 \mathrm{~K}$ and $1 \mathrm{~atm}$ )

$\begin{array}{llll}\text { Combustion } & \mathrm{C}+\mathrm{O}_{2} & \rightarrow \mathrm{CO}_{2} & \Delta \mathrm{H}^{\circ}=-394 \mathrm{~kJ} / \mathrm{mol} \\ \text { Gasification } & \mathrm{C}+1 / 2 \mathrm{O}_{2} & \rightarrow \mathrm{CO} & \Delta \mathrm{H}^{\circ}=-111 \mathrm{~kJ} / \mathrm{mol} \\ & \mathrm{C}+\mathrm{H}_{2} \mathrm{O}(\mathrm{g}) & \rightarrow \mathrm{CO}+\mathrm{H}_{2} & \Delta \mathrm{H}^{\circ}=+131 \mathrm{~kJ} / \mathrm{mol} \\ & \mathrm{C}+\mathrm{CO}_{2} & \rightarrow 2 \mathrm{CO} & \Delta \mathrm{H}^{\circ}=+173 \mathrm{~kJ} / \mathrm{mol}\end{array}$

At the temperature of the gasifier, cosl breaks down and reacts with steam and oxygen to produce a mixture of gases commonly called synthesis gas. Synthesis gas comprises carbon monoxide, hydrogen, carbon dioxide, and water vapor, along with varying amounts of methane and impurities. The precise composition of the mixture depends upon the makeup and origins of the coal, the proportion of air (oxygen), steam, or other reactants used, gasifier temperature, operating pressure, residence time of the coal, and other parameters. Generally, the gasifier type and operating conditions are chosen to produce a synthesis gas tailored for the intended application.

There are many commercial or nearly commercial gasification processes. The major features of four representative processes are shown in Table $\mathbf{2 . 3 , 1 , 5}$ 
Table 2. Survey of Maior Coal Gasification Processes

\begin{tabular}{|c|c|c|c|c|}
\hline Process & $\begin{array}{l}\text { Combustion } \\
\text { Engineering }\end{array}$ & $\begin{array}{l}\text { Koppers- } \\
\text { Totzek }\end{array}$ & Texaco & Lurgi \\
\hline $\begin{array}{l}\text { Development } \\
\text { status }\end{array}$ & $\begin{array}{l}\text { Pilot plants } \\
\text { operating }\end{array}$ & $\begin{array}{l}\text { Successful on } \\
\text { large indus- } \\
\text { trial scale }\end{array}$ & $\begin{array}{l}\text { Tested on } \\
\text { industrial } \\
\text { scale }\end{array}$ & $\begin{array}{l}\text { Successful } \\
\text { on large } \\
\text { scale }\end{array}$ \\
\hline $\begin{array}{l}\text { Coal } \\
\text { requirements }\end{array}$ & Any & Any & Any & $\begin{array}{l}\text { Lignites, } \\
\text { lump coal }\end{array}$ \\
\hline $\begin{array}{l}\text { Gasifying } \\
\text { medium }\end{array}$ & $\begin{array}{l}\text { Air and } \\
\text { steam }\end{array}$ & $\begin{array}{l}\mathrm{O}_{2} \text { and } \\
\text { stesm }\end{array}$ & $\begin{array}{l}\mathrm{O}_{2} \text { and } \\
\text { steam }\end{array}$ & $\begin{array}{l}\mathrm{O}_{2} \text { and } \\
\text { steam }\end{array}$ \\
\hline $\begin{array}{l}\text { Gasifier } \\
\text { type }\end{array}$ & $\begin{array}{l}\text { Entraiuled } \\
\text { flow }\end{array}$ & $\begin{array}{l}\text { Co-current, } \\
\text { entrained } \\
\text { flow }\end{array}$ & $\begin{array}{l}\text { Co-current, } \\
\text { entrained } \\
\text { flow }\end{array}$ & $\begin{array}{l}\text { Counter } \\
\text { current, } \\
\text { fixed bed }\end{array}$ \\
\hline $\begin{array}{l}\text { Operating } \\
\text { pressure }\end{array}$ & Atmospheric & Atmospheric & $40 \mathrm{~atm}$ & $20-30$ atm \\
\hline $\begin{array}{l}\text { Operating } \\
\text { temperature }\end{array}$ & $1750^{\circ} \mathrm{C}$ & $1800-1900^{\circ} \mathrm{C}$ & $1260-1430^{\circ} \mathrm{C}$ & $>1500^{\circ} \mathrm{C}$ \\
\hline By-products & None & None & None & $\begin{array}{l}\text { Tar, oil, } \\
\text { gas, naphth } \\
\mathrm{NH}_{3}\end{array}$ \\
\hline $\begin{array}{l}\text { Carbon con- } \\
\text { version } \\
\text { efficiency } \\
\end{array}$ & $99 \%$ & $90-96 \%$ & $90-98 \%$ & $99 \%$ \\
\hline $\begin{array}{l}\text { Gasification } \\
\text { efficiency }\end{array}$ & $\cdots$ & $70-77 \%$ & $75-80 \%$ & $75-85 \%$ \\
\hline $\begin{array}{l}\text { Thermal } \\
\text { efficiency }\end{array}$ & $-\cdots$ & $75-85 \%$ & $\leq 85 \%$ & $75 \%$ \\
\hline \multicolumn{5}{|l|}{$\begin{array}{l}\text { Raw Gas } \\
\text { Analysis }\end{array}$} \\
\hline $\begin{array}{l}\mathrm{H}_{2} \\
\mathrm{CO} \\
\mathrm{CO}_{2} \\
\mathrm{CH}_{4} \\
\mathrm{~N}_{2} \\
\end{array}$ & $\begin{array}{r}10 \% \\
23 \% \\
4 \% \\
0 \% \\
63 \% \\
\end{array}$ & $\begin{array}{c}22-32 \% \\
55-66 \% \\
7-12 \% \\
0.1 \% \\
--\end{array}$ & $\begin{array}{l}38 \% \\
40 \% \\
5-20 \% \\
0.8 \% \\
--\end{array}$ & $\begin{array}{c}36-40 \% \\
18-25 \% \\
27-32 \% \\
9-10 \% \\
--\end{array}$ \\
\hline $\begin{array}{l}\text { Calorific value } \\
\text { (Btu/scf) }\end{array}$ & 100 & $285-320$ & 300 & 310 \\
\hline
\end{tabular}


Gasification processes can be divided into two broad categories according to the composition and heating value of the synthesis gas stream produced. The Combustion Engineering process produces a low-Btu gas stream that has a high percentage of nitrogen and a heating value of 100-200 Btu/scf. Low-Btu gas producers are typically air blown, atmospheric pressure processes supplying boiler fuel gas for utility electric power generation. The second category, to which belong the Koppers-Totzek and Texaco processes, generate synthesis gas, a mixture of carbon monoxide, hydrogen, and carbon dioxide with a heating value around 250-400 Btu/scf. The heating value of these streams is higher than lowBtu streams because oxygen, rather than air, is used as the gasifying medium. Synthesis gas can be used as a source of hydrogen or it can be upgraded to methane or high Btu gas. Table 3 summarizes the types of gasification product streams, their heating values, and compositions.

Table 3. Gas Streams Produced by Coal Gasification Processes ${ }^{5}$

\begin{tabular}{llll}
\hline \multicolumn{1}{c}{ Gas } & Heating value & Composition & Use \\
\hline Low-Btu & $100-200 \mathrm{Btu} / \mathrm{scf}$ & $\mathrm{N}_{2}, \mathrm{H}_{2}, \mathrm{CO}, \mathrm{CO}_{2}$ & Boiler fuel gas \\
$\begin{array}{l}\text { Synthesis } \\
\text { gas }\end{array}$ & $250-400 \mathrm{Btu} / \mathrm{scf}$ & $\mathrm{H}_{2}, \mathrm{CO}_{2}, \mathrm{CO}$ & $\begin{array}{l}\text { Hydrogen production, } \\
\text { oxochemicals or up- } \\
\text { grade to high-Btu gas }\end{array}$ \\
High-Btu & $1000 \mathrm{Btu} / \mathrm{scf}$ & $\mathrm{CH}_{4}$ & \begin{tabular}{l} 
Synthetic natural gas \\
\hline
\end{tabular}
\end{tabular}

\section{B. The Texaco Coal Gasification Process}

It is clear from the above discussion that there are many processes to gasify coal and numerous variable parameters within these processes. To analyze the feasibility of producing hydrogen from coal via membrane separation, a specific process and its parameters need to be specified. Because of its simplicity and superior environmental properties, we selected the Texaco coal gasification method. This process evolved from the Texaco synthesis gas generation process developed for the partial oxidation of natural gas. Later developments led to the use of petroleum refinery residues as feedstock. The energy crisis of 1973 spurred the substitution of coal as the feed stock.

The Texaco process does not produce tars, carcinogenic compounds, or partially oxidized material which often require extensive wastewater treatment. Furthermore it produces a high hydrogen-to-carbon monoxide ratio and is therefore particularly suited to hydrogen production. The technical feasibility of the Texaco process with coal has been demonstrated recently in the Montebello Pilot Plant and the Cool Water Coal Gasification Program, both in California. These two plants and many others operating on petroleum residues provide a large body of operating experience. 4 
A flow diagram of the Texaco gasification process is shown in Figure 2. The major steps are optional air separation, coal gasification, carbon-monoxide shift conversion, carbon dioxide and hydrogen sulfide removal, and sulfur recovery.

The gasifier operates in the temperature range $1,200-1,430^{\circ} \mathrm{C}\left(2,300-2,600^{\circ} \mathrm{F}\right)$ and in the pressure range $600-1,200$ psig $(40-80 \mathrm{~atm})$. The coal-water slurry and oxygen from the air separation plant are fed into the gasifier, where the combustion reactions proceed to completion in a few seconds. The gases exiting the reactor are water quenched, removing particulates and ash and cooling the stream.

The gas then flows to the carbon monoxide shift converter, where carbon monoxide is catalytically converter to hydrogen and carbon dioxide by the reaction.

$$
\mathrm{CO}+2 \mathrm{H}_{2} \mathrm{O} \rightarrow \mathrm{CO}_{2}+2 \mathrm{H}_{2}
$$

The process gas from the shift converter then moves to the acid gas removal system (AGR). The $A G R$ separates $\mathrm{H}_{2} \mathrm{~S}$ and $\mathrm{CO}_{2}$ from the gas stream. The $\mathrm{H}_{2} \mathrm{~S}$ stream is sent to a Claus unit for conversion to sulfur by the reaction

$$
2 \mathrm{H}_{2} \mathrm{~S}+\mathrm{O}_{2} \rightarrow 2 \mathrm{H}_{2} \mathrm{O}+\mathrm{S}_{2}
$$

The carbon dioxide stream is treated to remove residual sulfur gases and is then vented. The hydrogen sulfide and carbon dioxide depleted stream leaving the AGR system now consists of $97-98 \%$ hydrogen, $1 \%$ carbon monoxide and traces of carbon dioxide and other gases.

In the process described above, oxygen is used as the gasifying medium. The oxygen is supplied from an air separation plant, which generally employs a standard cryogenic process with reversing flow heat exchangers, to produce high purity (99.5\% or better) gaseous oxygen. Membrane processes to separate oxygen from air exist, but the permeate oxygen concentration is fairly low, around 35$50 \%$. Using pure oxygen rather than air produces a nitrogen-free product gas. This is desirable because the presence of nitrogen will substantially reduce the value of the product in most applications, and low-cost methods of separating hydrogen from nitrogen have not been developed to date. However, the Texaco gasifier can operate equally well with air or oxygen-enriched air as the gasifying medium. Data from a Texaco gasifier operating with three different gasifying media are shown in Table 4.4.6 The gas produced in these processes was meant for utility boiler fuel rather than as a source of hydrogen. When air is the gasifying medium a substantial amount of nitrogen, almost $60 \%$, is present in the gas stream. Using air enriched to $35 \%$ oxygen results in a $43 \%$ nitrogen content in the product gas; using $100 \%$ oxygen gives only $0.5 \%$ nitrogen in the product gas. 


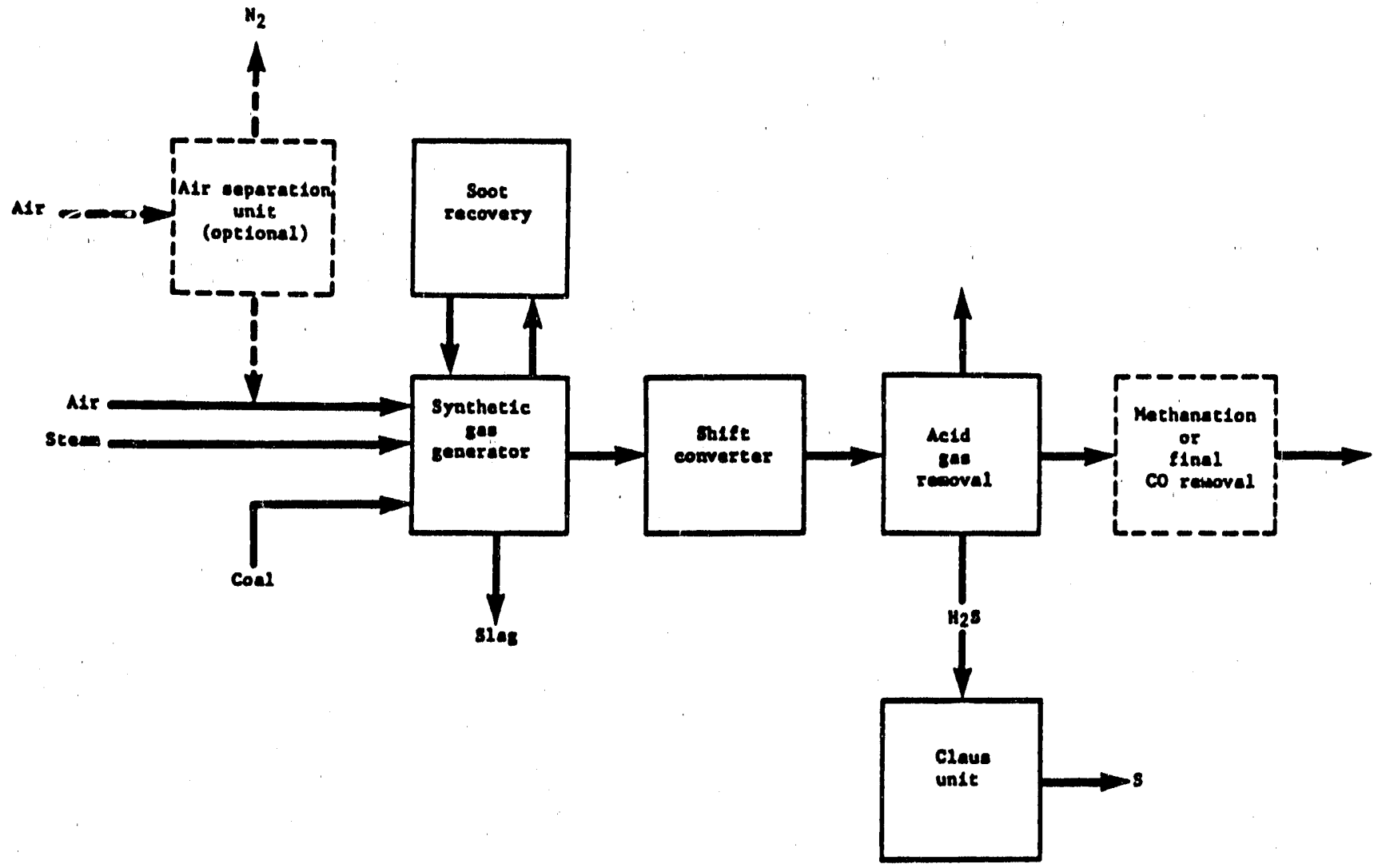

Figure 2. Flow diagram of the Texaco coal gasification process." 
Table 4. Product Gas Stream Composition with Air 35\% $\mathrm{Q}_{22}$ and $100 \% \mathrm{O}_{2}$ Used as the Gasifyine Medium

\begin{tabular}{|c|c|c|c|}
\hline \multirow{3}{*}{$\begin{array}{c}\text { Gas Stream Composition } \\
\text { (vol\%) }\end{array}$} & \\
\hline & \multicolumn{3}{|c|}{$21 \% \mathrm{O}_{2}$ (Air) $\quad 35 \% \mathrm{O}_{2} \quad 100 \% \mathrm{O}_{2}$} \\
\hline & & & \\
\hline $\begin{array}{l}\mathrm{H}_{2} \\
\mathrm{CO} \\
\mathrm{CO}_{2} \\
\mathrm{~N}_{2} \\
\mathrm{Ar}^{2} \\
\mathrm{H}_{2} \mathrm{~S}\end{array}$ & $\begin{array}{r}11.6 \\
19.5 \\
7.7 \\
59.7 \\
0.7 \\
>0.1\end{array}$ & $\begin{array}{r}17.8 \\
23.2 \\
11.6 \\
43.2 \\
0.5 \\
>0.1\end{array}$ & $\begin{array}{r}34.5 \\
41.6 \\
22.0 \\
0.5 \\
>0.1 \\
>0.1\end{array}$ \\
\hline
\end{tabular}

As described in Section IV, membrane processes are able to separate hydrogen from nitrogen with reasonable efficiency, so that the use of air or oxygen-enriched air in the gasifier would be possible. It is possible that the cost of the hydrogen/nitrogen membrane separation unit would be more than of fset by elimination of the cryogenic air separation plant.

\section{Synthesis Gas Purification by Conventional Processes}

The raw product gas that leaves the gasifier must be cleaned up, regardless of whether hydrogen, low-Btu gas, synthesis gas, or methane is the desired product. The specifications to be met by the clean gas vary with the intended application.

Typically the hot gas leaving the gasifier contains coal dust, ash, hydrochloric acid, ammonia and other impurities that can be removed by a simple water quench. This quench will also cool the stream, recovering some of the heat for use elsewhere and avoiding the technical problems associated with cleaning a hot gas stream. After the water quench the primary compounds of concern in the gas clean-up are hydrogen sulfide, carbon dioxide and carbon monoxide. These are removed in the shift conversion, acid gas removal, and sulfur recovery steps. Figure 3 shows the composition of the gas stream after each purification step when oxygen is used as the gasifying medium. ${ }^{6,7}$

As shown, the water quenched process gas is first passed to a shift converter, where the carbon monoxide is shifted to carbon dioxide for removal in the acid gas removal system that follows. The carbon monoxide content of the gas entering the converter is about $42 \%$. After full shift this level decreases to $2 \% .^{7}$ 


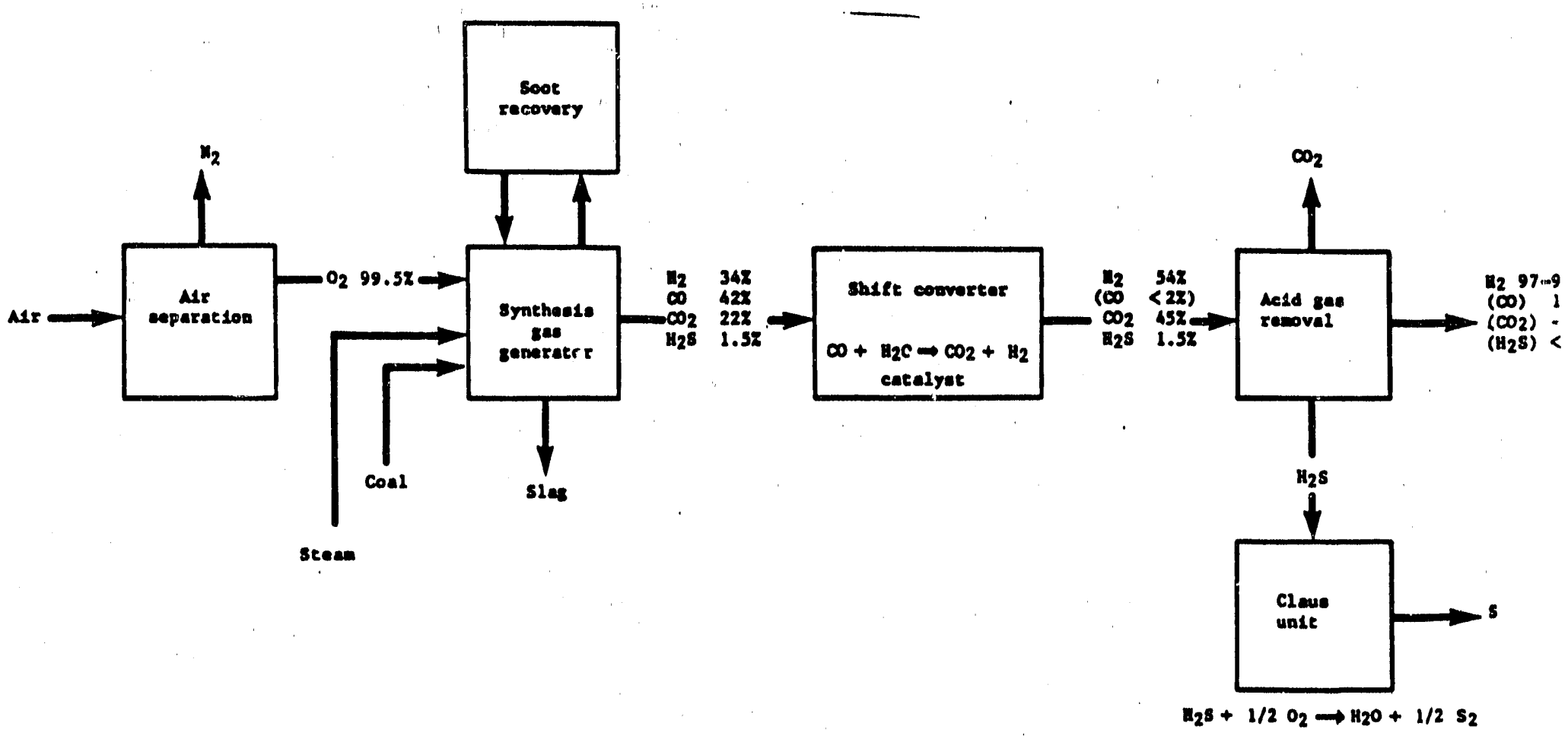

Figure 3. Approximate composition of the gas stream after each step of a coal gasification process. The numbers shown are average numbers taken from several sources and are not representative of any one particular process. 0,7 
The next purification step is separation of the acid gases. The goal of this separation is to remove most of the carbon dioxide and essentially all of the hydrogen sulfide from the feed stream. The separated gases leave the process in two streams, one containing carbon dioxide and no hydrogen sulfide the other containing all of the hydrogen sulfide and some carbon monoxide. The carbon dioxide stream is clean enough to be vented without further treatment and the hydrogen sulfide enriched stream is sent to a sulfur recovery process. For the process to be most economical, a system yielding a hydrogen sulfide stream with a hydrogen sulfide concentration of at least $15 \%$ is required. Several commercially developed systems meet this requirement. Most of them employ an absorption-desorption system in which a liquid phase selectively absorbs one or more components from the gas. The gas may simply dissolve in the liquid or it may react. After the absorption step, the pressure of the liquid-gas mixture is lowered, or the temperature raised, thereby desorbing the absorbed hydrogen and carbon dioxide separately from the mixture and regenerating the liquid phase.

Three classes of acid gas removal systems are commonly used. ${ }^{8}$ The first uses amine based solvents, such as monoethanol amine, diethanol amine, diglycol amine, and some tertiary amines. Each amine differs in its degree of selectivity in sulfur removal. In general, amine treatment in coal processing is not as efficient or as economical as other processes, because of the poor selectivity for hydrogen sulfide and higher operating costs at the larger operating pressures of the coal gasification process. The second class uses hot carbonate solutions to selectively remove the $\mathrm{CO}_{2}$. A proprietary process is usually employed and a reasonable degree of selectivity is obtained. A two-stage system will generate a sulfur-rich stream that is sufficiently concentrated for further recovery in a Claus unit. Physical solvent systems comprise the third group, and at least six processes, among them the Rectisol, Fluor and Selexol processes, have been commercialized. These systems utilize higher solubility of certain solvents for hydrogen sulfide and carbon dioxide than for the other fuel gas species. In most solvents the hydrogen sulfide is significantly more soluble than the $\mathrm{CO}_{2}$, allowing for a good separation of the two gases.

The choice of sulfur recovery process used to treat the hydrogen sulfide stream from the acid gas removal system will depend on the concentration of hydrogen sulfide in the stream. The Claus process, which recovers the sulfur according to the reaction

$$
2 \mathrm{H}_{2} \mathrm{~S}+\mathrm{O}_{2} \rightarrow 2 \mathrm{H}_{2} \mathrm{O}+\mathrm{S}_{2},
$$

is most effective with hydrogen sulfide concentrations around $15 \%$ or above. Alternative sulfur recovery techniques such as adsorption onto solids, activated carbon, or the Stretford process are used if the sulfur feed coucentration is below $10 \%$.

Together, these gas separation processes account for a large portion of the capital and operating costs of a coal gasification facility. A precise statement of actual separation system costs is difficult to make because of the variability of the gasification processes and the operating parameters. However, Billings ${ }^{7}$ gives a breakdown of the capital costs for a Winkler gasification process, as shown in Table 5. The coal gasification step represents only $20 \%$ of the total plant capital 
costs; the combined purification steps represent some $44 \%$. Clearly a reduction in gas separation costs would have a dramatic effect on the overall cost of the hydrogen produced.

Table 5. Capital Costs of the Purification Process for a Winkler Coal Gasification Plant Producing $\mathbf{H}_{2}{ }^{7}$

\begin{tabular}{lc}
\hline \multicolumn{1}{c}{ Item } & \% of Capital Cost \\
\hline Coal handling and preparation & 13.8 \\
Coal gasification & 20.5 \\
CO shift & 9.6 \\
Acid gas removal and sulfur recovery & 16.7 \\
Gas compression & 7.7 \\
Waste water treatment & 4.3 \\
Oxygen plant & 17.2 \\
Off-site and miscellaneous & 10.2 \\
& $\frac{100 \%}{\text { TOTAL }}$ \\
\hline
\end{tabular}

There are four potential membrane applications in coal gasification processes. These are discussed in more detail in Section V.

1. The separation of oxygen from air.

2. The separation of hydrogen from carbon monoxide before the shift reaction.

3. The separation of hydrogen from carbon dioxide after the shift reaction.

4. The separation of hydrogen from nitrogen after the AGR removal step in an air-blown gasifier process.

The separation of oxygen from air is outside the scope of this program. All efforts have concentrated on the hydrogen separation processes.

\section{MEMBRANE GAS SEPARATION}

\section{A. Mernbrane Theory}

Before we discuss the potential application of membranes to hydrogen production from coal, a very brief discussion of the principles underlying membrane gas separation is in order.

The separation of gases by permselective membranes has a long history dating back to the work of Thomas Graham. However, the first systematic studies with polymer membranes of the type used today did not begin until the 
1940s, when Van Amerongen, ${ }^{9}$ Barrer, ${ }^{10}$ and others ${ }^{11,12}$ laid the foundation of modern theories of gas permeation. Although progress has been made since that time, ${ }^{13-15}$ cur basic understanding of membrane science has not changed. What has changed is membrane technology. During the last decade, methods have been found to produce extremely thin (and hence high-flux) membranes in compact, high surface area membrane modules. As a result, there is now a surge of interest in using membranes to accomplish gas separations. Separation membranes can be divided into four categories: nonporous polymeric membranes, microporous membranes, racilitated transport membranes, and nonporous metal membranes.

Palladium can sorb large quantities of hydrogen, particularly at high temperatures, and films made from palladium or palladium alloys are permeable to hydrogen, but essentially impermeable to other gases. Attempts were made in the 1960 s to exploit this property commercially, but failed because the large temperature changes involved in the process damaged the membranes and because the films could not be made sufficiently thin to achieve high fluxes.

Almost all currently used gas separation membranes are made from nonporous polymeric materials, so we will limit our discussion to these. Permeation of gases through these membranes can be explained by the solution-diffusion model, which assumes that gas at the high-pressure side of the membrane dissolves in the membrane material and diffuses down a gradient in concentration to the low-pressure side of the membrane where the gas is desorbed. It is also assumed that the gas phases on either side of the membrane are in thermodynamic equilibrium with their respective polymeric interfaces, and that the interfacial sorption and desorption process is rapid compared to the rate of diffusion through the membrane. Thus, the rate-limiting step is diffusic ?, which is governed by Fick's law. For simple gases, Fick's law leads to the equation

$$
J=\frac{D K \Delta p}{\ell}
$$

which can be further simplified to

$$
J=\frac{P \Delta p}{l}
$$

where $J$ is the membrane flux $\left[\mathrm{cm}^{3}(\mathrm{STP}) / \mathrm{cm}^{2} \cdot \mathrm{s}\right.$, $D$ is the diffusion coefficient of the gas in the membrane $\left[\mathrm{cm}^{2} .5\right]$ and is a measure of the gas mobility, $K$ is the Henry's law sorption coefficient linking the concentration of the gas in the membrane material to the pressure in the adjacent $g$ as $\left[\mathrm{cm}^{3}(S T P) / \mathrm{cm}^{3} \cdot \mathrm{cmH}_{8}\right.$ ], and $\Delta p$ is the pressure difference across the membrane. $P$ is the permeability equal to the product DK and is a measure of the rate at which a particular gas moves through the membrane of a standard thickness $(1 \mathrm{~cm})$ under a standard pressure difference $(1 \mathrm{cmHg})$. The permeability unit is

$$
1 \times 10^{-10} \mathrm{~cm}^{3}(\mathrm{STP}) \mathrm{cm} / \mathrm{cm}^{2} \cdot \mathrm{s} \cdot \mathrm{cmH}_{8} \text {. }
$$

often called a Barrer, after R.M. Barrer, a pioneer in membrane permeation studies. 
A measure of the ability of a membrane to separate two gases, (1) and (2), is the ratio of their permeabilities, $\alpha$, called the membrane selectivity,

$$
\alpha=\frac{P_{(1)}}{\mathbf{P}_{(2)}} \text {. }
$$

The factors that determine membrane permeabilities can best be understood by considering the component terms $D$ and $K$. For simple gases, the diffusion coefficient tends to decrease with increasing molecular size, since large molecules interact with more segments of the polymer chains and are thus less mobile. On the other hand, the sorption coefficient of gases normally increases with molecular size, because larger molecules ars more condensable.

Polymeric materials can be characterized as glassy or rubbery. Highly crosslinked or glassy polymers with crystalline or rigid structures have permeation properties that terio to be dominated by the diffusion coefficient. They are typically very sensitive to molecular size, and hence, highly selective for small molecules over large molecules, but exhibit low gas fluxes. In rubbery polymers, the effect of the sorption coefficient dominates, so that the material tends to be selective for large condensable molecules over small ones. The selectivities of rubbery polymers are typically much lower than those of glassy materials, but the fluxes are higher.

This discussion highlights an inherent problem encountered by all gas separation membranes, namely that materials with good selectivity exhibit low fluxes, and materials with high fluxes are relatively unselective. The best solution to this problem to date has been to make the membrane extremely thin, because flux is inversely proportional to membrane thickness. Very thin membranes are, however, mechenically weak. This difficulty is overcome by separating the strength and permselective functions. Either the membrane may have an asymmetric structure, so that the separation properties are controlled by a very thin dense skin layer, but the strength is determined by the porous bulk of the membrane, or the membrane may be a composite of two different materials, a strong microporous substrate coated with a very thin dense permselective materials. Both of these approaches have been used in commercially successful systems.

\section{B. Membrane Modules and Systems}

When used in a separation process, membranes are usually packed in membrane modules having a feed flow inlet port and residue flow and permeate flow outlet ports. The residue is the fraction of the feed now that has not permeated the membrane. A membrane module serves two purposes: (1) to provide pathways for the feed flow such that the feed gas is in close contact with the membrane and for the permeate flow such that the permeate is able to exit the module, and (2) to efficiently incorporate a large membrane area into a small volume.

Membranes can be produced in two different forms: flat-sheet membranes and hollow-fiber membranes. Hollow-fiber membranes are membrane strands with a hollow bore. The bore side can be either the high-pressure side or the lowpressure side of the membrane. 
Hollow-fiber membranes are packed in plastic or metal pipe housings. This type of module is shown in Figure 4a. The feed gas enters the bores of the fibers. Gas permeates the membrane and the permeate exits from the shell via an outlet port. The remainder of the feed gas exits the fiber bores at the opposite side of the module. Hollow-fiber modules allow for arger packing density (membrane area/module volume) than spiral-wound modules. Consequently, they have larger resistance to flow on both the feed and permeate sides. Hollowfiber modules are, therefore, preferred in high-pressure applications where pressure drops are not a serious concern.

The preferred way to pack nat-sheet membranes is in spiral-wound modules. Figure $4 \mathrm{~b}$ shows this type of membrane module. In operation, the feed gas enters the modile and flows between the membrane leaves. The feed gas pathway is created by a spacer material. The fraction of the feed gas that permeates the membrane spirals inward to the central permeate collection pipe. Again a spacer material provides the pathway for the permeate gas. The remainder of the feed gas exits the module as the residue.

Membrane modules, whether of the spiral-wound or hollow-fiber type, are connected together to yield membrane system with a certain total membrane area. Any number of modules can be interconnected to yield a membrane system of certain size. There are several ways in which membrane modules can be configured and these configurations affect the performance of the membrane system. In the following paragraphs we will briefly discuss the key membrane configurations.

The simplest configuration is the single-stage system shown in Figure 5a, in which all membrane modules operate with the same feed gas mixture. The enrichment of the most permeable gas obtained in the permeate (enrichment is defined as permeate concentration divided by feed concentration) is limited by the membrane selectivity and by the system's operating conditions. A detailed analysis of the system's behavior is given in Section VIII.

There are several system configurations that overcome the limitations of a single-stage system. One possibility is single-stage system with permeate recycle as shown in Figure $5 b$. in this configuration, part of the permeate stream is recycled to the feed of the membrane modules. This increases the concentration of the more permeable gases in the module feed stream, resulting in higher concentrations of those gases in the permeate. A variation on the singlestage system with recycle is the two-step system shown in Figure 5c. The membrane modules are divided into two sets; the two sets of modules are connected in series. The permeate gas from the second set is recycled to the feed of the first set of modules. In this configuration, the two different sets of modules are referred to as the first and second steps. The two-step configuration is generally preferred if the feed gas stream is to be substantially depleted of the more permeable gases. 


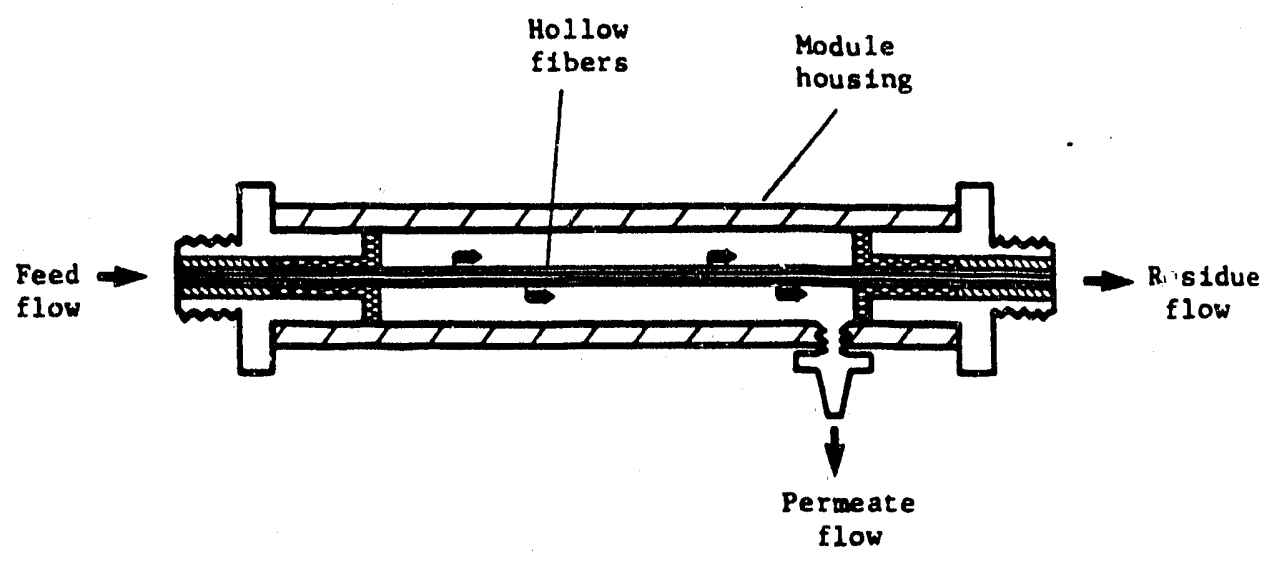

(a) Hollow-fiber membrane module

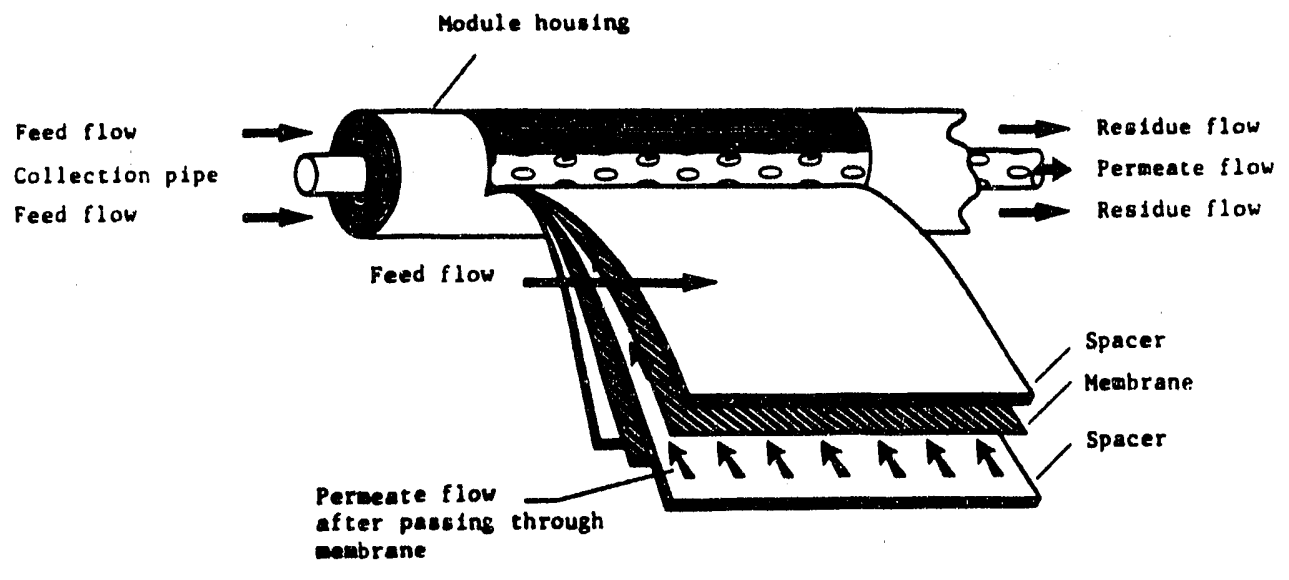

(b) Spiral-wound membrane module.

Figure 4. Schematic diagrams of a spiral-wound and a hollowfiber membrane module. 
A fourth possible system configuration, one that allows very high enrichments of the permeate to be achieved, is the two-stage system shown in Figure 5d. Here the membrane modules are again divided into two sets, but are connected as a cascade and the sets are called the first and second stages. The permeate gas from the first stage is used as the feed gas for the second stage, which effects a second enrichment of the more permeable gases. The residue of the second stage is recyeled to the feed of the first stage. The overall enrichment achieved with the two-stage system is equal to the product of the individual enrichments obtained in each separate stage.

All four membrane system configurations have been considered in the system analysis and economic evaluation. The most economical configurations appear to be the two-step and the two-stage systems. Depending on the type of separation required, either the two-step or the two-stage system represents the optimum configuration. Section VIII addresses these issues in detail.

\section{MEMBRANE GAS SEPARATION OPPORTUNITIES IN SYNTHESIS GAS PURIFICATION}

To select the appropriate permselective materials to be used in the membrane development work, we first had to decide which separations could potentially reduce the costs of synthesis gas purification. This section discusses the three points in the coal gasification process that rave been the focus of the present program.

Figure 6 gives a schematic flow diagram of a coal gasifier including the shift converter and the acid gas removal (AGR) unit. The gasifier uses either pure oxygen ("oxygen-blown") or air ("air-blown") as the gasifying medium. Included in the flow diagram are three positions where a membrane system could be incorporated. A discussion of these three opportunities for membrane gas separation systems follows.

\section{A. Final Separation}

If synthesis gas is produced by an air-blown gasifier, the final hydrogen stream obtained after the acid gas removal unit will contain large amounts of nitrogen, in the range $60-70 \%$. This nitrogen must be removed, but the separation of hydrogen from nitrogen is difficult by conventional processes. As a result, oxygen-blown gasifiers are always used to produce hydrogen from synthesis gas. However, polymer membranes are much more permeable to hydrogen than to nitrogen making the separation of hydrogen from nitrogen relatively straightforward. The use of an air-blown gasifier followed by a membrane hydrogen/nitrogen separation system would be attractive if the membrane system costs proved to be less than the costs of producing oxygen from air (typically done by cryogenic separation). 
(a) Single-stage system

(b) Single-stage system with recycle

(c) Two-step system

(d) Two-stage system
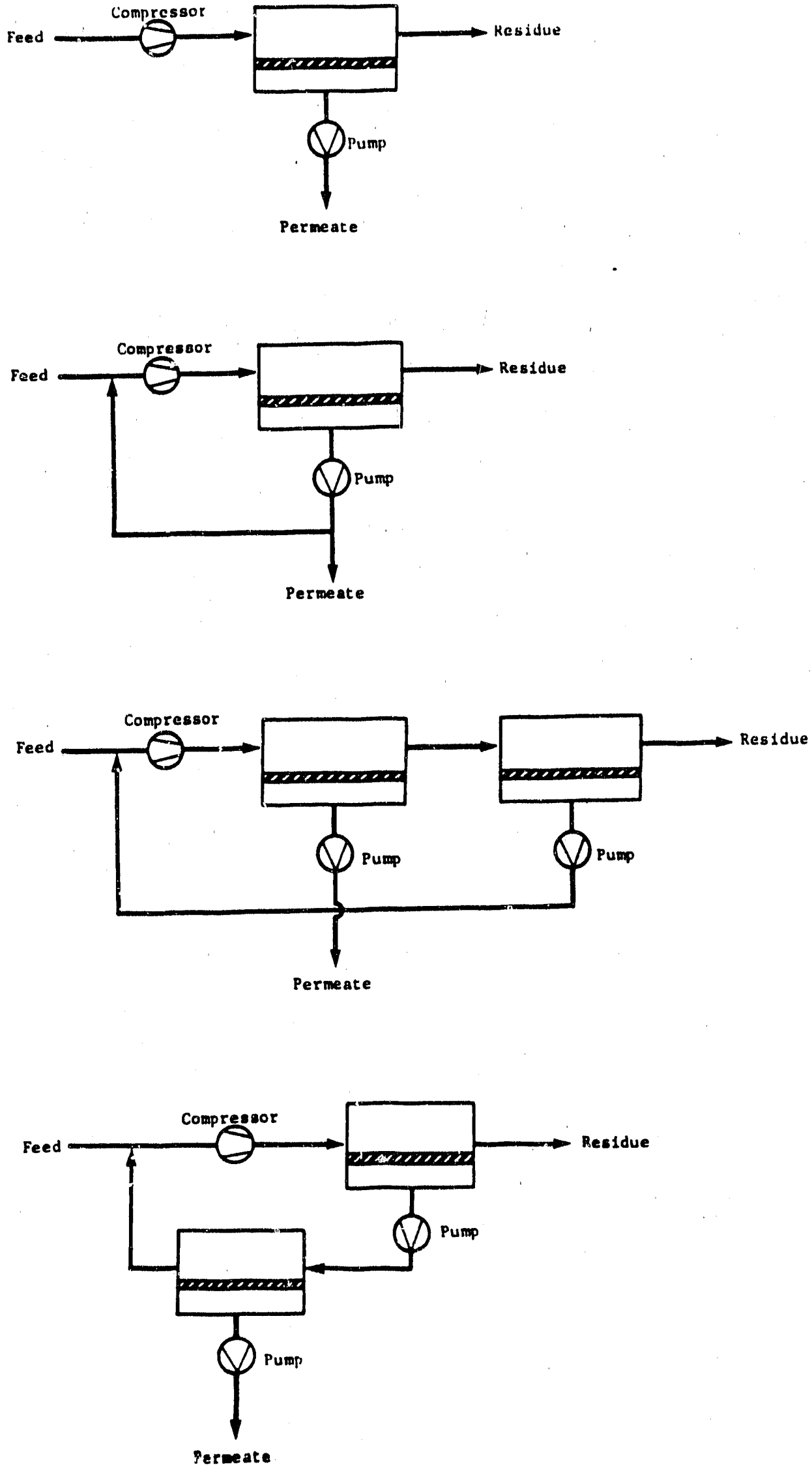

Figure 5. Flow diagrams of four different membrane system configurations. 


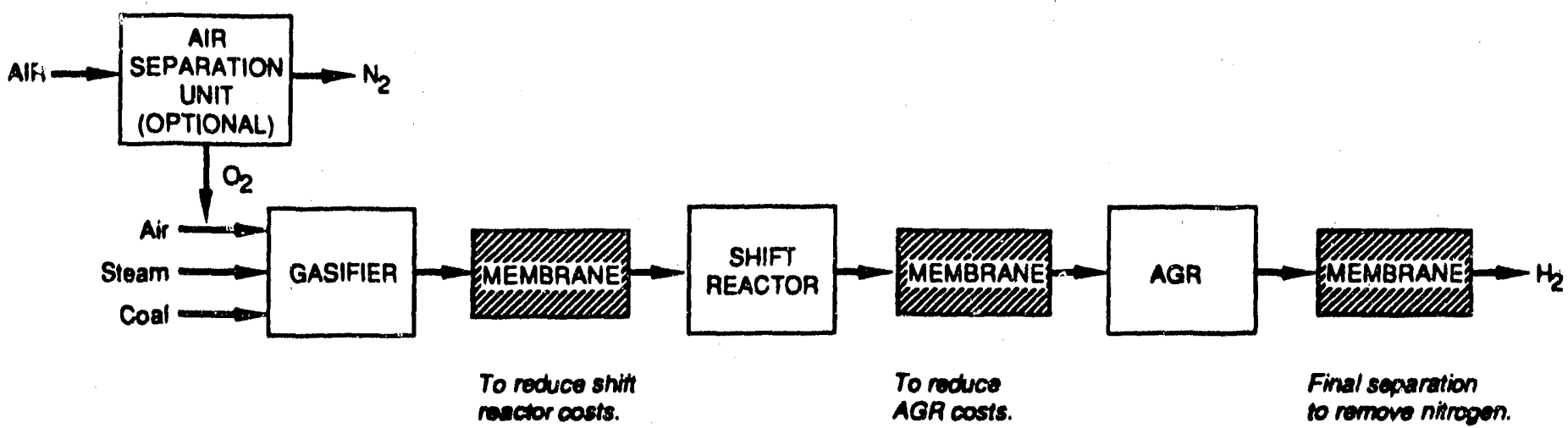

Figure 6. Flow diagram of a coal gasifier indicating potential positions for membrane gas separation systems.

AA.M. $1732 \cdot 26$ 


\section{B. AGR Cost Reduction}

The acid gas removal (AGK) unit, which removes carbon dioxide and hydrogen sulfide, is a major cost element in the production of hydrogen from synthesis gas. Therefore it will be of interest to investigate whether a membrane system could eliminate or reduce the size of the AGR unit.

In an airblown gasifier the gas stream entering the AGR consists mainly of hydrogen, carbon dioxide and hydrogen sulfide. It would be beneficial to effect a separation between the hydrogen and the acid gases by a membrane system. Depending on the purity of the produced hydrogen, the hydrogen stream could then be directly used or sent to a smaller AGR unit for total acid gas removal.

In the case of an air-blown gasifier, the gas stream entering the AGR contains a large amount of nitrogen as well. There now are two opportunities for membrane systems: (1) to remove nitrogen from the hydrogen and the acid gases, thereby reducing the volume flow rate entering the $A G R$, and (2) to separate the acid gases and hydrogen, as for the oxygen-blown gasifier.

\section{Shift Converter Cost Reduction}

The shift converter contributes a relatively minor part of the total costs of producing hydrogen from synthesis gas. However, some savings may be obtained by modifying the composition of the gas entering the shift converter to increase the conversion of carbon monoxide to hydrogen. The objective is to remove carbon dioxide from the gas stream prior to entering the shift converter. If too much hydrogen is lost in the carbon dioxide vent stream, this stream could bypass the shift converter and be routed to the AGR unit. The objective of changing the equilibrium in the shift converter could be achieved in both oxygen and airblown gasifiers.

Summarizing, the three membrane separation opportunities in the coal gasification process focus on the following chemical separations:

1. the separation of hydrogen from nitrogen,

2. the separation of carbon dioxide and hydrogen from carbon monoxide and nitrogen, and

3. the separation of carbon dioxide and hydrogen sulfide from hydrogen and nitrogen.

All three of these separations were considered in the membrane development work. 


\section{MEMBRANE DEVELOPMENT AND TESTING}

\section{A. Introduction and Overview}

The previous section identified three different separations of particular interest to synthesis gas purification by membranes. In the membrane development work, we focussed mainly on two polymers as the membrane permiselective materials: (1) polyetherimide for the separation of hydrogen from nitrogen and the separation of hydrogen and carbon dioxide from nitrogen and carbon monoxide, and (2) a polyamide copolymer for the separation of hydrogen sulfide and carbon dioxide from hydrogen. Membranes and membrane modules were successfully prepared with both polymers. Some development work was performed with palladium/silver alloys, which are permeable to hydrogen and, in principle, impermeable to all other gases.

\section{B. Selection of Permselective Polymer Materials}

Table 6 lists the hydrogen and nitrogen permeabilities of five different polymers. All polymers are selective for hydrogen over nitrogen, but the selectivity varies from 3.7 to 230 . In general, the hydrogen and nitrogen permeability decreases with increasing selectivity. However, of the three most selective materials, i.e., cellulose acetate, polysulfone and polyetherimide, the most attractive combination of permeability and selectivity is presented by the polyetherimide. This polymer has by far the highest selectivity and has a hydrogen permeability larger than most glassy membranes. Therefore, polyetherimide was selected as the permselective material for the membrane development work. The permeabilities of nitrogen and carbon monoxide are approximately equal for all polymers. Thus, polyetherimide is also expected to be suited for the separation of hydrogen from carbon monoxide. The development of polyetherimide membranes is described in Section VI(C).

Table 6. Gas Permeabilities of Candidate Permselective Materials for $\mathrm{H}_{2} / \mathrm{N}_{2}$ Separation

\begin{tabular}{|c|c|c|c|}
\hline \multirow[t]{2}{*}{ Polymer } & \multicolumn{2}{|c|}{$\begin{array}{c}\text { Permeability* } \\
10^{-10} \times \mathrm{cm}^{3}(\mathrm{STP}) \mathrm{cm} / \mathrm{cm}^{2} \cdot \mathrm{s} \cdot \mathrm{cmHg}\end{array}$} & \multirow{2}{*}{$\begin{array}{r}\mathrm{H}_{2} / \mathrm{N}_{2} \\
\text { Selectivity }\end{array}$} \\
\hline & $\mathbf{H}_{2}$ & $\mathbf{N}_{2}$ & \\
\hline Silicone rubber & 930 & 250 & 3.7 \\
\hline Ethyl cellulose & 144 & 76 & 19 \\
\hline Cellulose acetate & 24 & 0.50 & 48 \\
\hline Polysulfone & 13 & 0.18 & 72 \\
\hline Polyetherimide & 25 & 0.11 & 230 \\
\hline
\end{tabular}

- Permeabilities obtained at MTR except for polysulfone $e^{16}$ 
Table 7. Gas Permeabilities of Candidate Permselective Materials for $\mathrm{H}_{2} \mathrm{~S} / \mathrm{N}_{2}$ and $\mathrm{CO}_{2} / \mathrm{N}_{2}$ Separation

\begin{tabular}{|c|c|c|c|c|c|}
\hline \multirow[t]{2}{*}{ Polymer } & \multicolumn{3}{|c|}{$\begin{array}{c}\text { Permeability" } \\
10^{-10} \times \mathrm{cm}^{3}(\mathrm{STP}) \mathrm{cm} / \mathrm{cm}^{2} \cdot \mathrm{s} \cdot \mathrm{cmHg}_{\mathrm{g}}\end{array}$} & \multicolumn{2}{|c|}{ Selectivity } \\
\hline & $\mathrm{H}_{2} \mathrm{~S}$ & $\mathrm{CO}_{2}$ & $\mathrm{H}_{2}$ & $\mathrm{H}_{2} \mathrm{~S} / \mathrm{H}_{2}$ & $\mathrm{CO}_{2} / \mathrm{H}_{2}$ \\
\hline Silicone rubber & 8400 & 3200 & 930 & 9.0 & 3.3 \\
\hline Polyamide copolymer & 1200 & 135 & 14 & 85 & 10 \\
\hline Methyl cellulose & - & 3.0 & 0.075 & - & 40 \\
\hline Polysulfone & 3.1 & 6.9 & 13 & 0.24 & 0.53 \\
\hline Polyetherimide & - & 6.5 & 25 & - & 0.26 \\
\hline
\end{tabular}

- Permeabilities obtained at MTR, except for polysulfone ${ }^{34}$ and methyl cellulose ${ }^{36}$.

The gas permeabilities of five candidate permselective polymers and their selectivities for hydrogen sulfide over hydrogen and carbon dioxide over hydrogen are given in Table 7. The first two polymers listed, silicone rubber and the polyamide copolymer, are rubbery materials and are selective for the acid gases over hydrogen. The last two polymers, polysulfone and polyetherimide, are glassy polymers and, in contrast to rubbery polymers, are selective for hydrogen over the acid gases. The data presented for methyl cellulose are puzzling: the very low permeabilities suggest the polymer is, in the glassy state, whereas the material is extremely selective for carbon dioxide over hydrogen which is a feature of rubbery polymers. The preliminary results with methyl cellulose did not look promising, so work with this polymer was discontinued early in the program. The most promising material for acid gas/hydrogen separation is the polyamide copolymer. The best candidate for hydrogen/nitrogen separation is the polyetherimide. Detailed development work with each of these materials was performed.

\section{Polyetherimide Membranes}

The development of polyetherimide membranes focussed on two different types of membrane structures: (1) asymmetric, and (2) composite. Figure 7 shows cross-sectional views of the two membrane structures. 


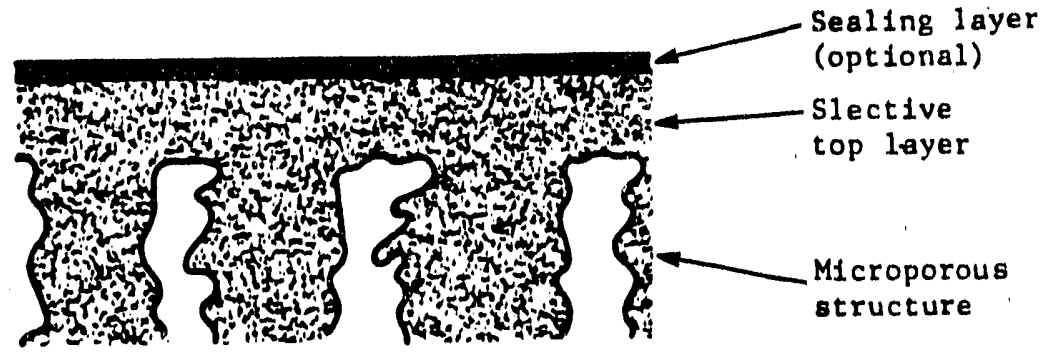

(a) Asymmetric membrane with o tional sealing layer

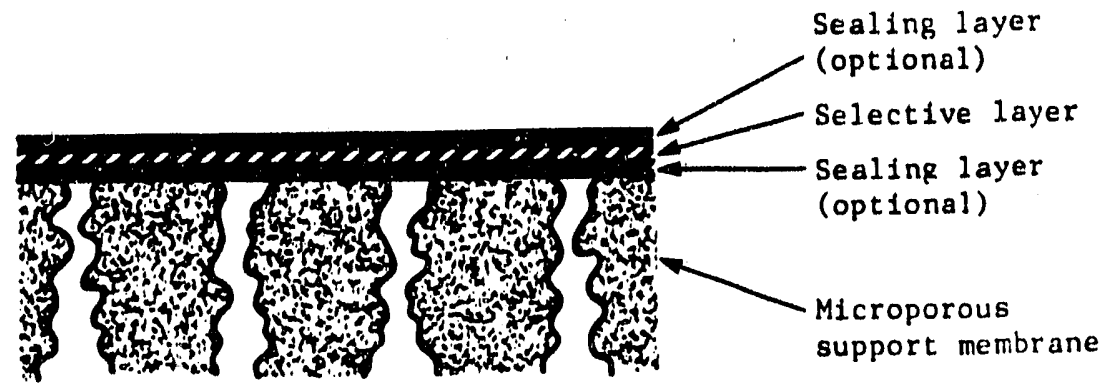

(b) Multilayer composite membrane

Figure 7. Cross-sectional representations of an asymmetric membrane and a multilayer composite membrane. 
An asymmetric membrane consists of a dense top layer backed by a microporous layer. The membrane is made in one step by the immersion precipitation process. The polymer is dissolved in a solvent, the solution is spread as a thin film and subsequently immersed in a water bath. The solvent diffuses into the water bath and the polymer precipitates as a layer with an asymmetric structure. The dense top layer is responsible for the selective properties of the membrane, whereas the microporous layer gives the membrane r.jechanical strength. The permeation rate of the membrane can be increased by making the dense layer thinner. However, the thinner the skin layer becomes, the greater is the occurrence of small pores from the microporous layer extending through the dense layer, a phenomenon which severely reduces the membrane's selectivity. It is therefore advantageous to treat the membrane top surface to close the defects. Several methods have been suggested. ${ }^{16,17,18} \mathrm{~A}$ particularly useful method was developed by Monsanto and involves a thin rubbery sealing layer coated onto the top surface. ${ }^{16}$ This layer does not contribute to the membrane's selectivity but merely prevents bulk flow of gases through eventual defects.

Composite membranes, as shown in Figure $7 \mathrm{~b}$, consist of a microporous support membrane covered by a selective layer. The microporous support and the selective layer are made in a two-step process and are usually made from different materials. The support membrane is made by the immersion precipitation process described earlier and the selective layer is coated onto the support membrane in a solution coating process. An advantage of composite membranes is that the permselective material does not need to have great mechanical strength. Thus, rubbery materials can be used as the permselective materials whereas asymmetric membranes can only be prepared from glassy polymers. Composite membranes can have one or twn sealing layers, as shown in Figure $7 \mathrm{~b}$. The sealing layer between the microporous support and the selective layer can facilitate the coating step of the selective material. The top sealing layer serves to plug any defects, much like the sealing layer on an asymmetric membrane.

Both composite and asymmetric polyetherimide membranes were prepared and initially tested with pure gases at 50 psig feed pressure. Both membrane structures yielded promising membranes. However, all composite mernbranes showed poor performance at feed pressures over 100 psig. The membrane structure of choice is, therefore, the asymmetric structure and membrane characterization has been done with this type of membrane only.

\section{Asymmetric Polyetherimide Membranes}

Polyetherimide membranes of the asymmetric structure shown in Figure 7a were prepared using the immersion precipitation process. Flat-sheet membranes were cast from a solution containing dichloromethane as the principal solvent and coagulated in an acetone bath. A typical casting solution composition is given in Table 8. ${ }^{20}$ The resulting membranes were tested with pure hydrogen and nitrogen at 50 psig feed pressure and showed hydrogen/nitrogen selectivities in the range of 10 to 25 . The membranes were then coated with a thin layer of silicone rubber to seal any defects in the selective polyetherimide layer. The membrane's hydrogen/nitrogen selectivities increased significantly and ranged from 
150 to 220, indicating the pring of small defects in the polyetherimide asymmetric membrane. MTR also obtained some flat-sheet asymmetric polyetherimide membranes from GKSS Research Center, a German government research institute located in Geesthacht, West Germany. Table 9 gives the properties of this membrane, made by essentially the same procedure as used by MTR. The membrane performance is basically identical.

Table 8. Typical Composition of Castine Solution for Preparation of Asymmetric Polvetherimide Membranes ${ }^{20}$

Polyetherimide

Dichloromethane

1,1,2,2-Tetrachloroethane

Xylene

Acetic acid
$15.9 w t \%$

$54.6 w t \%$

$4.8 w t \%$

$17.6 \mathrm{wt} \%$

$7.1 \mathrm{wt} \%$

Table 9. Performance of GKSS Polvetherimide Membranes for Hydrogen/Nitrogen Separation

\begin{tabular}{|c|c|c|c|}
\hline Membrane & $\begin{array}{c}\text { Normaliz } \\
\left(\mathrm{cm}^{3}(\mathrm{STP}) /\right. \\
\mathrm{N}_{2}\end{array}$ & $\begin{array}{l}\text { Flux } \\
\qquad \mathrm{H}_{2}\end{array}$ & $\begin{array}{l}\text { Selectivity } \\
\qquad \mathrm{H}_{2} / \mathrm{N}_{2}\end{array}$ \\
\hline $\begin{array}{l}\text { GKSS integral- } \\
\text { asymmetric } \\
\text { poly(etherimide), } \\
\text { uncoated }\end{array}$ & $5 \times 10^{-6}$ & $1 \times 10^{-4}$ & 20 \\
\hline $\begin{array}{l}\text { MTR integral- } \\
\text { asymmetric } \\
\text { poly(etherimide) + } \\
\text { silicone rubber } \\
\text { coating }\end{array}$ & $3.5 \times 10^{-7}$ & $7 \times 10^{-5}$ & 200 \\
\hline
\end{tabular}

The procedure for preparing high-performance flat-sheet polyetherimide membranes involved the use of an acetone coagulation bath. The use of large baths containing organic solvents presents several problems, the most important being explosion hazards. Therefore, water would be a much preferred coagulant in any industrial membrane preparation process. Several attempts were made to prepare flat-sheet polyetherimide membranes using hydrophilic solvents in the casting solution and water as the coagulant. However, severe shrinkage of the polymer solution during the coagulation step occurred, which rendered the membrane unusable. However, shrinkage of the polymer solution is a much lesser 
problem if the membrane is made in the hollow-fiber form. Table 10 gives the properties of asymmetric polyetherimide hollow fibers made from various spinning dopes and coagulated into a water bath. Good quality hollow-fiber membranes were prepared by this procedure with selectivities close to those of flat-sheet membranes and with permeation rates within $50 \%$ of those obtained with flat-sheet membranes. Thus, asymmetric polyetherimide membranes with approximately identical properties could be prepared in both the flat-sheet and hellow-fiber configuration. Despite the slightly inferior performance, the hollow-fiber would probably be the preferred configuration for scale-up to the industrial level because water, instead of acetone, can be used as the coagulant in the membrane preparation process.

Table 10. Performance of Polyetherimide/Silicone Rubber Hollow Fibers for Hydrogen/Nitrogen Separation

\begin{tabular}{|c|c|c|c|}
\hline $\begin{array}{l}\text { Composition of } \\
\text { spinning dope } \\
\text { (wt \%) }\end{array}$ & $\begin{array}{l}\text { Normaliz } \\
\left(\mathrm{cm}^{3}(\mathrm{STP}\right. \\
\mathbf{N}_{2}\end{array}$ & 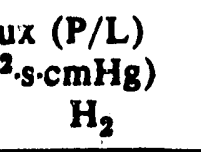 & $\begin{array}{l}\text { Selectivity } \\
\mathrm{H}_{2} / \mathrm{N}_{2}\end{array}$ \\
\hline $\begin{array}{l}18.8 \% \text { poly(etherimide } \\
1.5 \% \text { polyvinylpyrrolidone, } \\
79.7 \% \text { N-methylpyrrolidone }\end{array}$ & $8.2 \times 10^{-8}$ & $1.2 \times 10^{-5}$ & 150 \\
\hline $\begin{array}{l}20.5 \% \text { poly(etherimide } \\
1.5 \% \text { poly-vinylpyrrolidone, } \\
78.0 \% \mathrm{~N}, \mathrm{~N} \text {-dimethyl-acetamide }\end{array}$ & $2.0 \times 10^{-7}$ & $3.3 \times 10^{-5}$ & 170 \\
\hline $\begin{array}{l}25 \% \text { polyetherimide } \\
75 \% \text { N,N-dimethylacetamide }\end{array}$ & $1.7 \times 10^{-7}$ & $3.3 \times 10^{-6}$ & 190 \\
\hline
\end{tabular}

The polyetherimide asymmetric membranes were evaluated with five different gases: hydrogen, carbon dioxide, carbon monoxide, methane and nitrogen. The high-pressure permeability test system used is shown in Figure 8 . The experiments were all carried out with flat-sheet membranes but the results are valid for the hollow-fiber polyetherimide membranes as well. Figure 9 shows the pure gas permeation rates of the five gases as a function of the feed pressure up to 500 psig. The permeation rates are independent of the feed pressure which indicates that plasticization of the membrane by the permeate gas does not occur. Figure 10 gives the selectivity of the membrane for various gas pairs. The selectivity is the ratio of the pure gas permeation rates. The selectivity of the membrane for hydrogen over the other gases is greater than 100 with the exception of carbon dioxide. The hydrogen/carbon dioxide selectivity is $5-7$. Figure 10b gives the selectivity for carbon dioxide over the other gases. 


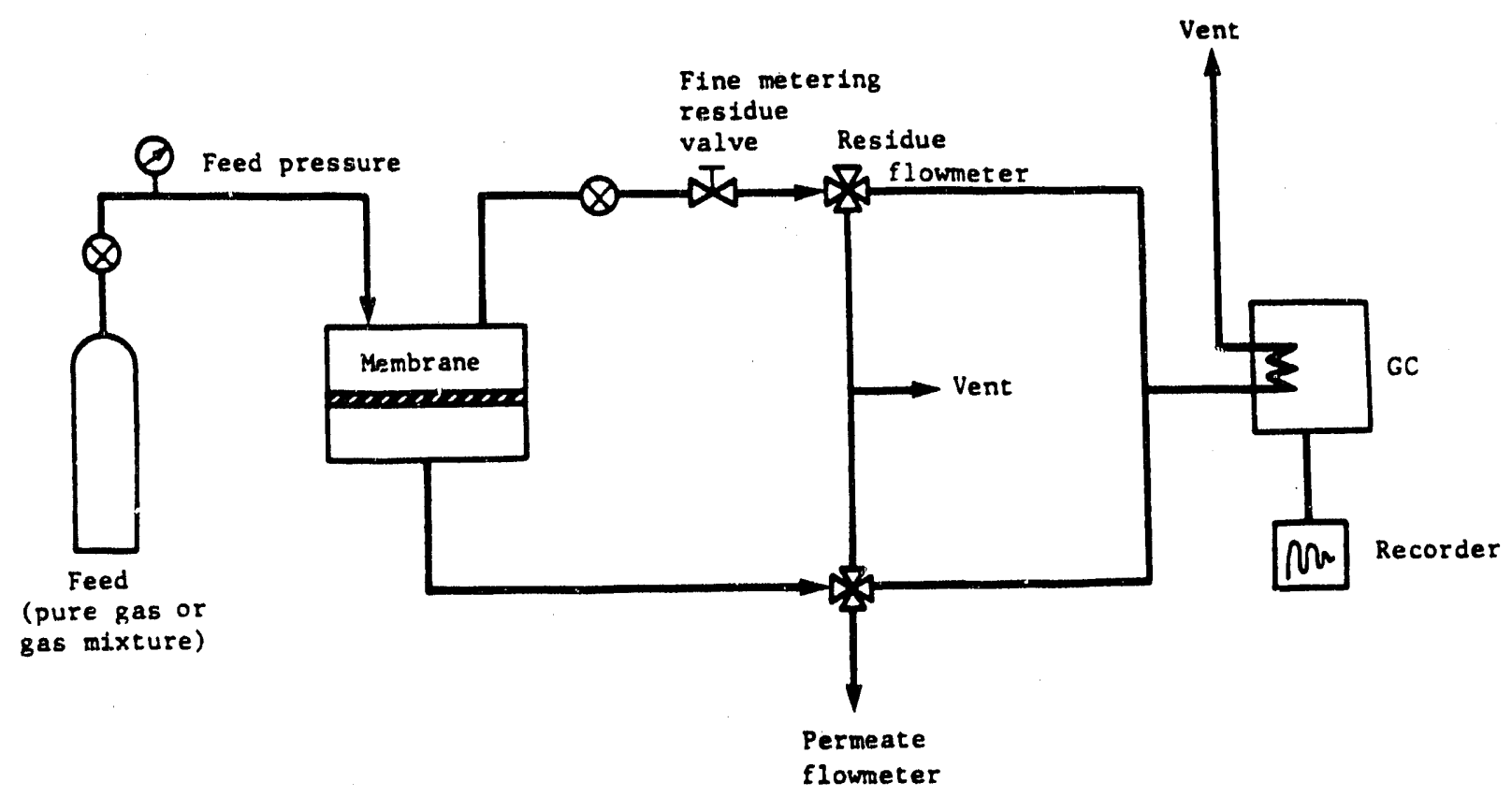

Figure 8. High-pressure permeability test system for pure gases and gas mixtures. 


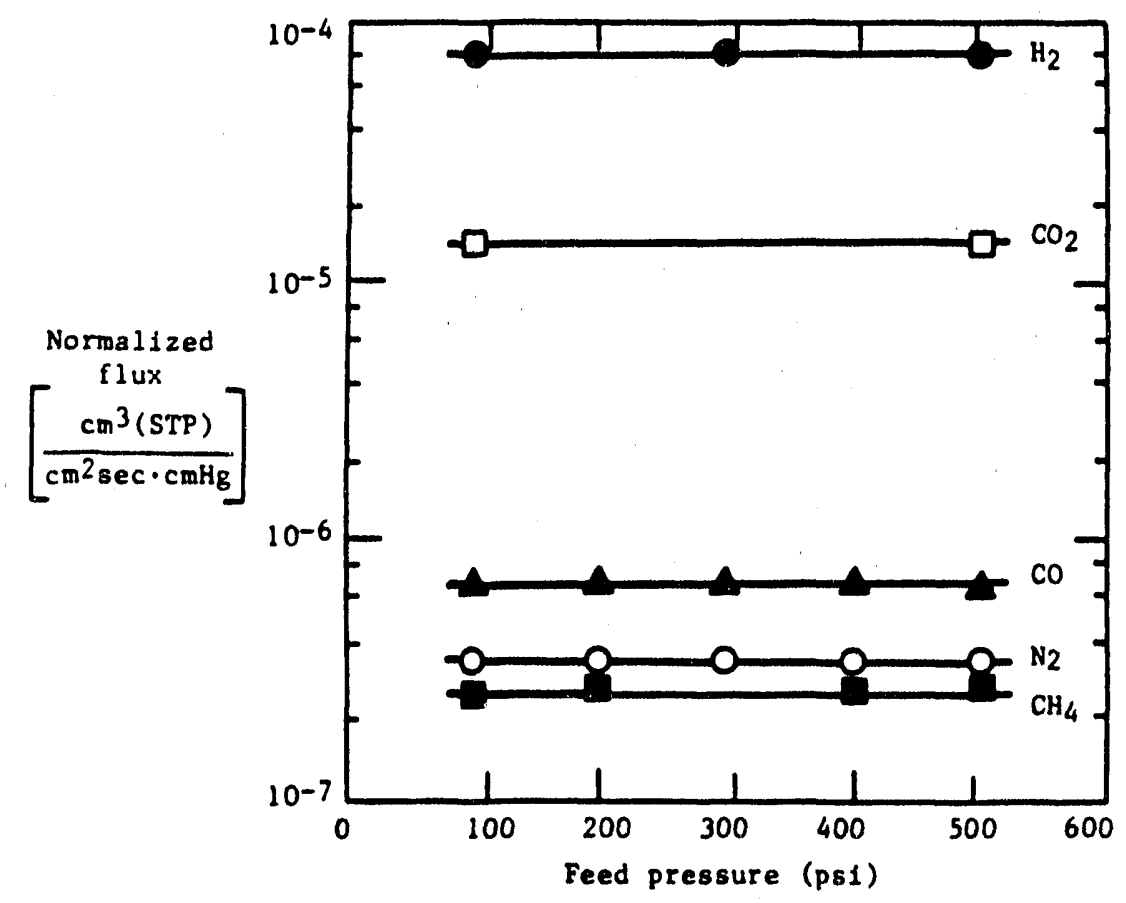

Figure 9. Normalized fluxes of asymmetric polyetherimide membranes with a silicone rubber sealing layer as a function of feed pressure. 


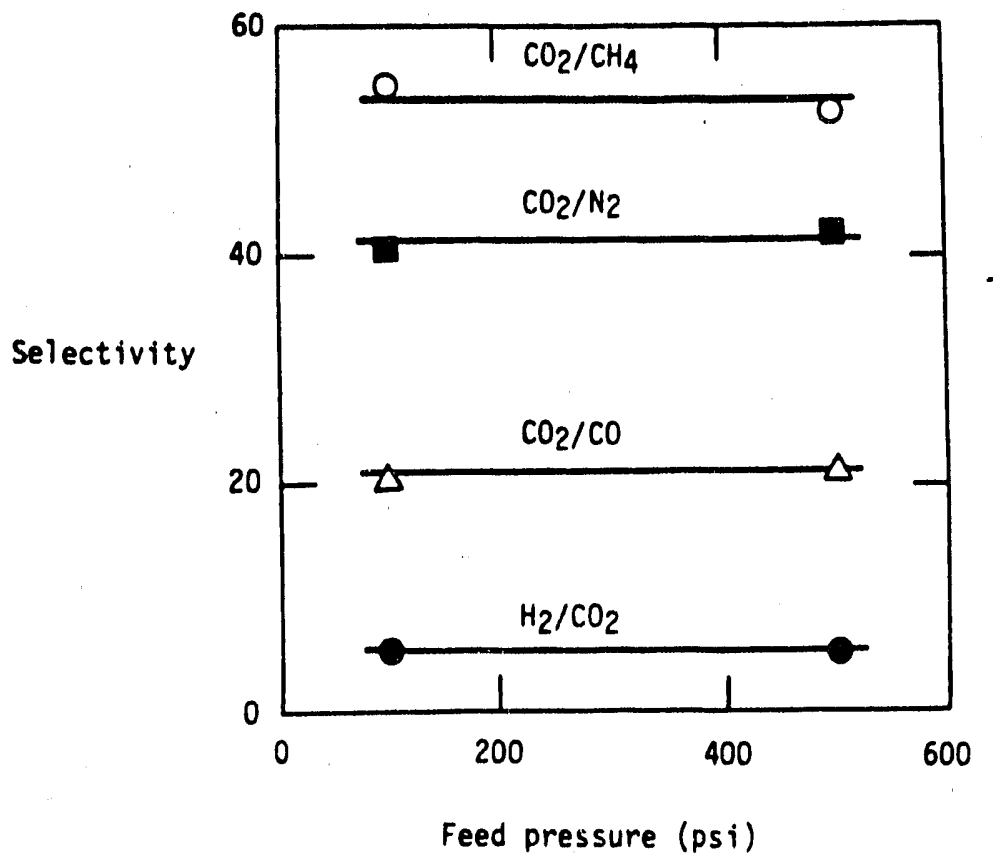

(a)

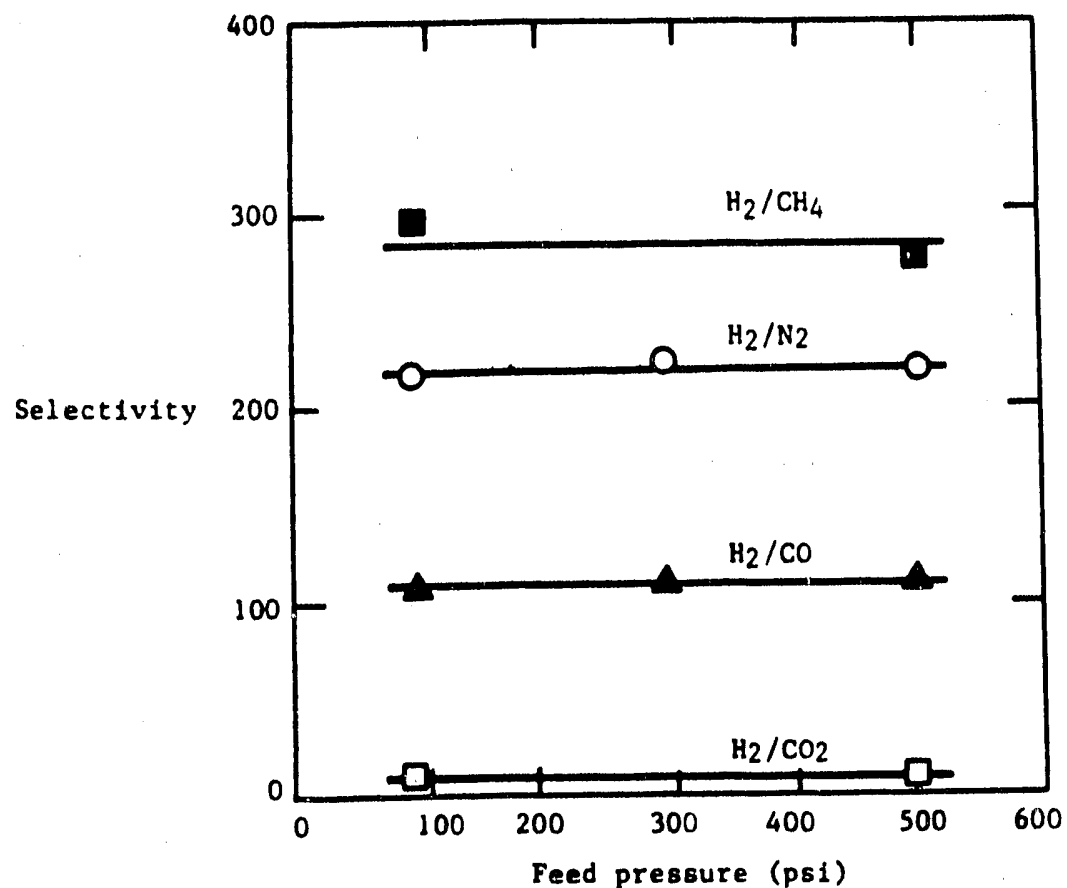

(b)

Figure 10. Selectivities of asymmetric polyetherimide membranes with a silicone rubber sealing layer as a function of feed pressure. Temperature: $25^{\circ} \mathrm{C}$. 
The asymmetric polyetherimide membranes were further characterized by measuring the permeation rates of the test gases as a function of temperature. Figure 11 shows that the permeation rates increase with temperature and can be described by the Arrhenius equation as is expected for a diffusion-controlled process. The relative increase in permeation rate is the largest for nitrogen and the smallest for carbon dioxide. The smaller increase in the case of carbon dioxide can be expiained because the solubility of carbon dioxide decreases with increasing temperature. Because the relative increase of the permeation rate with temperature is different for each gas, the selectivity is also a function of temperature, as shown in Figure 12. The hydrogen/nitrogen selectivity decreases from 240 at room temperature to 110 at $85^{\circ} \mathrm{C}$. The hydrogen/carbon dioxide selectivity increases very modestly from 6.2 at room temperature to 7.0 at $85^{\circ} \mathrm{C}$.

A number of experiments with the asymmetric polyetherimide membrane was carried out with hydrogen/nitrogen feed gas mixtures instead of pure gases. It is not uncommon that the behavior of a membrane with a gas mixture is different than its behavior with pure gases, because of the effect of one or more gases on the membrane material, or for other reasons. The permeate composition was determined with a gas chromatograph and the apparent hydrogen/nitrogen selectivity was calculated. Figure 13 gives the calculated selectivities obtained with two different mixtures as a function of the feed pressure. The calculated selectivity is independent of the feed pressure and depends slightly on the feed gas composition. Moreover, the selectivities observed with the gas mixtures are very close to the selectivity obtained from the pure gas experiments, especially at high hydrogen concentrations. From this result we conclude that, at least in the case of the polyetherimide membrane, using single gas permeation data to predict the performance of the membrane with gas mixtures is acceptable.

\section{Composite Polvetherimide Membranes}

A number of composite membranes with the structure shown in Figure $7 \mathrm{~b}$, were prepared. A microporous support membrane prepared from an amorphous polyamide was coated with a rubbery polymer to form an intermediate layer, onto which a thin polyetherimide layer was finally coated. Alternatively, the polyetherimide layer was coated directly onto the polyamide support. The solvents used in the polyetherimide coating solution are halogenated hydrocarbons, mostly dichloromethane. The resulting composite membrane can be used as is, or can be overcoated with a final rubbery layer, to seal defects and to protect the thin polyetherimide layer. The composite membranes were tested with pure hydrogen and nitrogen at 50 psig feed pressure. Table 11 summarizes the results. In general, much better selectivities, with relatively small losses in flux, were obtained from the composites with a top sealing layer. The properties of the composite membranes approached those of the asymmetric membranes, although selectivities were somewhat lower. The best composite membranes had hydrogen/nitrogen selectivities around 180 . 


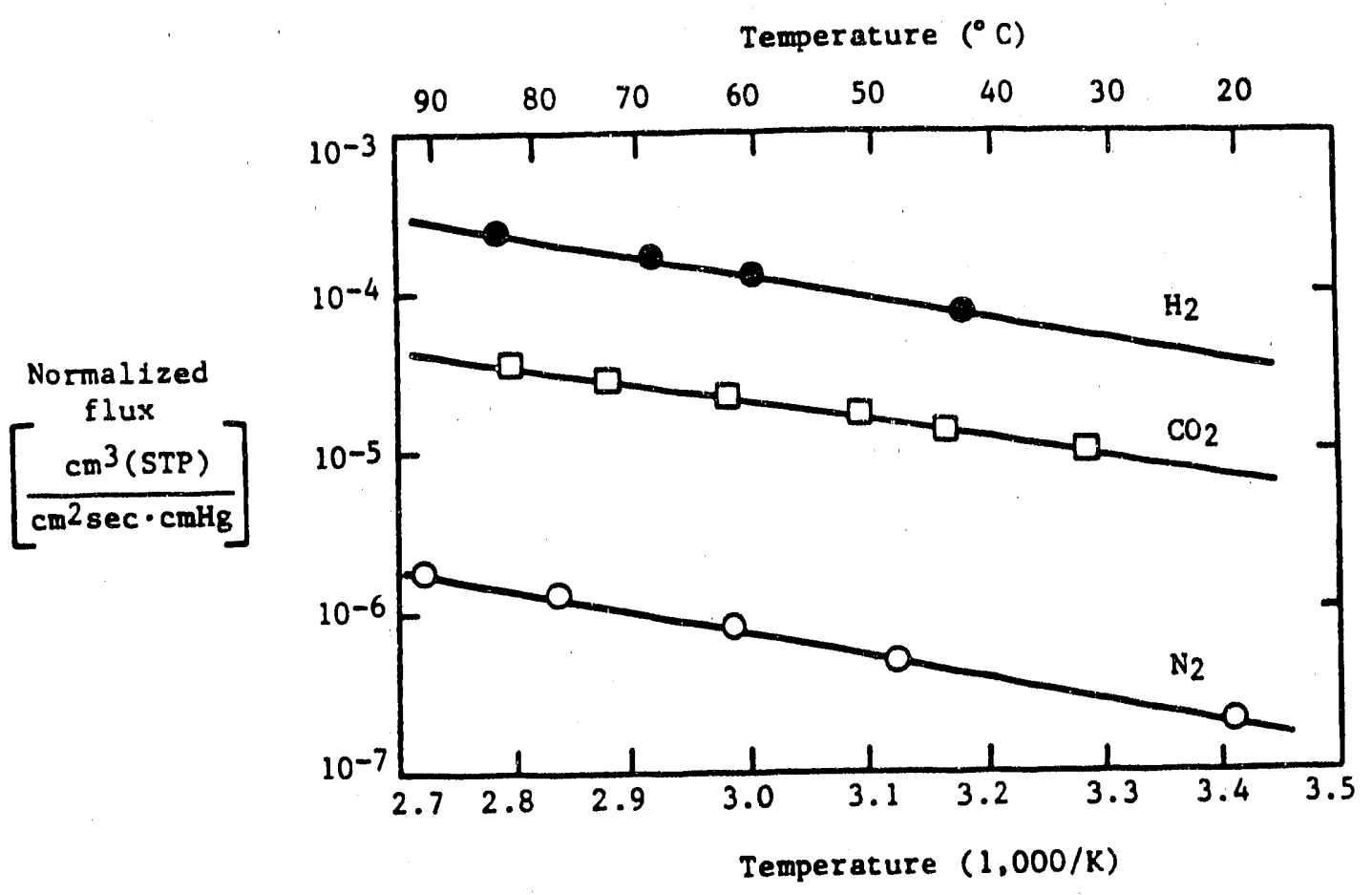

Figure 11. Normalized fluxes of asymmetric polyetherimide membranes with a silicone rubber sealing layer as a function of feed temperature. Feed pressure: 50 psig. 


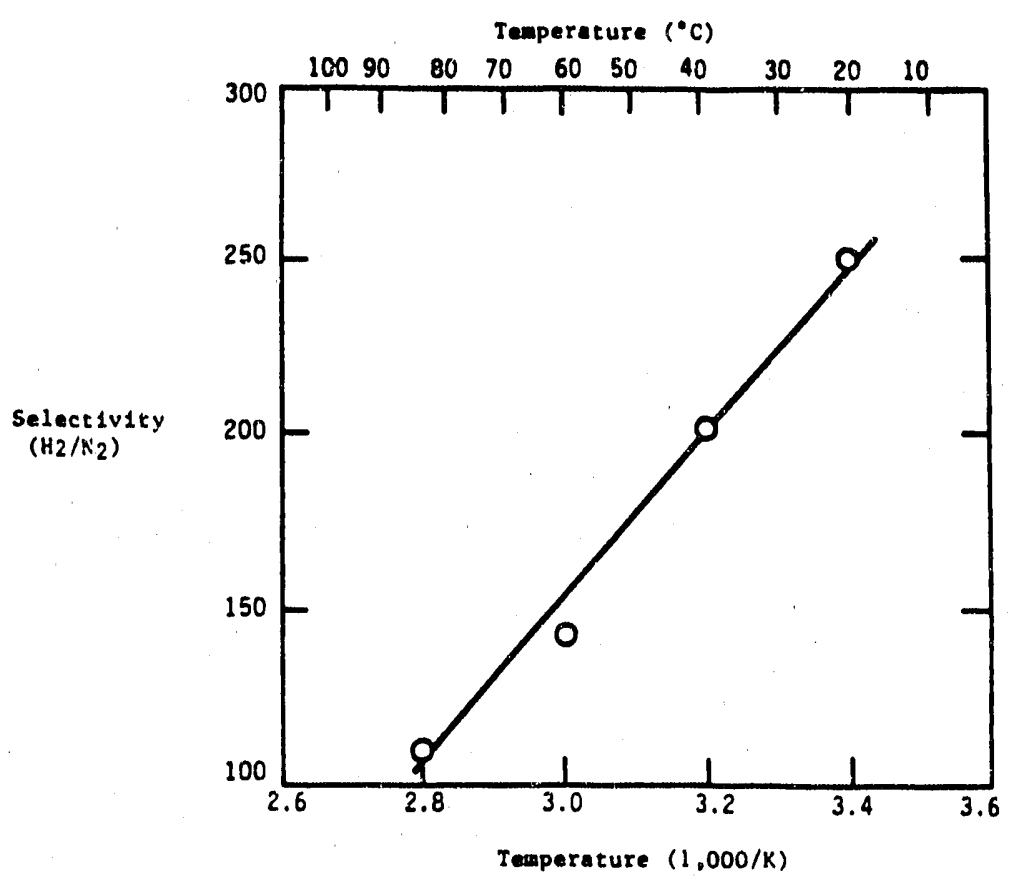

Figure 12a. Hydrogen/nitrogen selectivity of asymmetric polyetherimide membranes with a silicone rubber sealing layer as a function of feed temperature.

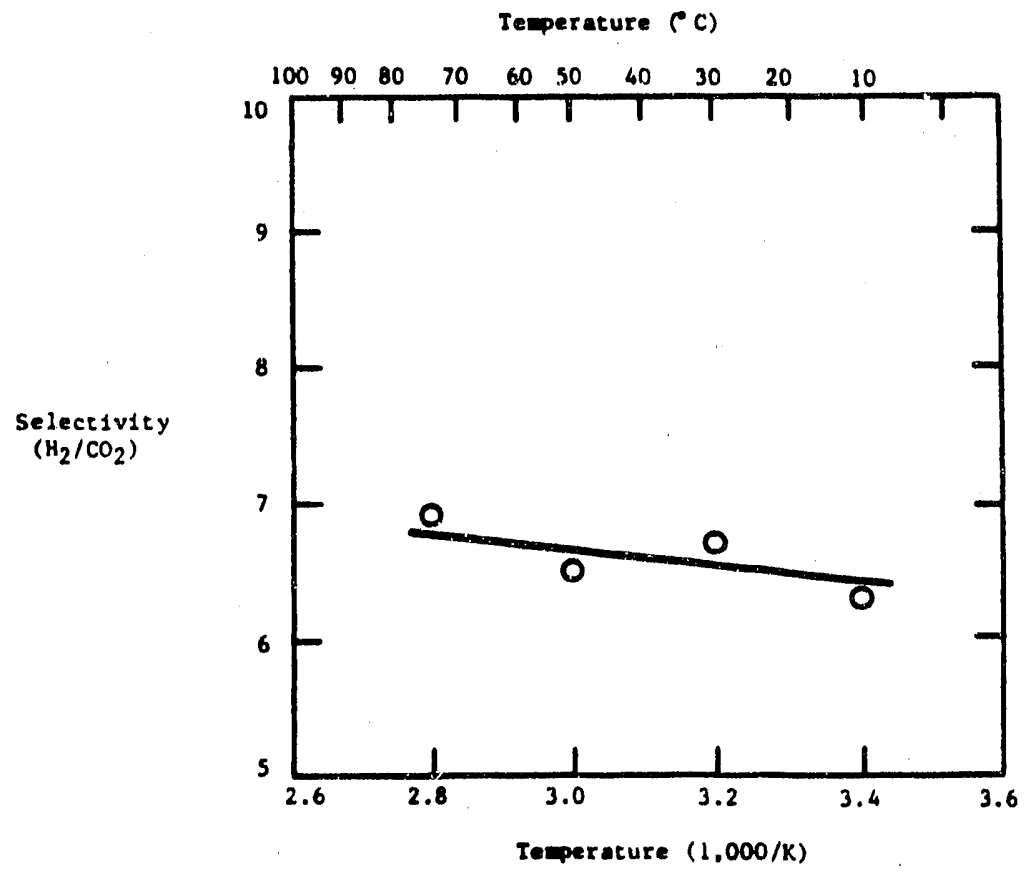

Figure 12b. Hydrogen/carbon dioxide selectivity of asymmetric polyetherimide membranes with a silicone rubber sealing layer as a function of feed temperature. 


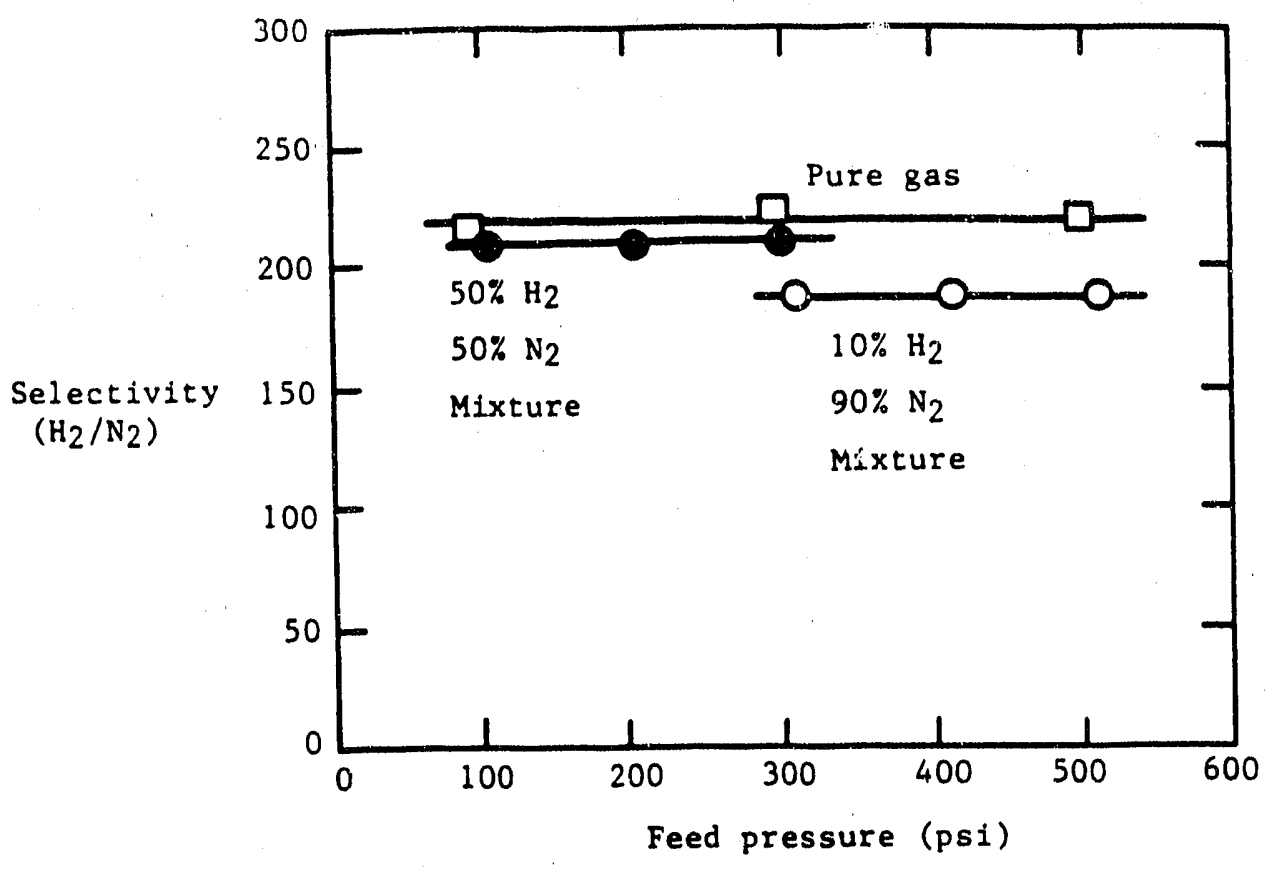

Figure 13. Hydrogen/nitrogen selectivity of asymmetric polyetherimide membranes with a silicone rubber sealing layer as a function of feed pressure. Temperature: $25^{\circ} \mathrm{C}$. 
After initial testing of the composite membranes at 50 psig feed pressures, additional testing was performed at 100 psig. All membranes tested showed a sudden large increase of gas permeability, accompanied by loss of all, or nearly all, selectivity. The membranes are clearly not stable at elevated pressure, most likely due to collapse of the polyetherimide layer where this layer bridges the pores in the support membrane. The presence of an intermediate layer did not seem to alleviate this problem. Polyetherimide is a glassy polymer with a much lower tensile strength than rubbery materials which probably explains the ineffectiveness of the intermediate rubbery layer. In light of the poor mechanical stability of the composite membranes and the successful development of asymmetric polyetherimide membranes, polyetherimide composite membranes were not further considered.

Table 11. Performance of Different Polvetherimide Composite Membranes (Pure $\mathrm{H}_{2}$ and $\mathrm{N}_{2}$ fluxes measured at $25^{\circ} \mathrm{C}$ and 50 psig feed pressure.)

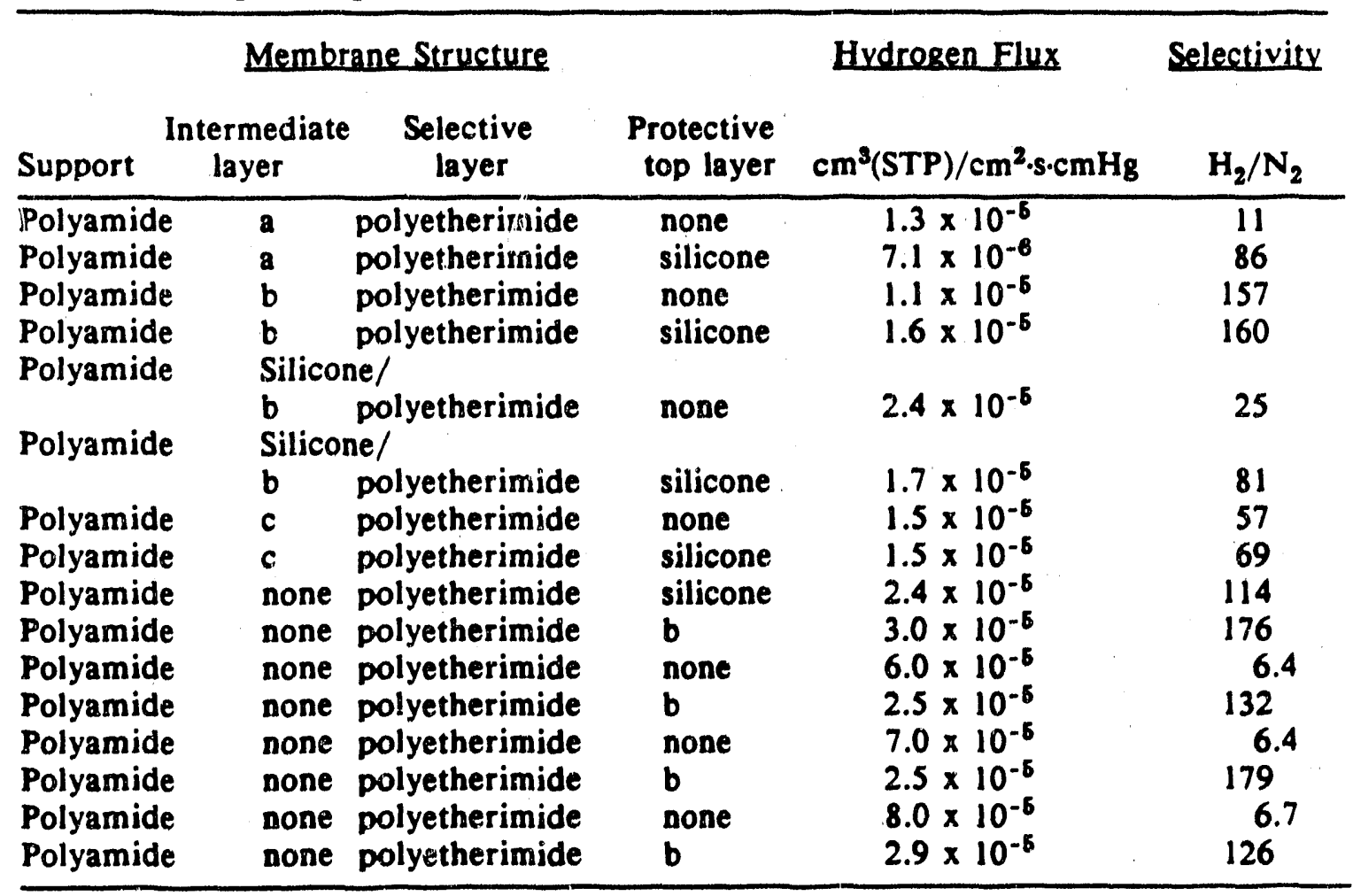

a) polystyrene-butadiene copolymer

b) polymethylpentene

c) polyamide copolymer

\section{Polyamide Copolymer Membranes}

The polyamide copolymer selected as the ca.ıdidate permselective material for the separation of acid gases from hydrogen is a rubbery polymer. Preparation of asymmetric membranes was thus not possible and the membrane development work focussed on composite membranes of the general structure shown in Figure $7 \mathrm{~b}$. 
The specific structure of the polyamide copolymer membranes is shown in Figure 14. A polysulfone microporous layer is coated with a silicone rubber layer of approximately $1-\mu \mathrm{m}$ thickness. A polyamide copolymer layer is then coated on top of the silicone rubber layer by a solution coating technique to produce a finished permselective membrane thickness of $0.4 \mu \mathrm{m}$. As before, some polyamide copolymer composite membranes were overcoated with a final silicone rubber layer to protect the membrane.

Poiyamide copolymer composite membranes were characterized by measuring their pure hydrogen and carbon dioxide permeation rates at 50 psig feed pressure. The results are listed in Table 12. The carbon dioxide flux, at $4 \times 10^{-4}$ $\mathrm{cm}^{3}(\mathrm{STP}) / \mathrm{cm}^{2} \cdot \mathrm{s} \cdot \mathrm{cmH}_{\mathrm{g}}$, is very high. The carbon dioxide/hydrogen selectivity is approximately 10.5 for composites without a top sealing layer and 9.2 for composites with the layer. The silicone rubber top layer decreases the selectivity because its carbon dioxide/hydrogen selectivity is 3.5 , very low compared to the polyamide copolymer.

\section{Table 12. Performance of Polvamide Copolvmer Comoosite Membranes for Carbon Dioxide/Hydrosen Separation Feed Pressure: 50 psig}

\begin{tabular}{lcccc}
\hline & \multicolumn{5}{c}{$\begin{array}{c}\text { Normalized Flux } \\
\left(\mathrm{cm}^{3}(\mathrm{STP}) / \mathrm{cm}^{2} .5 \cdot \mathrm{cmHg}\right)\end{array}$} \\
Membrane & Sample \# & $\mathrm{H}_{2}$ & $\mathrm{CO}_{2}$ & $\begin{array}{c}\text { Selectivity } \\
\mathrm{CO}_{2} / \mathrm{H}_{2}\end{array}$ \\
\hline Polysulfone/ & 1 & $3.9 \times 10^{-5}$ & $4.2 \times 10^{-4}$ & 10.8 \\
silicone rubber/ & 2 & $4.3 \times 10^{-5}$ & $4.3 \times 10^{-4}$ & 10.0 \\
polyamide co- & 3 & $3.8 \times 10^{-5}$ & $4.0 \times 10^{-4}$ & 10.5 \\
polymer & 5 & $3.7 \times 10^{-5}$ & $4.0 \times 10^{-4}$ & 10.9 \\
& 6 & $3.9 \times 10^{-5}$ & $4.2 \times 10^{-4}$ & 10.7 \\
& 7 & $4.4 \times 10^{-5}$ & $4.5 \times 10^{-4}$ & 10.3 \\
& 8 & $3.9 \times 10^{-5}$ & $4.1 \times 10^{-4}$ & 10.5 \\
\hline Polysulfone/ & 1 & $4.8 \times 10^{-6}$ & $4.3 \times 10^{-4}$ & 9.0 \\
silicone rubber/ & 2 & $4.6 \times 10^{-5}$ & $4.3 \times 10^{-4}$ & 9.4 \\
polyamide co- & 3 & $4.8 \times 10^{-5}$ & $4.4 \times 10^{-4}$ & 9.2 \\
polymer/silicone & 4 & $4.9 \times 10^{-5}$ & $4.4 \times 10^{-4}$ & 8.9 \\
rubber & 5 & $4.7 \times 10^{-5}$ & $4.2 \times 10^{-4}$ & 9.0 \\
& 6 & $4.6 \times 10^{-5}$ & $4.4 \times 10^{-4}$ & 9.6 \\
& 7 & $5.0 \times 10^{-6}$ & $4.4 \times 10^{-4}$ & 8.8 \\
& 8 & $4.7 \times 10^{-5}$ & $4.3 \times 10^{-4}$ & 9.1 \\
\hline
\end{tabular}


Silicone rubber

(optional)

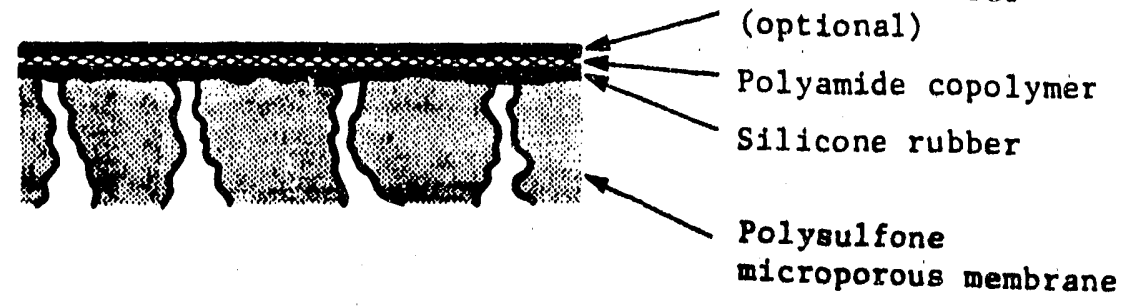

Figure 14. Cross-section of polyamide copolymer composite membrane. 
Pure gas permeation rates of the polyamide copolymer membrane were determined using the set-up shown in Figure 8 for the gases hydrogen sulfide, carbon dioxide, hydrogen, methane and nitrogen. The results are given in Figure 15. The permeation rates increase with increasing pressure, in contrast with the polyetherimide membranes discussed in the previous section. The pressure dependence of gas permeation rates is a well-known property of rubbery materials and is the result of plasticization of the material by the permeant. As a consequence the pure gas selectivities are also a function of the feed pressure, as shown in Figure 16, and increase with increasing pressure. However, plasticization causes the pure gas selectivities to be substantially different from the selectivities observed with gas mixtures. An example is shown in Figure 17, where the carbon dioxide/hydrogen selectivity is plotted as a function of feed pressure. The selectivity obtained with a $50 / 50$ mixture decreases with increasing pressure, whereas the pure gas selectivity increases. The pure gas and mixture selectivities converge at zero feed pressure which is in accordance with the plasticization phenomenon. Thus, the prediction of membrane performance using pure gas data will not be possible in the case of the polyamide copolymer membrane.

Figure 18 shows the dependence of pure gas normalized fluxes on temperature. The normalized flux increases with temperature and follows the Arrhenius equation. The relative flux increase with temperature is approximately the same for hydrogen, methane and nitrogen, whereas the relative increase is much less in the case of carbon dioxide. This means that the pure gas selectivity for carbon dioxide over the other gases decreases with increasing temperature, as shown in Figure 19. Most importantly, the carbon dioxide/hydrogen selectivity drops from 9 at room temperature to less than 2 at $75^{\circ} \mathrm{C}$. Combining this result with the observation that the selectivity obtained with gas mixtures will be even less than the pure gas selectivity, we conclude that the performance of the polyamide copolymer membrane is a strong function of the operating temperature and pressure.

\section{E. Palladium Membranes}

Palladium and palladium/silver alloys are permeable to hydrogen and impermeable to all other gases. Thus, a thin palladium/silver film has potential as a hydrogen separating membrane. MTR has previously developed techniques to produce composite membranes which incorporate a thin palladium/silver layer under a contract with the Department of the Army. ${ }^{21}$ Under this program, composites membranes were prepared with hydrogen normalized fluxes in the range of $5 \times 10^{-6}$ to $1 \times 10^{-4} \mathrm{~cm}^{3}(\mathrm{STP}) / \mathrm{cm}^{2} \cdot \mathrm{s} \cdot \mathrm{cmH}_{8}$ and with hydrogen/nitrogen selectivities of $150-600$. Hydrogen/carbon dioxide selectivities ranged from 5 to as high as 20, which are unusually high values. As can be seen by comparing the selectivities, carbon dioxide permeated the membranes faster than nitrogen, showing that at least some gas transport was through defects in the metal layer. Reproducibility of the membrane preparation procedure was a problem throughout the project, attributable partially to the simplicity of the sputtering apparatus. In the present program, a limited effort was undertaken to prepare palladium/silver composite membranes using asymmetric polyetherimide membranes as the support membrane, an approach that was not used in the Army program. The polyetherimide membranes are already selective for hydrogen over carbon dioxide and the objective was to improve this selectivity by means of the palladium/silver layer. 


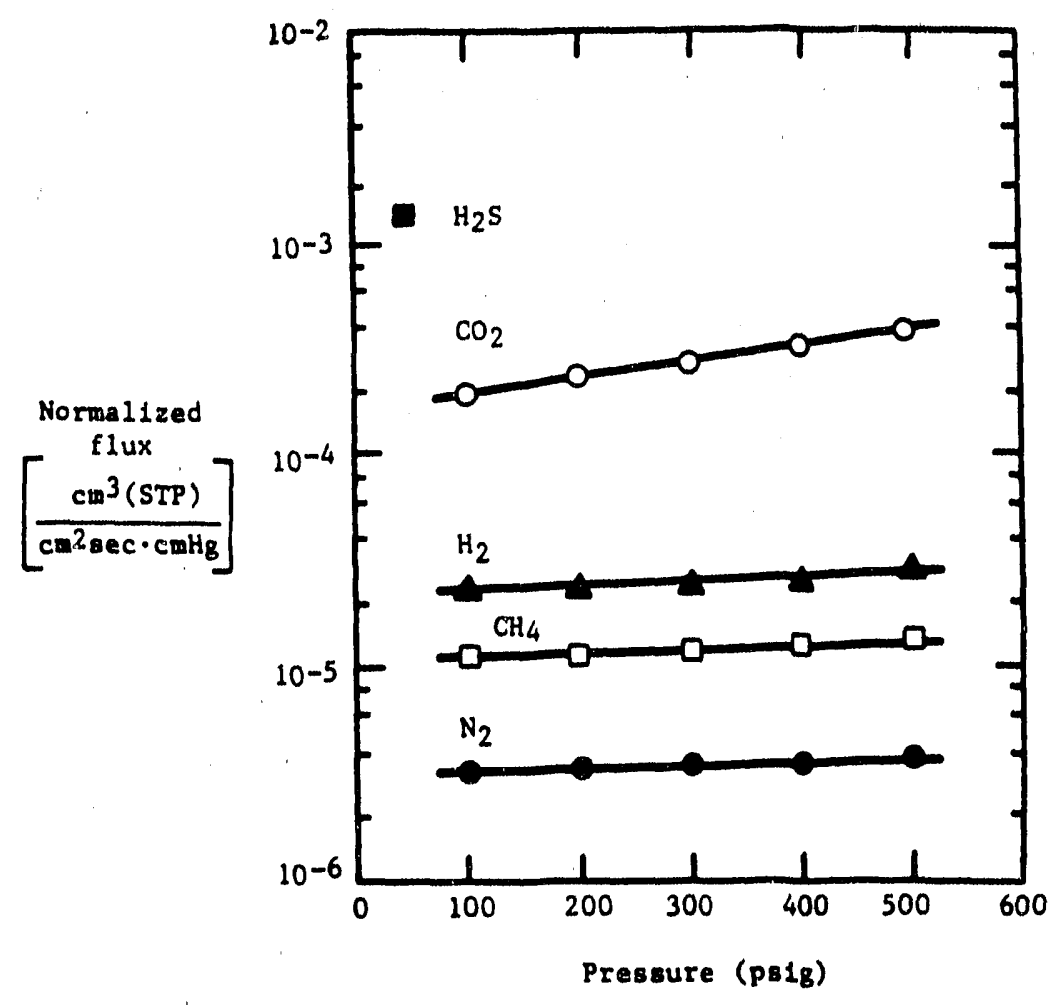

Figure 15. Normalized fluxes of polyamide copolymer composite membrane as a function of feed pressure. Temperature: $22^{\circ} \mathrm{C}$. 


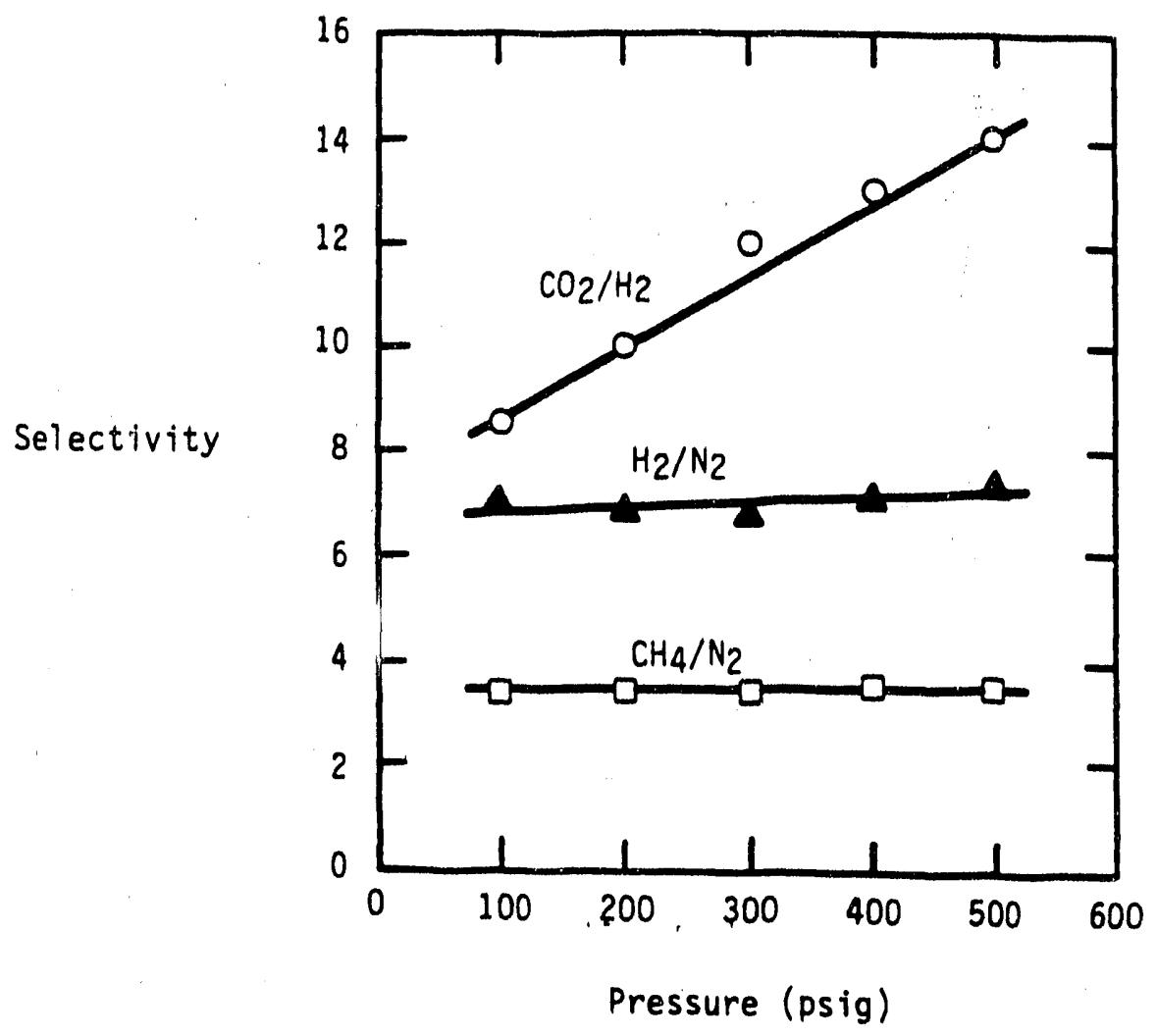

Figure 16. Selectivity of polyamide copolymer composite membranes as a function of feed pressure. Measurements made with pure gases. 


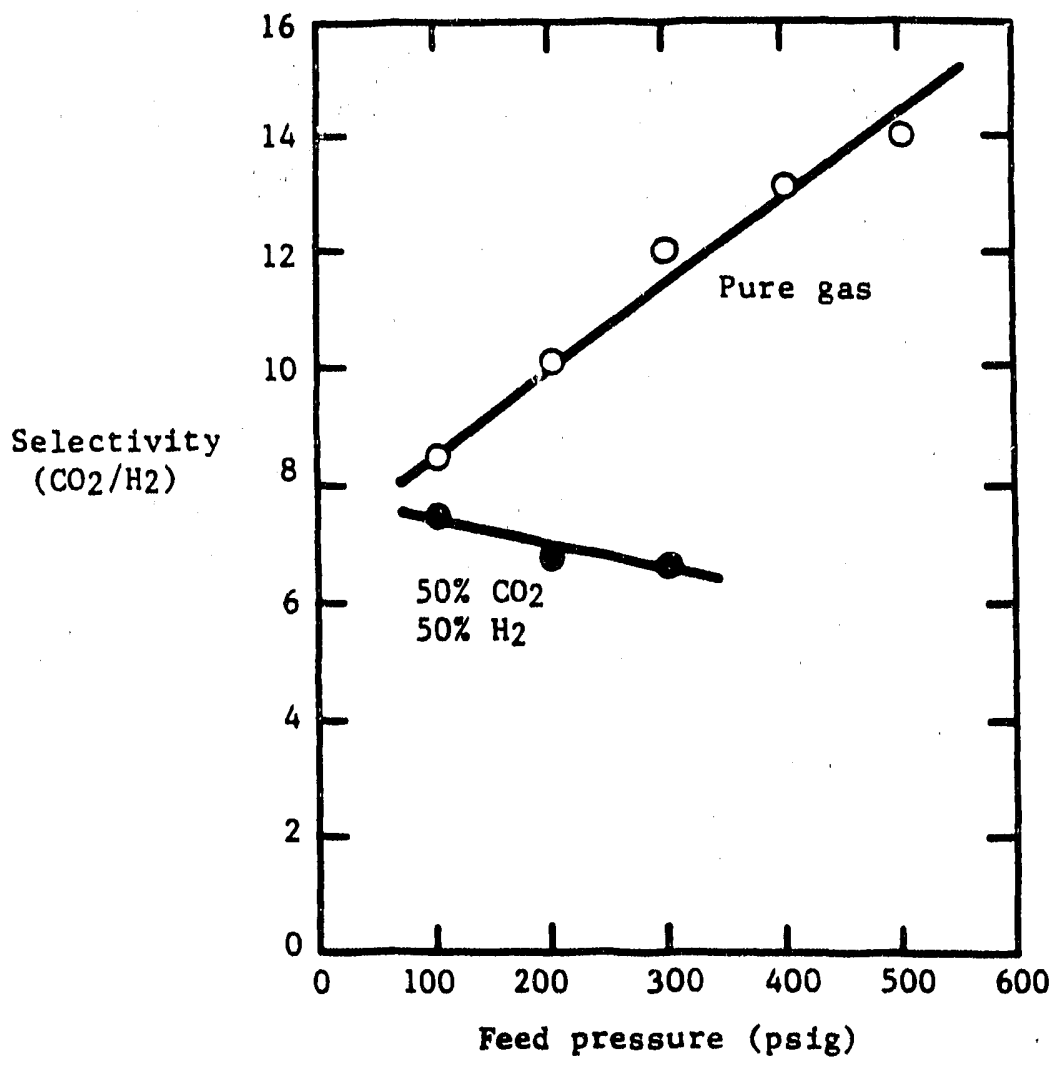

Figure 17. Carbon monoxide/hydrogen selectivity of polyamide copolymer composite membrane as a function of feed pressure. Measurements made with pure gases and gas mixtures, Temperature: $22^{\circ} \mathrm{C}$. 


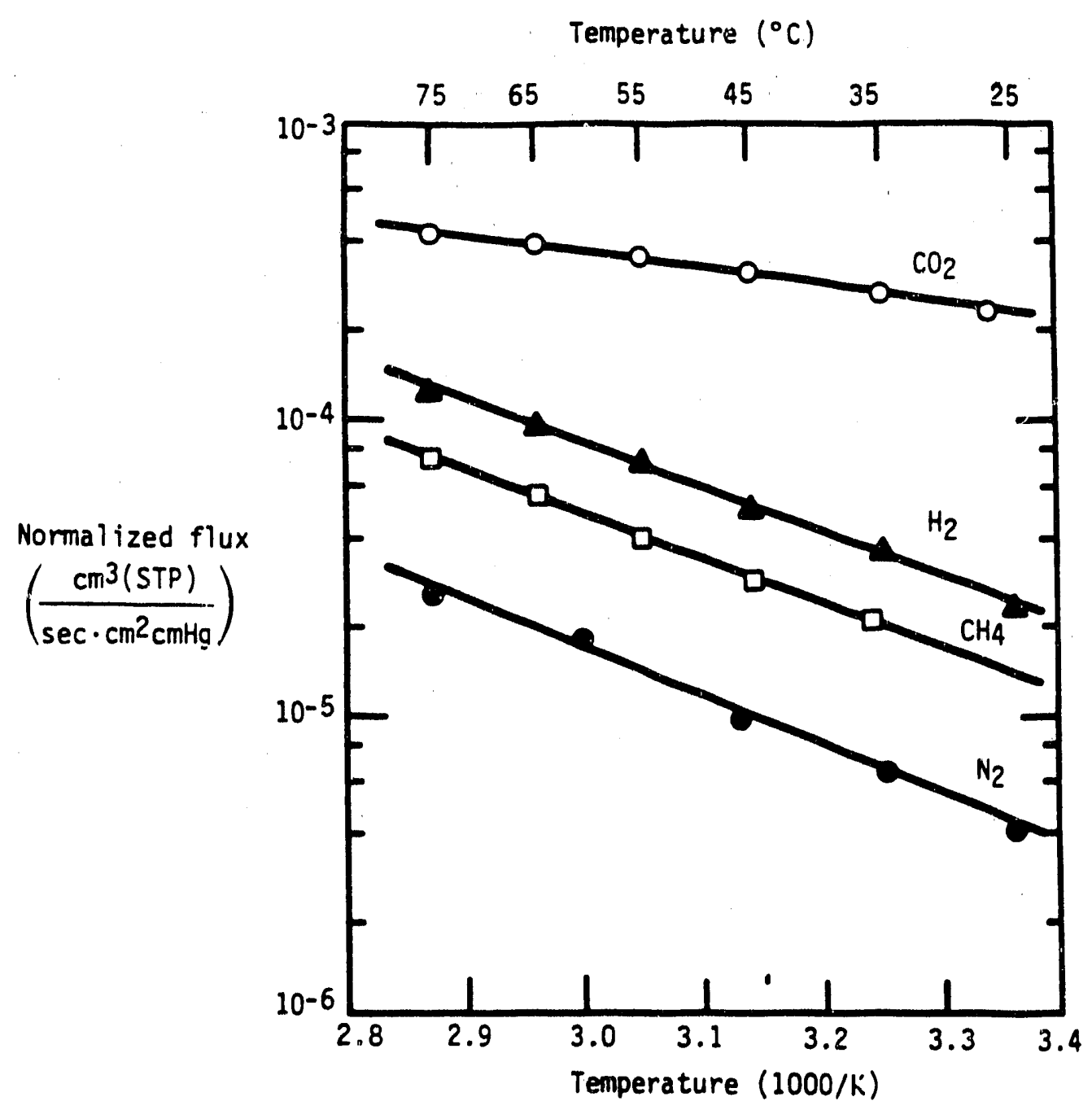

Figure 18. Normalized fluxes of polyamide copolymer composite membrane as a function of temperature. Feed pressure: $100 \mathrm{psig}$. 


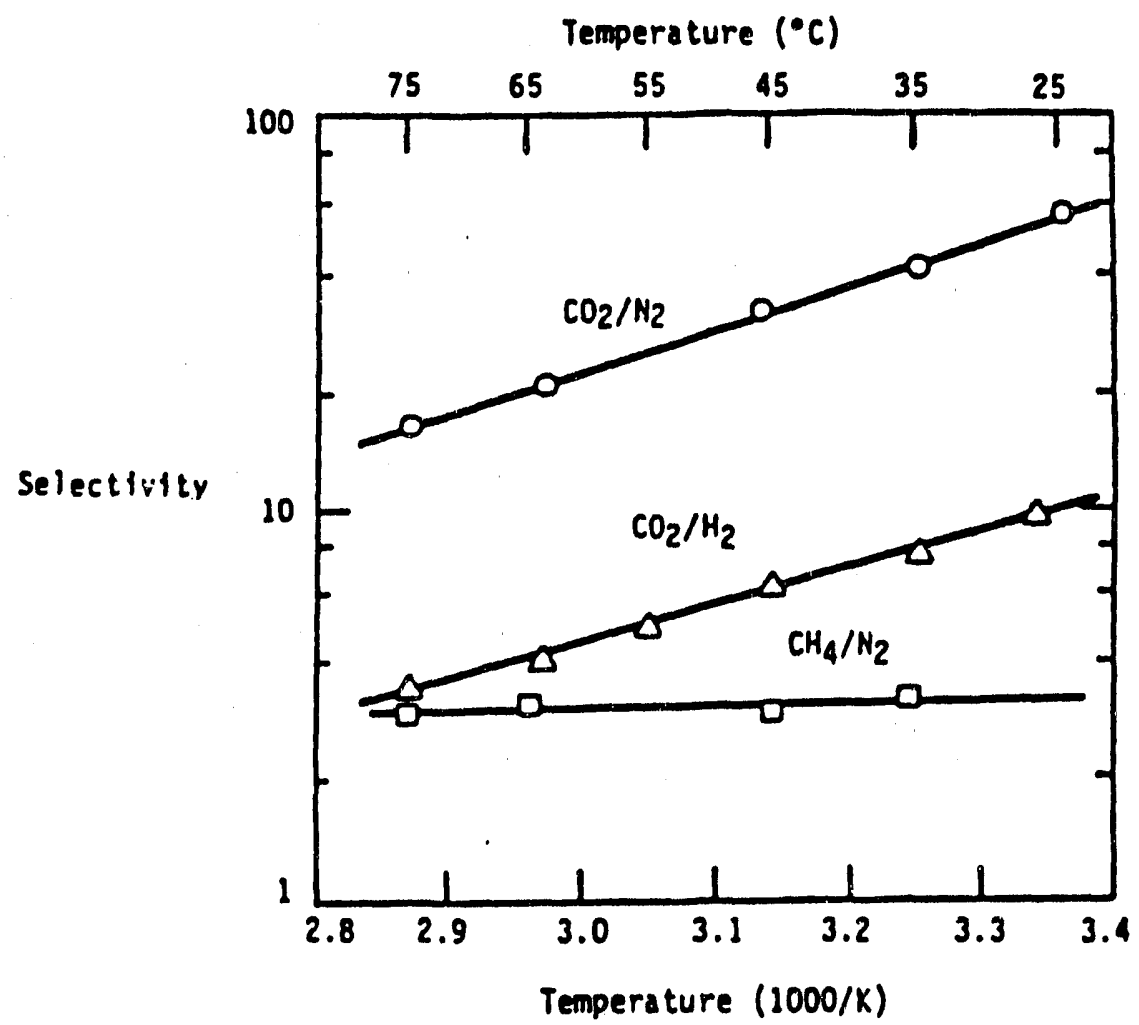

Figure 19. Pure gas selectivity of polyamide copolymer composite membranes as a function of temperature. Feed pressure: 100 psig. 
Flat-sheet asymmetric polyetherimide membranes were sputtered with a palladium/silver alloy (76\% palladium) using a Hummer VI Sputtering System (Anatech, Ltd). Sputtering times ranged from 0.25 to 5 minutes in a low-pressure (20 to 60 millitorr) argon atmosphere. The resulting membranes were tested with pure hydrogen and carbon dioxide to determine membrane performance. In some cases, the palladium/silver composite membrane was overcoated with a thin silicone rubber layer to prevent bulk flow through surface defects. Variation of the sputter times showed that the best membranes were obtained at short sputter times of approximately 0.25 minutes. This is in agreement with the earlier results. ${ }^{21}$ Table 13 lists some of the results obtained at 0.25 minutes sputtering. Applying the palladium/silver layer clearly improves the hydrogen/carbon dioxide selectivity, although, as would be expected, a loss of membrane flux results. The data in Table 13 also show that overcoating the composite membrane with a thin silicone rubber layer further improves membrane performance, as was the case with regular asymmetric polyetherimide membranes. The selectivity of $11-13$, obtained for the sputtered and overcoated membranes is very high, and represents a substantial improvement over the asymmetric membrane results reported in Section VI(C). Further work on polymer/metal composites was beyond the scope of the present program. Because the technology to manufacture such membranes reproducibly by a continuous process has yet to be developed, we did not include these membranes in our economic evaluation work. However, the limited work that could be done showed that the palladium/silver layer obviously contributes to membrane performance and that using metal/polymer composites is a significant way to improve the hydrogen selectivity of membranes. We believe this could form the basis of an interesting and useful research program in the future.

Table 13. Performance of Palladium-Silver Composite Membranes for the Separation of Hydrogen from Carbon Dioxide

\begin{tabular}{lcccc}
\hline Membrane & $\begin{array}{c}\text { Feed } \\
\text { Pressure }\end{array}$ & \multicolumn{2}{c}{$\begin{array}{c}\text { Normalized Flux } \\
\left(\mathrm{cm}^{3}(\mathrm{STP}) / \mathrm{cm}^{2} \cdot \mathrm{s} \cdot \mathrm{CmH}^{3}\right)\end{array}$} & Selectivity \\
& (psig) & $\mathrm{CO}_{2}$ & $\mathrm{H}_{2}$ & $\mathrm{H}_{2} / \mathrm{CO}_{2}$ \\
\hline Polyetherimide, & 300 & $1.67 \times 10^{-6}$ & $8.44 \times 10^{-6}$ & 5.1 \\
asymmetric & 400 & $1.95 \times 10^{-6}$ & $9.15 \times 10^{-6}$ & 4.7 \\
& 500 & $1.84 \times 10^{-6}$ & $8.87 \times 10^{-6}$ & 4.8 \\
Polyetherimidis/ & 300 & $2.83 \times 10^{-6}$ & $2.49 \times 10^{-6}$ & 8.8 \\
palladium-silver & 400 & $3.01 \times 10^{-6}$ & $2.52 \times 10^{-5}$ & 8.4 \\
& 500 & $3.46 \times 10^{-6}$ & $2.58 \times 10^{-6}$ & 7.5 \\
& & & & \\
Polyetherimide/ & 300 & $7.47 \times 10^{-7}$ & $8.44 \times 10^{-6}$ & 11.3 \\
palladium-silver/ & 400 & $7.67 \times 10^{-7}$ & $1.05 \times 10^{-6}$ & 13.7 \\
silicone rubber & 500 & $1.05 \times 10^{-6}$ & $1.25 \times 10^{-6}$ & 11.9 \\
\hline
\end{tabular}




\section{F. Summary of Membrane Properties}

Polyetherimide asymmetric membranes have been developed in both flat-sheet and hollow-fiber form. The membrane is characterized by the normalized permeation rates given in Table 14 . The permeation rates at $150^{\circ} \mathrm{C}$ have been obtained by extrapolating the data shown in Figure 11 . The data in Table 14 are mostly based on pure gas permeation experiments. However, the permeation rates obtained in gas mixture experiments are very close to the pure gas data. Thus, the data of Table 14 are expected to be a reasonable estimate to be used in the economic evaluation of Section IX.

Table 14. Permeation Rates of the Asymmetric Polvetherimide Membrane

\begin{tabular}{llc} 
Gas & \multicolumn{2}{c}{$\begin{array}{c}\text { Normalized Permeation Rate } \\
\left(\mathrm{cm}^{3}(\mathrm{STP}) / \mathrm{cm}^{2} \mathrm{~s} \cdot \mathrm{cm} \text { Hg }\right)\end{array}$} \\
& $25^{\circ} \mathrm{C}$ & $150^{\circ} \mathrm{C}$ \\
\hline $\mathrm{H}_{2}$ & $7.1 \times 10^{-6}$ & $6.7 \times 10^{-4}$ \\
$\mathrm{CO}_{2}$ & $1.3 \times 10^{-5}$ & $9.1 \times 10^{-6}$ \\
$\mathrm{CO}$ & $6.8 \times 10^{-7}$ & -- \\
$\mathrm{N}_{2}$ & $3.3 \times 10^{-7}$ & $9.9 \times 10^{-6}$ \\
$\mathrm{CH}_{4}$ & $2.4 \times 10^{-7}$ & $9.9 \times 10^{-6}$ \\
\hline
\end{tabular}

Polyamide copolymer composite membranes were developed and tested with pure gases and gas mixtures. Table 15 gives the pure gas permeation rates at room temperature. Permeation rates obtained with gas mixtures containing carbon dioxide differ substantially from the pure gas data, because of plasticization of the membrane by carbon dioxide. Thus, pure gas data cannot be used as a basis for economic evaluations. Testing the polyamide copolymer membrane with gas mixtures, therefore, formed the main part of the module testing efforts described in the following section. 
Table 15. Permeation Rates of the Polyamide Copolymer Membrane

\begin{tabular}{ll}
\hline Gas & $\begin{array}{c}\text { Normalized Permeation Rate } \\
\left(\mathrm{cm}^{3}(\mathrm{STP}) / \mathrm{cm}^{2} \cdot \mathrm{s} \cdot \mathrm{cmH}_{\mathrm{g}}\right)\end{array}$ \\
\hline $\mathrm{H}_{2}$ & $1.7 \times 10^{-5}$ \\
$\mathrm{CO}_{2}$ & $2.0 \times 10^{-4}$ \\
$\mathrm{CO}$ & $2.1 \times 10^{-6}$ \\
$\mathrm{~N}_{2}$ & $1.0 \times 10^{-6}$ \\
$\mathrm{CH}_{4}$ & $3.1 \times 10^{-6}$ \\
\hline
\end{tabular}

\section{MODULE DEVELOPMENT AND TESTING}

A. Introduction and Overview

Both polyetherimide membranes and polyamide copolymer membranes were incorporated in membrane modules. The purpose of these modules is to economically pack large membrane areas into compact devices which also provide pathways for the feed gas to contact the membrane and pathways for the permeate gas to exit the moduie.

Most of the work focussed on the preparation and testing of spiral-wound modules with flat-sheet polyamide copolymer membrane. A few hollow-fiber modules were made with the polyetherimide membrane and tested with pure gases. Polyamide copolymer modules were tested with hydrogen mixtures containing hydrogen sulfide and carbon dioxide at $25^{\circ} \mathrm{C}$ to $40^{\circ} \mathrm{C}$ and pressures up to 500 psig. The selectivity is a strong function of the feed pressure and the feed gas composition; the selectivity for the acid gases, hydrogen sulfide and carbon dioxide, over hydrogen is very much reduced compared to pure gas selectivities. A temperature stability test was carried out up to $140^{\circ} \mathrm{C}$ and the spiral-wound modules appeared stable to $100^{\circ} \mathrm{C}$. 


\section{B. Polyetherimide Membrane Modules}

Hollow-fiber polyetherimide membranes were assembled into a hollow-fiber module containing approximately $600 \mathrm{~cm}^{2}$ membrane area. The fibers were prepared from a spinning dope, consisting of $20.5 \%$ polyetherimide, $1.5 \%$ poly(vinylpyrrolidone) and $78 \%$ dimethylacetamide. A schematic of the module is shown in Figure 20. The module is 2.25 inches in diameter and 12 inches in length. Before testing the module with pure nitrogen and hydrogen, the inside of the fibers was coated with a thin silicone rubber layer to seal defects in the top layer of the membrane. Testing was performed at 50 and 100 psig pressure and the calculated permeation rates are given in Table 16. No effect of feed pressure on permeation rates was observed. The nitrogen permeation rate is equal to the rate observed for single fibers, shown in Table 10. The hydrogen/nitrogen selectivity is low'er, but at 110 is still very acceptable.

Table 16. Performance of Polyetherimide Hollow-Fiber Membrane Module

Area: $\quad 600 \mathrm{~cm}^{2}$

Feed Pressure: 50 and 100 psig

\begin{tabular}{ccc}
\multicolumn{2}{c}{$\begin{array}{c}\text { Permeation Rate } \\
\left(\mathrm{cm}^{3}(\mathrm{STP}) / \mathrm{cm}^{2} \text {.s.cmHg }\right)\end{array}$} & Selectivity \\
$\mathrm{H}_{2}$ & $\mathrm{~N}_{2}$ & $\mathrm{H}_{2} / \mathrm{N}_{2}$ \\
\hline $2.2 \times 10^{-2}$ & $2.0 \times 10^{-7}$ & 110 \\
\hline
\end{tabular}

Although only one hollow-fiber module was made, it can be concluded that assembling polyetherimide hollow-fiber modules does not present any major problems and that further scale-up would be relatively straightforward. 


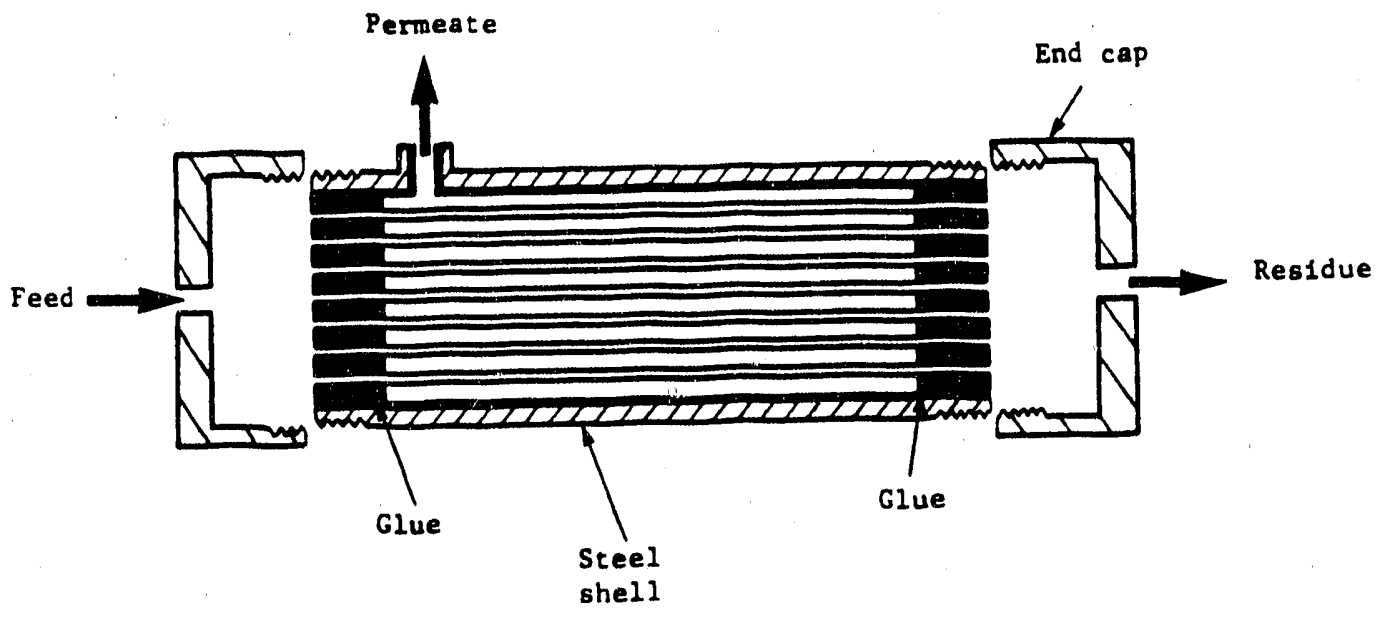

Figure 20. Schematic drawing of a hollow-fiber membrane module. 


\section{Polyamide Copolymer Membrane Modules}

Flat-sheet polyamide copolymer membranes have been incorporated into spiral-wound modules. This type of module is the preferred method of packing large areas of flat-sheet membrane into small separation devices. A schematic of a spiral-wound module is given in Figure 21. In operation, feed gas enters the module and flows between the membrane leaves. Certain components of the feed will go through the membrane more readily than others. The fraction of the feed that permeates the membrane spirals inward to a central permeate collection pipe. The remainder of the feed flows across the membrane surface and exits as the residue. The driving force for permeation can be generated by pressurizing the feed gas and/or by reducing the pressure on the permeate side. In the present case the feed gas is pressurized and the spiral-wound module is housed in a metal pressure vessel. The vessel contains a feed inlet and permeate and residue outlets.

Spiral-wound modules containing the polyamide copolymer membirane were used in a number of different experiments. These experiments were:

1. Pure gas testing to determine the module's pressure and temperature stability,

2. Gas mixture testing to determine the effect on separation of gas velocity in the module, and

3. Gas mixture testing to characterize the polyamide copolymer membrane.

These three sets of experiments are described and discussed below.

\section{Module Stability}

An important aspect of making spiral-wound modules is the choice of spacer materials that create the flow channels for the feed gas and the permeate gas. Requirements are the most stringent for the permeate spacer, since this material has to support the membrane against the pressure difference between feed and permeate, and still has to provide an adequate pathway for the permeate gas to reach the collection pipe without a substantial pressure build-up. This presents a trade-off, as a more open permeate spacer will reduce permeate pressure drop, yet will reduce the module's pressure stability. 


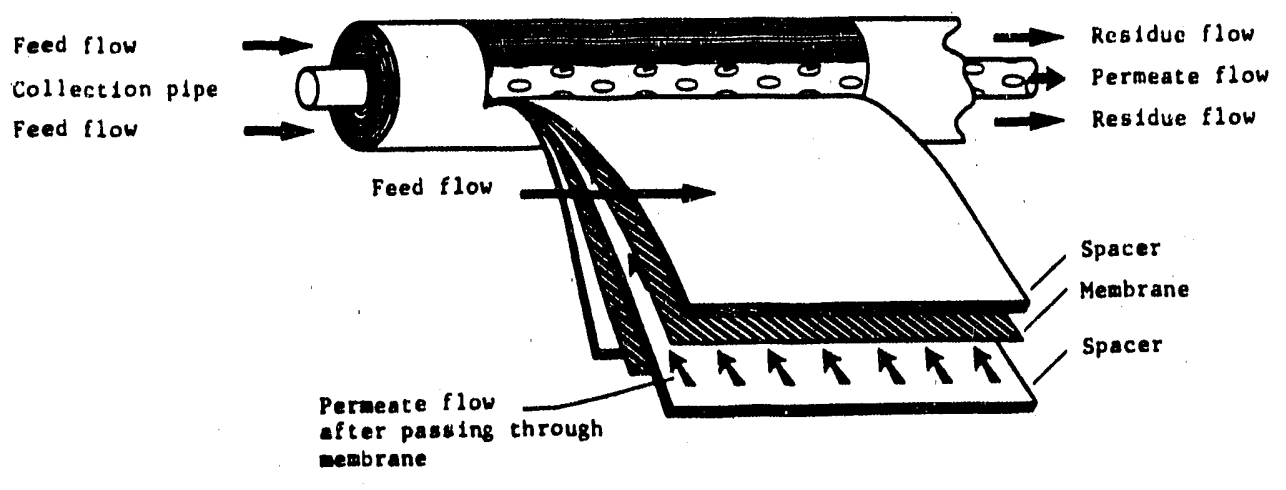

Figure 21. A schematic drawing of a spiral-wound module. 
Three different types of modules were prepared using two different spacer materials, and were evaluated with pure hydrogen and nitrogen gas at varying feed pressures. The results are summarized in Table 17. Module \#1 contains spacer A, a open polypropylene mesh material, on both the feed and the permeate sides. Module $\# 2$ contains spacer $B$, a very finely woven material, on both feed and permeate sides. Module $\# 3$ contains material $A$ on the feed side and material $B$ on the permeate side. The normalized permeation rates of module $\# 1$ increased with increasing pressure, indicating that the membrane is destroyed by the transmembrane pressure difference. The modules using the more dense spacer $B$ on the permeate side are stable, which shows that this spacer material sufficiently supports the membrane. Spacer B also provides ample pathway for the permeating gas since the hydrogen/nitrogen selectivities observed with modules $\# 2$ and $\# 3$ are ciose to the selectivity measured with the membrane alone. Based on these results, spacer $A$ and spacer B were selected as, respectively, the feed and the pernieate spacer materials. More than ten modules were prepared and tested with pure gases up to 500 psig feed pressure. No module failure was observed. Typical results are shown in Table 18. The nitrogen-normalized permeation rate is almost independent of pressure, the small dependence which was observed in all modules being most likely an experimental artifact.

Table 17. Performance of Polyamide Copolymer Spiral-Wound Modules

\begin{tabular}{|c|c|c|c|c|c|c|}
\hline Module \# & $\begin{array}{l}\text { Feed } \\
\text { Spacer }\end{array}$ & $\begin{array}{l}\text { Permeate } \\
\text { Spacer }\end{array}$ & $\begin{array}{l}\text { Feed } \\
\text { Pressure } \\
\text { (psig) }\end{array}$ & $\begin{array}{r}\text { Nor } \\
\text { Perme } \\
\left(\mathrm{cm}^{3}(\mathrm{STP}\right. \\
\mathrm{N}_{2}\end{array}$ & $\begin{array}{l}\text { Rate } \\
\text { R.s.cmHg) } \\
\mathrm{H}_{2}\end{array}$ & $\begin{array}{r}\text { Selectivity } \\
\mathrm{H}_{2} / \mathrm{N}_{2}\end{array}$ \\
\hline 1 & $\mathbf{A}$ & $\mathbf{A}$ & $\begin{array}{l}10 \\
10 \\
50\end{array}$ & $\begin{array}{l}0.018 \\
0.035 \\
0.084\end{array}$ & $\begin{array}{c}0.115 \\
-- \\
0.420\end{array}$ & $\begin{array}{l}6.3 \\
-- \\
5.1\end{array}$ \\
\hline 2 & B & B & $\begin{array}{l}15 \\
30 \\
50 \\
80 \\
15\end{array}$ & $\begin{array}{l}0.020 \\
0.020 \\
0.021 \\
0.021 \\
0.020\end{array}$ & $\begin{array}{c}0.115 \\
0.115 \\
0.115 \\
-- \\
--\end{array}$ & $\begin{array}{l}5.6 \\
5.5 \\
5.4 \\
-- \\
--\end{array}$ \\
\hline 3 & $\mathbf{A}$ & B & $\begin{array}{l}10 \\
25 \\
50\end{array}$ & $\begin{array}{l}0.015 \\
0.015 \\
0.016\end{array}$ & $\begin{array}{l}0.087 \\
0.088 \\
0.089\end{array}$ & $\begin{array}{l}5.9 \\
5.8 \\
5.7\end{array}$ \\
\hline
\end{tabular}


Table 18. Normalized Nitrosen Permeation Rates of Two Polvamide Corolymer Membrane Modules at Yarvine Feed Pressures (Permeate pressure: 0 psig)

\begin{tabular}{|c|c|c|}
\hline $\begin{array}{c}\text { Feed Pressure } \\
\text { (psig) } \\
10 \\
20\end{array}$ & \multicolumn{2}{|c|}{$\begin{array}{l}\text { Nitrogen } \\
\text { Normalized Permeation Rate } \\
\left(\mathrm{cm}^{3}(\mathrm{STP}) / \mathrm{cm}^{2} \cdot \mathrm{s} \cdot \mathrm{cmH} \mathbf{H}\right)\end{array}$} \\
\hline $\begin{array}{r}10 \\
20 \\
100 \\
200 \\
300 \\
400 \\
500 \\
400 \\
300 \\
200 \\
100\end{array}$ & $\begin{array}{l}0.013 \\
0.014 \\
0.015 \\
0.016 \\
0.017 \\
0.017 \\
0.017 \\
0.017 \\
0.017 \\
0.017 \\
0.016\end{array}$ & $\begin{array}{l}0.013 \\
0.013 \\
0.011 \\
0.014 \\
0.015 \\
0.016 \\
0.017 \\
0.018 \\
0.017 \\
0.016 \\
0.015\end{array}$ \\
\hline
\end{tabular}

Two spiral-wound modules containing the polyamide copolymer membrane were tested for their temperature stability. The modules were exposed for five-day periods to five different temperatures in an air-ventilated oven. After each fiveday exposure period, the hydrogen and carbon dioxide fluxes were measured at room temperature and at $50 \mathrm{psig}$ feed pressure. The hydrogen normalized permeation rates and the calculated carbon dioxide/hydrogen selectivities are shown in Figure 22 as a function of oven temperature.

The data show that the modules are stable up to approximately $100^{\circ} \mathrm{C}$. After $100^{\circ} \mathrm{C}$, both the selectivity and the flux decrease dramatically. Following the measurements after the five-day exposure to $140^{\circ} \mathrm{C}$, the modules were inspected internally. The spacer material had disintegrated and it was evident that the glue had melted during the exposure to the higher temperature. However, the overall mechanical integrity of the modules has not been affected. The hydrogen permeation rate of membrane stamps taken from the modules was lower by a factor of three compared to the original value. The carbon dioxide/hydrogen selectivity of the membrane stamps ranged from 0.3 to 1 , i.e., the membrane had become selective for hydrogen. This shows that above $100^{\circ} \mathrm{C}$ the polysulfone support structure is affected so that its porosity is decreased, thereby reducing the gas flux through the membrane and making the polysulfone support membrane a permeation rate-determining part of the composite membrane. Polysulfone preferentially permeates hydrogen over carbon dioxide.

Summarizing the results of the module stability tests, spiral-wound modules were prepared that are stable at pressures up to 500 psig and temperatures up to $100^{\circ} \mathrm{C}$. The limiting factor in the temperature stability seems to be the polysulfone support membrane. Thus, a more temperature-resistant polymer has to be used if the polyamide copolymer membrane is operated at more than $100^{\circ} \mathrm{C}$. 


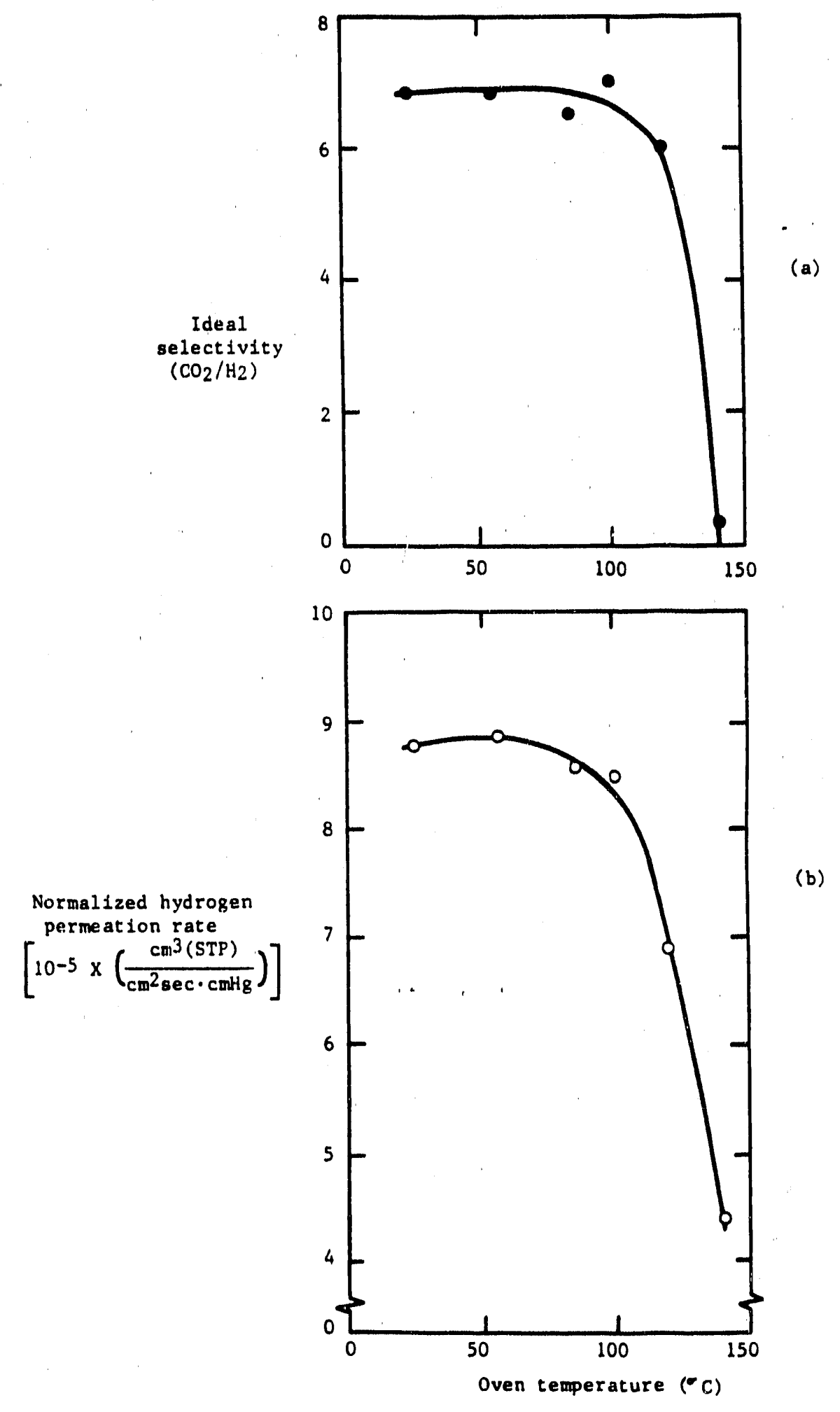

Figure 22. Temperature stability test of polyamide copolymer modules. Two modules were placed in an oven for five days at the test temperature. The modules were subsequently removed and tested at room temperature with pure hydrogen and carbon dioxide. 


\section{Effect of Feed Gas Velocity Inside the Module}

The feed gas flowing through a spiral-wound module is in direct contact with the membrane surface and consequently a stagnant boundary layer develops adjacent to the membrane. Because of the selective properties of the membrane the boundary layer is continuously depleted of the more permeable components and a concentration profile is generated across the boundary layer. The boundary layer thus represents a diffusion resistance in addition to the permeation resistance of the membrane and, if the boundary layer is thick enough, may actually slow down the permeation rate of the more permeable components. It is thus important to minimize the boundary layer thickness and this is usually done by increasing the velocity of the feed gas flowing over the membrane surface. For a specific module design containing a specific membrane, this means that there is a minimum feed flow rate at which the module should be operated. In other words, the module has a maximum stage-cut (permeate flow rate/feed flow rate) which should not be exceeded. A number of experiments were performed to determine the effect of feed gas velocity for the polyamide copolymer membrane modules.

Two different modules were prepared both containing about $330 \mathrm{~cm}^{2}$ of polyamide copolymer membrane. The two module designs are shown in Figure 23. The crucial difference between the two module types is that, although both modules have equal membrane area, the bimodule is twice as long as the single module. Thus, the membrane length to membrane area ratio of the bimodule is twice that of the single module. This means that at a given feed flow rate, and thus at a given stage-cut, the feed gas velocity inside the membrane envelopes is two times higher for the bimodule compared to the single module. Both modules were tested with a feed gas mixture containing 50\% hydrogen and 50\% carbon dioxide at 200 psig. The residue and permeate compositions were determined as a function of the stage-cut, i.e., as a function of the feed flow rate. Based on these results, the effective carbon dioxide/hydrogen selectivity was calculated as a function of the stage-cut. The results given in Figure 24 show that the bimodule and the single module are equivalent at small stage-cuts, i.e., at high feed flow rates, but that the bimodule performs better at larger stage-cuts. For the bimodule design, the effective selectivity is only slightly dependent on stage-cut, indicating that in this module design the boundary layer does not significantly influence the separation achieved. Therefore, all subsequent experiments characterizing the performance of polyamide copolymer modules were carried out with modules equivalent to the bimodule design.

\section{Evaluation of Polvamide Copolymer Membrane Module Performance}

Gas separation experiments were carried out using the set-up shown in Figure 25. In this set-up, the feed gas is passed through a membrane module, which is housed in a pressure vessel. The residue gas and the recompressed permeate gas are recycled to a mixing vessel and are reused as the feed gas. The system can handle feed gas pressures up to 500 psig; the permeate gas pressure is 0 psig. Feed, residue and permeate lines are connected on-line with a gas chromatograph for determination of the composition of the streams. 
(a) Single module design

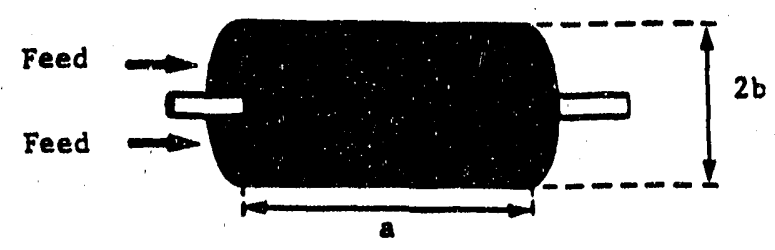

(b) Bimodule design

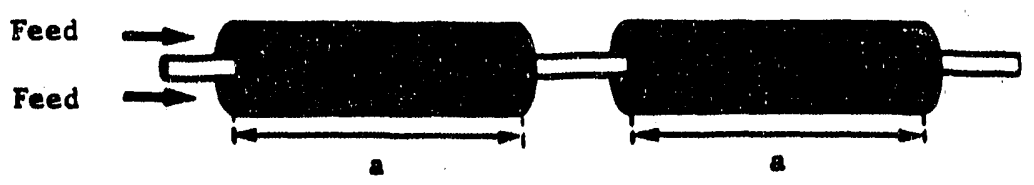

Figure 23. Schematic drawings of a single module and a bimodule design. The two designs have equal total membrane areas. 


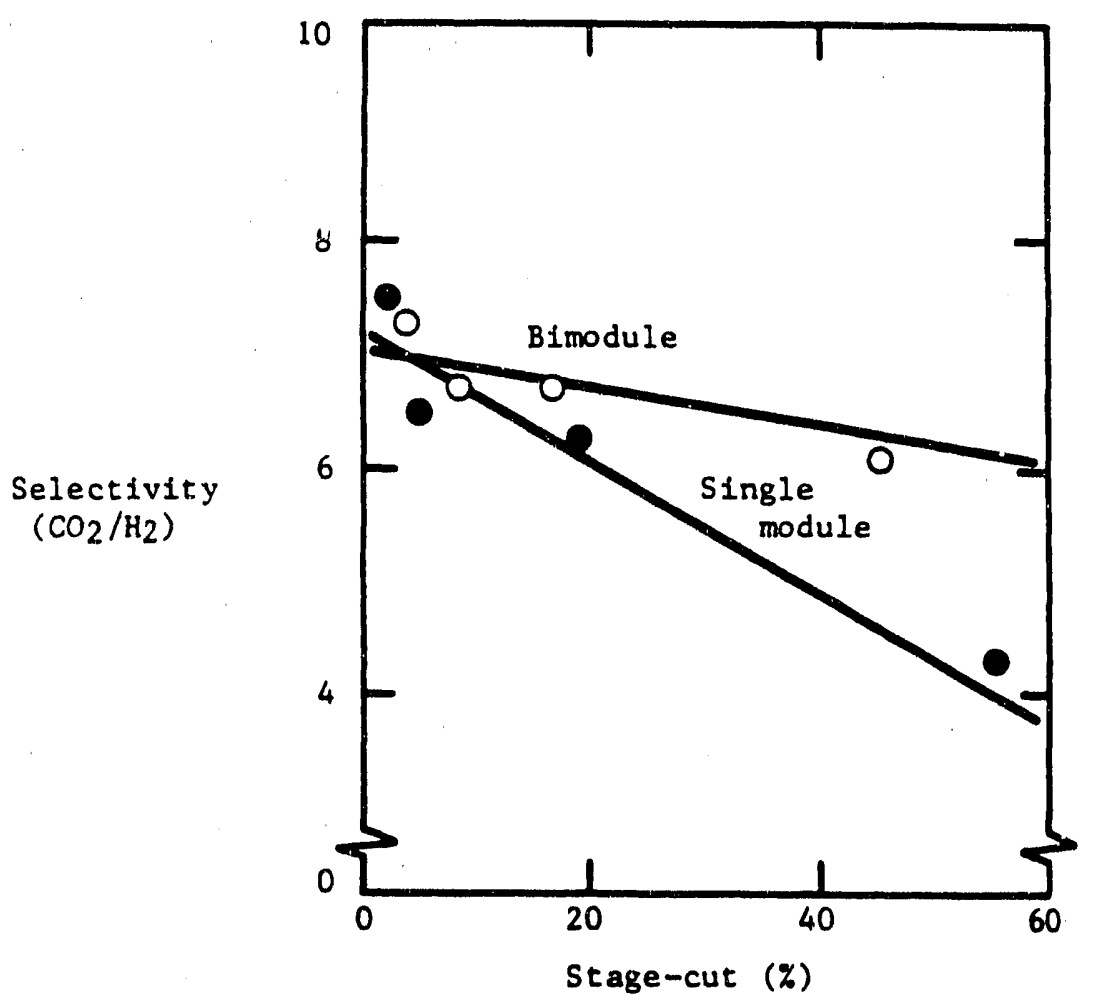

Figure 24. Effective carbon dioxide/hydrogen selectivities of bimodule and single module designs. Selectivities are calculated from experiments with a gas mixture containing $50 \%$ carbon dioxide and $50 \%$ hydrogen at 200 psig. (Permeate pressure: 0 psig, room temperature.) 


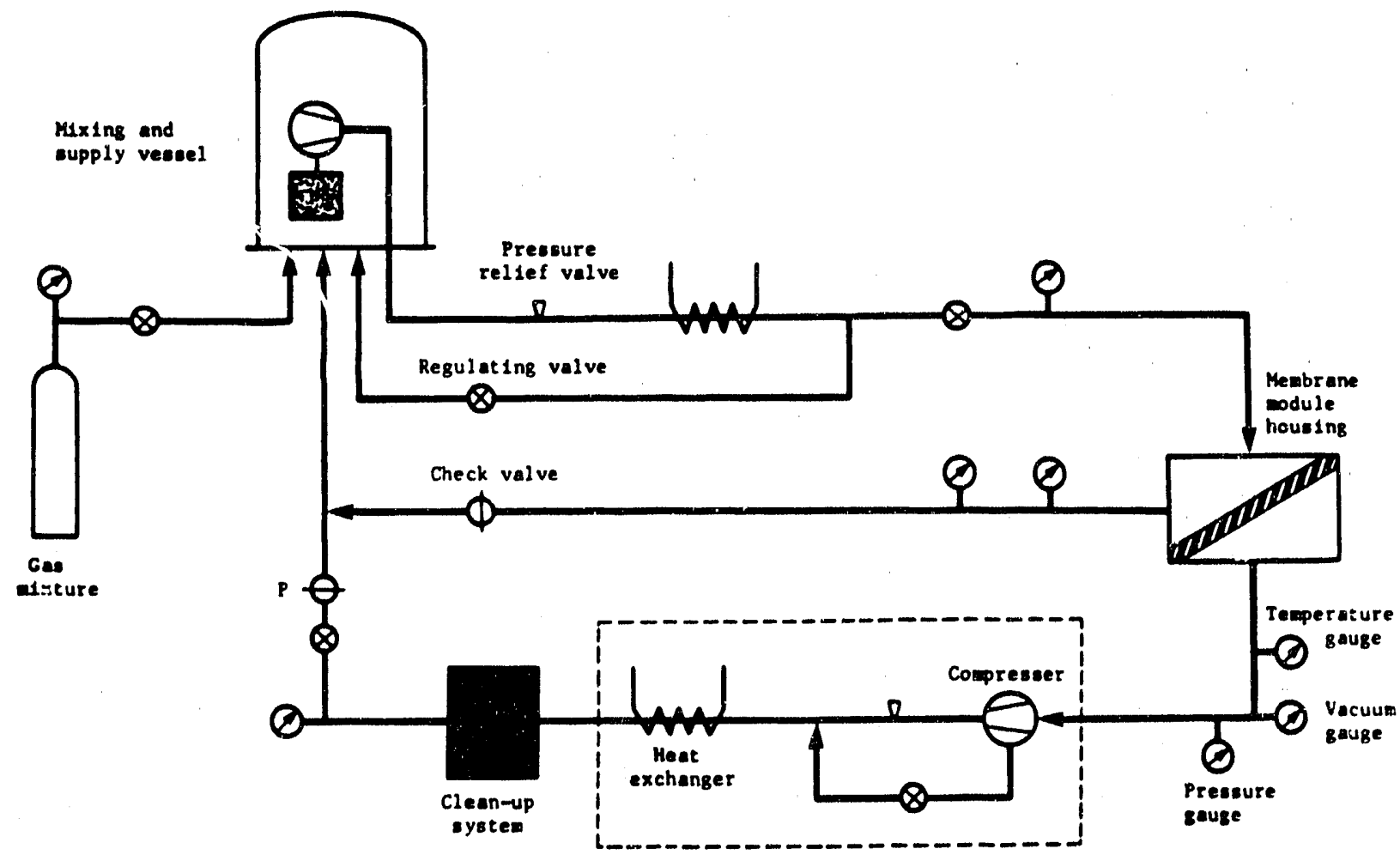

Figure 25. Process flow diagram of gas permeation system for module testing at elevated temperature and elevated pressure. 
Polyamide copolymer membrane modules were evaluated with binary gas mixtures containing hydrogen and carbon dioxide, and with ternary gas mixtures containing hydrogen, carbon dioxide and hydrogen sulfide. The results are discussed below.

Tables 19,20 and 21 list the results obtained in experiments with $75 / 25$, $50 / 50$ and $25 / 75$ carbon dioxide/hydrogen gas mixtures. The experiments were carried out at room temperature and at feed pressures ranging from 50 to 500 psig. For each pressure, the residue and permeate compositions were determined as a function of the stage-cut. Based on these compositions and the operating conditions, such as pressure and stage-cut, the effective carbon dioxide/hydrogen selectivity is determined, using a computer program that solves the basic gas permeation equations. The selectivities are listed in the tables and are relatively independent of stage-cut and pressure, but vary strongly with the feed gas carbon dioxide content. The latter observation is illustrated in Figure 26. The effective selectivity increases with increasing carbon dioxide content and, at $75 \%$ carbon dioxide, is substantially higher than the intrinsic carbon dioxide/hydrogen selectivity of the module measured with pure gases at 50 psig. This behavior is puzzling. The dependence of selectivity on carbon dioxide content suggests that the carbon dioxide partial pressure affects the separation, as has been observed with many polymers. However, in this case the selectivity should be a strong function of feed pressure, and the selectivity would be expected to decrease with increasing carbon dioxide content.

Also included in Tables 19 through 21 is the hydrogen recovery, defined as the amount of hydrogen present in the hydrogen-enriched residue stream relative to the amount of hydrogen present in the feed gas. As expected, the hydrogen recovery decreases with increasing purity of the inydrogen product stream. For example, treating a typical $50 / 50$ carbon dioxide/hydrogen stream with a singlestage polyamide copolymer membrane system would recover $65 \%$ of the hydrogen at $90 \%$ purity. For most applications, both these purity and recovery levels would not be acceptable. Thus, it is expected that multistage systems will have to be considered. 


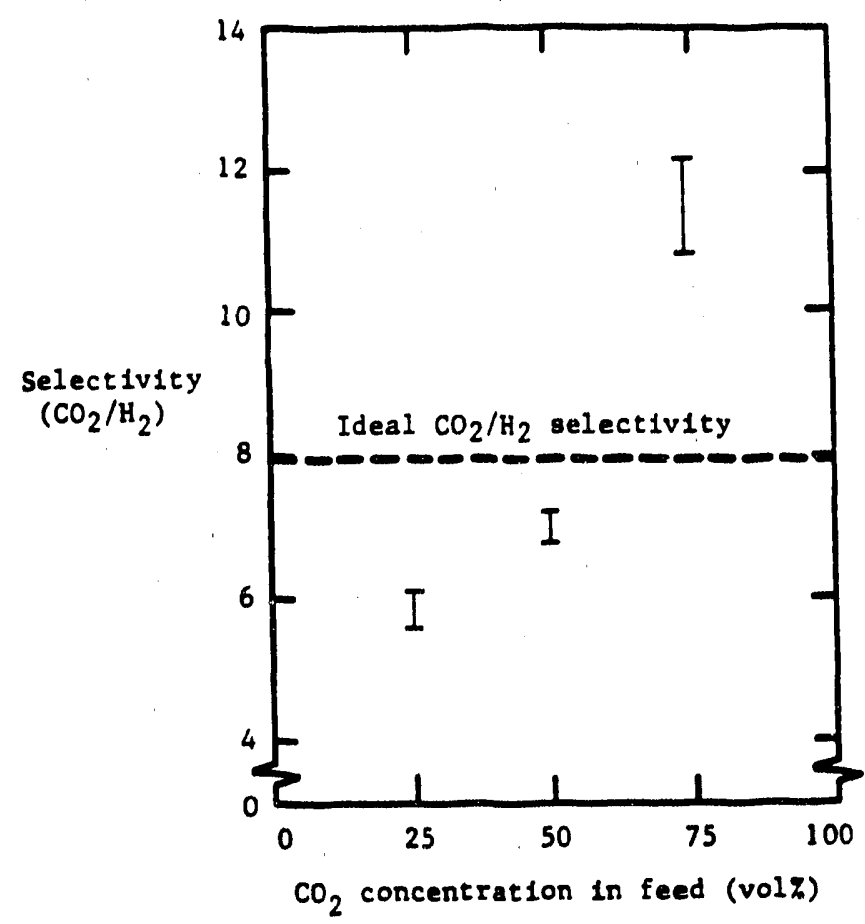

Figure 26. The effect of carbon dioxide feed gas concentration on carbon dioxide/hydrogen selectivity of a polyamide copolymer composite membrane module. Feed pressure: 50, 100, 200, 500 psig; zero stage-cut. 
Table 19. Polyamide Copolymer Composite Membrane Bimodule Separation

Data at $25^{\circ} \mathrm{C}$ with a $75 / 25$ Mixture of $\mathrm{CO}_{2} / \mathrm{H}_{2}$

Permeate pressure: 0 psig

Membrane area: $\quad 330 \mathrm{~cm}^{2}$

\begin{tabular}{|c|c|c|c|c|c|c|c|c|c|}
\hline \multirow{2}{*}{$\begin{array}{l}\text { Feed } \\
\text { pressure } \\
\text { (psig) }\end{array}$} & \multirow{2}{*}{$\begin{array}{l}\text { Stage- } \\
\text { cut } \\
(\%)\end{array}$} & \multirow{2}{*}{$\begin{array}{l}\text { Permeate } \\
\text { Flow } \\
\left(\mathrm{cm}^{3} / \mathrm{min}\right)\end{array}$} & \multirow{2}{*}{$\begin{array}{c}\text { Feed } \\
\text { Flow } \\
\left(\mathrm{cm}^{3} / \mathrm{min}\right)\end{array}$} & \multicolumn{2}{|c|}{$\begin{array}{l}\text { Residue comp. } \\
\text { (\%) }\end{array}$} & \multicolumn{2}{|c|}{$\begin{array}{c}\text { Permeate comp. } \\
(\%)\end{array}$} & \multirow{2}{*}{$\begin{array}{c}\mathrm{H}_{2} \\
\text { Recovery } \\
(\%)\end{array}$} & \multirow{2}{*}{$\begin{array}{c}\text { Selectivity } \\
\mathrm{CO}_{2} / \mathrm{H}_{2}\end{array}$} \\
\hline & & & & $\mathrm{CO}_{2}$ & $\mathrm{H}_{2}$ & $\mathrm{CO}_{2}$ & $\mathrm{H}_{2}$ & & \\
\hline $\begin{array}{l}50 \\
50 \\
50 \\
40\end{array}$ & $\begin{array}{r}1.6 \\
5.3 \\
17.3 \\
46.0\end{array}$ & $\begin{array}{l}840 \\
680 \\
650 \\
550\end{array}$ & $\begin{array}{r}51,600 \\
12,600 \\
3,700 \\
1,200\end{array}$ & $\begin{array}{l}73 \\
72 \\
69 \\
57\end{array}$ & $\begin{array}{l}27 \\
28 \\
31 \\
43\end{array}$ & $\begin{array}{l}95.5 \\
96 \\
95.5 \\
96\end{array}$ & $\begin{array}{l}4.5 \\
4 \\
4.5 \\
6\end{array}$ & $\begin{array}{l}99.7 \\
99.5 \\
96.9 \\
89.0\end{array}$ & $\begin{array}{r}9.6 \\
11.3 \\
10.8 \\
11.1\end{array}$ \\
\hline $\begin{array}{l}100 \\
100 \\
100 \\
100\end{array}$ & $\begin{array}{r}2.8 \\
7.7 \\
15.0 \\
51.0\end{array}$ & $\begin{array}{l}1,430 \\
1,440 \\
1,500 \\
1,300\end{array}$ & $\begin{array}{r}51,500 \\
18,500 \\
10,100 \\
2,500\end{array}$ & $\begin{array}{l}73.8 \\
70.5 \\
69 \\
52.5\end{array}$ & $\begin{array}{l}26.2 \\
29.5 \\
31 \\
47.5\end{array}$ & $\begin{array}{l}97 \\
97 \\
96.5 \\
94\end{array}$ & $\begin{array}{l}3 \\
3 \\
3.5 \\
6\end{array}$ & $\begin{array}{l}99.8 \\
99.2 \\
98.5 \\
87.6\end{array}$ & $\begin{array}{r}12.9 \\
13.4 \\
11.9 \\
9.4\end{array}$ \\
\hline $\begin{array}{l}200 \\
200 \\
200\end{array}$ & $\begin{array}{r}1.9 \\
8.3 \\
42.0\end{array}$ & $\begin{array}{l}3,640 \\
4,100 \\
3,600\end{array}$ & $\begin{array}{r}190,000 \\
49,000 \\
8,600\end{array}$ & $\begin{array}{l}73 \\
71 \\
55.5\end{array}$ & $\begin{array}{l}27 \\
29 \\
44.5\end{array}$ & $\begin{array}{l}97 \\
96.5 \\
94\end{array}$ & $\begin{array}{l}3 \\
3.5 \\
6\end{array}$ & $\begin{array}{l}99.9 \\
99.3 \\
89.9\end{array}$ & $\begin{array}{r}11.7 \\
11.2 \\
7.9\end{array}$ \\
\hline $\begin{array}{l}500 \\
500 \\
500\end{array}$ & $\begin{array}{r}7.8 \\
16.0 \\
40.5\end{array}$ & $\begin{array}{r}11,900 \\
11,800 \\
9,850\end{array}$ & $\begin{array}{r}152,000 \\
75,000 \\
24,400\end{array}$ & $\begin{array}{l}71.5 \\
69 \\
57.5\end{array}$ & $\begin{array}{l}28.5 \\
31 \\
42.5\end{array}$ & $\begin{array}{l}97 \\
96.5 \\
95.5\end{array}$ & $\begin{array}{l}3 \\
3.5 \\
4.5\end{array}$ & $\begin{array}{l}99.0 \\
98.1 \\
92.7\end{array}$ & $\begin{array}{r}11.7 \\
9.9 \\
10.9\end{array}$ \\
\hline
\end{tabular}


Table 20. Polyamide Copolymer Composite Membrane Bimodule Separation Data at $23^{\circ} \mathrm{C}$ with a $50 / 50$ mixture of $\mathrm{CO}_{2} / \mathrm{H}_{2}$

\section{Permeate pressure: 0 psig}

Membrane area: $\quad 330 \mathrm{~cm}^{2}$

\begin{tabular}{|c|c|c|c|c|c|c|c|c|c|}
\hline \multirow{2}{*}{$\begin{array}{l}\text { Feed } \\
\text { pressure } \\
\text { (psig) }\end{array}$} & \multirow{2}{*}{$\begin{array}{c}\text { Stage } \\
\text { cut } \\
(\%)\end{array}$} & \multirow{2}{*}{$\begin{array}{c}\text { - Permeate } \\
\text { Flow } \\
\left(\mathrm{cm}^{3} / \mathrm{min}\right)\end{array}$} & \multirow{2}{*}{$\begin{array}{c}\text { Feed } \\
\text { Flow } \\
\left(\mathrm{cm}^{3} / \mathrm{min}\right)\end{array}$} & \multicolumn{2}{|c|}{$\begin{array}{c}\text { Residue comp. } \\
(\%)\end{array}$} & \multicolumn{2}{|c|}{$\begin{array}{c}\text { Permeate comp. } \\
(\%)\end{array}$} & \multirow{2}{*}{$\begin{array}{c}\mathrm{H}_{2} \\
\text { Recovery } \\
(\%)\end{array}$} & \multirow{2}{*}{$\begin{array}{l}\text { Selectivity } \\
\mathrm{CO}_{2} / \mathrm{H}_{2}\end{array}$} \\
\hline & & & & $\mathrm{CO}_{2}$ & $\mathbf{H}_{2}$ & $\mathrm{CO}_{2}$ & $\mathbf{H}_{2}$ & & \\
\hline $\begin{array}{l}50 \\
7.2\end{array}$ & 0.1 & 490 & 48,000 & 49.5 & 50.5 & 83 & 17 & 99.65 & \\
\hline $\begin{array}{l}50 \\
50 \\
50\end{array}$ & $\begin{array}{r}1.5 \\
15.0 \\
46.6\end{array}$ & $\begin{array}{l}400 \\
440 \\
410\end{array}$ & $\begin{array}{r}25,200 \\
2,900 \\
890\end{array}$ & $\begin{array}{l}48.9 \\
42 \\
28\end{array}$ & $\begin{array}{l}51.1 \\
58 \\
72\end{array}$ & $\begin{array}{l}82 \\
80 \\
74.5\end{array}$ & $\begin{array}{l}18 \\
20 \\
25.5\end{array}$ & $\begin{array}{l}99.4 \\
93.9 \\
76.2\end{array}$ & $\begin{array}{l}5.9 \\
6.6 \\
6.6\end{array}$ \\
\hline $\begin{array}{l}100 \\
100 \\
100 \\
100\end{array}$ & $\begin{array}{r}1.6 \\
4.5 \\
14.5 \\
48.0\end{array}$ & $\begin{array}{l}1,010 \\
1,010 \\
1,000 \\
900\end{array}$ & $\begin{array}{r}62,700 \\
22,800 \\
6,900 \\
1,900\end{array}$ & $\begin{array}{l}49.6 \\
46 \\
41.5 \\
27\end{array}$ & $\begin{array}{l}50.4 \\
54 \\
58.5 \\
73\end{array}$ & $\begin{array}{l}85.5 \\
84.5 \\
83.5 \\
75\end{array}$ & $\begin{array}{l}14.5 \\
14.5 \\
16.5 \\
25\end{array}$ & $\begin{array}{l}99.5 \\
98.7 \\
95.2 \\
76\end{array}$ & $\begin{array}{l}7.2 \\
6.9 \\
7.0 \\
6.2\end{array}$ \\
\hline $\begin{array}{l}200 \\
200 \\
200\end{array}$ & $\begin{array}{r}3.7 \\
16.3 \\
44.0\end{array}$ & $\begin{array}{l}2,490 \\
2,100 \\
2,000\end{array}$ & $\begin{array}{r}66,900 \\
13,500 \\
4,500\end{array}$ & $\begin{array}{l}49.1 \\
42 \\
27\end{array}$ & $\begin{array}{l}50.9 \\
58 \\
73\end{array}$ & $\begin{array}{l}86.5 \\
84 \\
78\end{array}$ & $\begin{array}{l}13.5 \\
16 \\
22\end{array}$ & $\begin{array}{l}98.9 \\
96.8 \\
80.5\end{array}$ & $\begin{array}{l}7.3 \\
6.6 \\
6.2\end{array}$ \\
\hline $\begin{array}{l}500 \\
500 \\
500 \\
500\end{array}$ & $\begin{array}{r}2.8 \\
9.5 \\
15.0 \\
49.3\end{array}$ & $\begin{array}{l}7,100 \\
7,700 \\
7,100 \\
6,600\end{array}$ & $\begin{array}{r}248,000 \\
82,500 \\
47,700 \\
13,400\end{array}$ & $\begin{array}{l}47 \\
45 \\
40 \\
27\end{array}$ & $\begin{array}{l}53 \\
55 \\
60 \\
73\end{array}$ & $\begin{array}{l}85.5 \\
83 \\
82 \\
76\end{array}$ & $\begin{array}{l}14.5 \\
17 \\
18 \\
24\end{array}$ & $\begin{array}{l}99.2 \\
96.8 \\
94.4 \\
77.4\end{array}$ & $\begin{array}{l}6.2 \\
5.5 \\
5.4 \\
5.4\end{array}$ \\
\hline
\end{tabular}


Table 21. Polyamide Copolymer Composite Membrane Bimodule Separation Data at $23^{\circ} \mathrm{C}$ with $25 / 75 \mathrm{CO}_{2} / \mathrm{H}_{2}$ Mixture

Permeate pressure: $\quad 0$ psig

Membrane area: $\quad 330 \mathrm{~cm}^{2}$

\begin{tabular}{|c|c|c|c|c|c|c|c|c|c|}
\hline \multirow{2}{*}{$\begin{array}{l}\text { Feed } \\
\text { pressure } \\
\text { (psig) }\end{array}$} & \multirow{2}{*}{$\begin{array}{l}\text { Stage- } \\
\text { cut } \\
(\%)\end{array}$} & \multirow{2}{*}{$\begin{array}{l}\text { Permeate } \\
\text { Flow } \\
\text { (mL/min) }\end{array}$} & \multirow{2}{*}{$\begin{array}{c}\text { Feed } \\
\text { Flow } \\
(\mathrm{mL} / \mathrm{min})\end{array}$} & \multicolumn{2}{|c|}{$\begin{array}{l}\text { Residue comp. } \\
(\%)\end{array}$} & \multicolumn{2}{|c|}{$\begin{array}{l}\text { Permeate comp. } \\
(\%)\end{array}$} & \multirow{2}{*}{$\begin{array}{c}\mathrm{H}_{\mathbf{2}} \\
\text { Recovery } \\
(\%)\end{array}$} & \multirow{2}{*}{$\begin{array}{l}\text { Selectivity } \\
\mathrm{CO}_{2} / \mathrm{H}_{2}\end{array}$} \\
\hline & & & & $\mathrm{CO}_{2}$ & $\mathbf{H}_{2}$ & $\mathrm{CO}_{2}$ & $\mathbf{H}_{2}$ & & \\
\hline $\begin{array}{l}50 \\
50 \\
50 \\
55\end{array}$ & $\begin{array}{l}0.5 \\
2.5 \\
19 \\
46\end{array}$ & $\begin{array}{l}240 \\
250 \\
260 \\
120\end{array}$ & $\begin{array}{r}49,000 \\
10.300 \\
1,600 \\
270\end{array}$ & $\begin{array}{l}24.5 \\
24 \\
18 \\
16\end{array}$ & $\begin{array}{l}75.5 \\
76 \\
82 \\
84\end{array}$ & $\begin{array}{l}54 \\
54 \\
51 \\
39\end{array}$ & $\begin{array}{l}46 \\
46 \\
49 \\
61\end{array}$ & $\begin{array}{l}99.7 \\
98.5 \\
87.5 \\
62.9\end{array}$ & $\begin{array}{l}6.0 \\
6.1 \\
7.2 \\
4.0\end{array}$ \\
\hline $\begin{array}{l}100 \\
100 \\
100 \\
100\end{array}$ & $\begin{array}{l}1 \\
6.7 \\
16 \\
46\end{array}$ & $\begin{array}{l}580 \\
570 \\
600 \\
630\end{array}$ & $\begin{array}{r}56,000 \\
8,500 \\
3,700 \\
1,400\end{array}$ & $\begin{array}{l}24.5 \\
22 \\
18 \\
6.5\end{array}$ & $\begin{array}{l}75.5 \\
78 \\
82 \\
93.5\end{array}$ & $\begin{array}{l}60 \\
57 \\
55 \\
44\end{array}$ & $\begin{array}{l}40 \\
43 \\
45 \\
56\end{array}$ & $\begin{array}{l}99.4 \\
96.1 \\
90.3 \\
66.0\end{array}$ & $\begin{array}{l}6.0 \\
5.2 \\
5.9 \\
5.4\end{array}$ \\
\hline $\begin{array}{l}200 \\
200 \\
200 \\
200\end{array}$ & $\begin{array}{l}2.2 \\
7 \\
13.5 \\
50\end{array}$ & $\begin{array}{l}1,400 \\
1,460 \\
1,300 \\
1,120\end{array}$ & $\begin{array}{r}63,700 \\
19,700 \\
9,700 \\
2,260\end{array}$ & $\begin{array}{l}23.5 \\
22 \\
18 \\
5\end{array}$ & $\begin{array}{l}76.5 \\
78 \\
82 \\
95\end{array}$ & $\begin{array}{l}62 \\
60 \\
59 \\
46\end{array}$ & $\begin{array}{l}38 \\
40 \\
41 \\
54\end{array}$ & $\begin{array}{l}98.9 \\
96.0 \\
92.6 \\
64.3\end{array}$ & $\begin{array}{l}5.9 \\
6.3 \\
5.9 \\
7.0\end{array}$ \\
\hline $\begin{array}{l}500 \\
500 \\
500 \\
500\end{array}$ & $\begin{array}{l}3 \\
5.4 \\
14 \\
49\end{array}$ & $\begin{array}{l}4,200 \\
4,160 \\
4,020 \\
3,990\end{array}$ & $\begin{array}{r}138,800 \\
77,100 \\
27,500 \\
8,140\end{array}$ & $\begin{array}{r}22 \\
23 \\
18 \\
9\end{array}$ & $\begin{array}{l}76 \\
77 \\
89 \\
91\end{array}$ & $\begin{array}{l}61 \\
59 \\
58 \\
47\end{array}$ & $\begin{array}{l}39 \\
41 \\
42 \\
53\end{array}$ & $\begin{array}{l}98.4 \\
97.1 \\
91.8 \\
72.3\end{array}$ & $\begin{array}{l}5.2 \\
4.8 \\
5.2 \\
5.2\end{array}$ \\
\hline
\end{tabular}


A polyamide copolymer membrane bimodule with an intrinsic selectivity of 8.2 and an effective membrane area of $105 \mathrm{~cm}^{2}$ was tested with a feed gas mixture containing $1.3 \%$ hydrogen sulfide, $47.5 \%$ carbon dioxide, and $51.2 \%$ hydrogen. The experiment was carried out at room temperature and $50 \mathrm{psig}$ feed pressure. The results are shown in Table 22. The calculated permeation rates and selectivities are listed in Table 23.

Table 22. Gas Mixture Separation Data of a Polyamide Copolymer Membrane Bimodule with a Feed Gas Mixture Containing Hydrogen Sulfide Carbon Dioxide, and Hydrosen

(Effective Membrane Area: $105 \mathrm{~cm}^{2}$, Temperature: $22^{\circ} \mathrm{C}$ ).

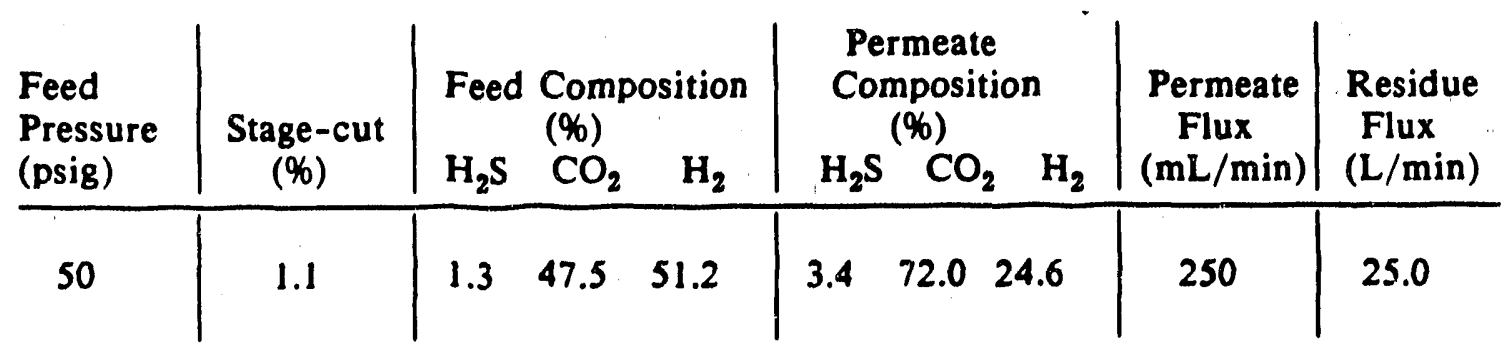

Table 23. Permeation Rates and Selectivities of a Polvamide Copolymer Membrane Bimodule for a Feed Gas Mixture Containine 1.3\% Hudrosen Sulfide. 47.5\% Carbon Dioxide, and $51.2 \%$ Hydrogen

(Temperature: $20^{\circ} \mathrm{C}$, Feed Pressure: $50 \mathrm{psig}$ ).

\begin{tabular}{|c|c|c|c|}
\hline & \multicolumn{2}{|c|}{$\begin{array}{c}\text { Permeation Rate } \\
{\left[\mathrm{cm}^{3}(\mathrm{STP}) /\left(\mathrm{cm}^{2} \cdot \sec \cdot \mathrm{cmHg}\right)\right]}\end{array}$} & \multirow{2}{*}{$\begin{array}{l}\text { Selectivity (calculated } \\
\text { using mixture data) }\end{array}$} \\
\hline & Mixture Data & Pure Gas Data & \\
\hline $\mathrm{H}_{2} \mathrm{~S}$ & $8.0 \times 10^{-4}$ & - & $\mathrm{CO}_{2} / \mathrm{H}_{2}=4.5$ \\
\hline $\mathrm{CO}_{2}$ & $2.9 \times 10^{-4}$ & $3.3 \times 10^{-4}$ & $\mathrm{H}_{2} \mathrm{~S} / \mathrm{H}_{2}=12.3$ \\
\hline $\mathrm{H}_{2}$ & $6.5 \times 10^{-6}$ & $4.0 \times 10^{-5}$ & $\mathrm{H}_{2} \mathrm{~S} / \mathrm{CO}_{2}=2.8$ \\
\hline
\end{tabular}


Compared to the ideal hydrogen sulfide/hydrogen selectivity of 69 (using pure gases at a feed pressure of $50 \mathrm{psig}$ ), the selectivity of 12.3 in the gas mixture measurements is significantly lower. This suggests that the permeability of hydrogen sulfide is a strong function of its partial pressure in the feed gas. Nonetheless, even though the hydrogen sulfide/hydrogen selectivity in the gas mixture tests is significantly lower than the ideal hydrogen sulfide/hydrogen selectivity, it is still a relatively high selectivity for a polymeric membrane. The presence of hydrogen sulfide also increases the permeability of the membrane for hydrogen, thereby reducing the carbon dioxide/hydrogen selectivity. This is most likely a result of membrane plasticization by the hydrogen sulfide.

A polyamide copolymer spiral-wound bimodule with an intrinsic carbon dioxide/hydrogen selectivity of 9.2 and an effective membrane area of $105 \mathrm{~cm}^{2}$ was tested with a feed gis mixture containing $0.3 \%$ hydrogen sulfide, $46 \%$ carbon dioxide and $53.7 \%$ hydrogen. The tests were conducted with the high pressure test loop (see Figure 25) which was operated continuously for several hours at $40^{\circ} \mathrm{C}$ and at 100 and 200 psig feed pressure. The results are shown in Table 24. The calculated permeation rates and selectivities are shown in Table 25. Included for corsparison in Table 25 are also the permeation rates and the selectivities observed with pure gases.

The carbon dioxide/hydrogen and hydrogen sulfide/hydrogen selectivities at e:evated temperature and pressures are much lower than those measured with pure gases or with a gas mixture at room temperature and 50 psig (see Tables 22 and 23). For example, the carbon dioxide/hydrogen selectivity measured with gas mixtures dropped from 4.5 at $20^{\circ} \mathrm{C}$ and $50 \mathrm{psig}$ to just over 1 at $40^{\circ} \mathrm{C}$ and elevated pressures. However, the hydrogen sulfide/carbon dioxide selectivity increased from 2.8 at $50 \mathrm{psig}$ and room temperature to 5.3 at $100 \mathrm{psig}$ and $40^{\circ} \mathrm{C}$. The permeation rates for all of the gases are also much higher at 100 and 200 psig and $40^{\circ} \mathrm{C}$ compared to the rates at $50 \mathrm{psig}$ and $20^{\circ} \mathrm{C}$. This is probably the result of the plasticization effect of hydrogen sulfide. Membrane failure was not responsible, because the membrane module was retested after the experiments and still possessed an intrinsic carbon dioxide/hydrogen selectivity of 9 .

Table 24. Gas Mixture Separation Data of a Polyamide Copolymer Membrane Bimodule with a Feed Gas Mixture Containing Hydrosen Sulfide. Carbon Dioxide, and Hydrosen

(Effective membrane area: $105 \mathrm{~cm}^{2}$; Temperature: $40^{\circ} \mathrm{C}$ )

\begin{tabular}{|c|c|c|c|c|c|c|c|c|c|}
\hline \multirow{2}{*}{$\begin{array}{l}\text { Feed } \\
\text { pressure } \\
\text { (psig) }\end{array}$} & \multirow{2}{*}{$\begin{array}{l}\text { Stage-cut } \\
(\%)\end{array}$} & \multicolumn{3}{|c|}{$\begin{array}{l}\text { Feed composition } \\
(\%)\end{array}$} & \multicolumn{3}{|c|}{$\begin{array}{c}\text { Permeate } \\
\text { composition } \\
(\%)\end{array}$} & \multirow{2}{*}{$\begin{array}{l}\text { Permeate } \\
\text { flux } \\
(\mathrm{mL} / \mathrm{min})\end{array}$} & \multirow{2}{*}{$\begin{array}{l}\text { Residue } \\
\text { flux } \\
\text { (mL/min) }\end{array}$} \\
\hline & & $\overline{\mathrm{H}_{2} \mathrm{~S}}$ & $\mathrm{CO}_{2}$ & $\mathbf{H}_{2}$ & $\mathrm{H}_{2} \mathrm{~S}$ & $\mathrm{CO}_{2}$ & $\mathrm{H}_{2}$ & & \\
\hline $\begin{array}{l}100 \\
200\end{array}$ & $\begin{array}{l}34 \\
36\end{array}$ & $\begin{array}{l}0.3 \\
0.3\end{array}$ & $\begin{array}{l}46.0 \\
46.0\end{array}$ & $\begin{array}{l}53.7 \\
53.7\end{array}$ & $\begin{array}{l}0.7 \\
0.6\end{array}$ & $\begin{array}{l}48 \\
47\end{array}$ & $\begin{array}{l}51.3 \\
52.4\end{array}$ & $\begin{array}{r}5,200 \\
13,000\end{array}$ & $\begin{array}{r}9,900 \\
22,900\end{array}$ \\
\hline
\end{tabular}


Table 25. Permeation Rates and Selectivities of a Polyamide Copolymer Bimodule for a Feed Gas Mixture Containing 0.3\% Hydrosen Sulfide $46 \%$ Carbon Dioxide and $53.7 \%$ Hydrogen

\begin{tabular}{|c|c|c|c|c|c|c|c|}
\hline \multicolumn{4}{|c|}{$\begin{array}{c}\text { Permeation Rate } \\
\left(\mathrm{cm}^{3}(\mathrm{STP}) / \mathrm{cm}^{2} \cdot \mathrm{s} \cdot \mathrm{cmH}\right)\end{array}$} & \multicolumn{4}{|c|}{ Selectivity } \\
\hline & $\begin{array}{l}\text { Mixture data } \\
100 \mathrm{psig} \\
40^{\circ} \mathrm{C}\end{array}$ & $\begin{array}{l}\text { Mixture data } \\
200 \text { psig, } \\
40^{\circ} \mathrm{C}\end{array}$ & $\begin{array}{l}\text { Pure gases } \\
50 \text { psig, } \\
23^{\circ} \mathrm{C}\end{array}$ & & $\begin{array}{l}\text { ture data } \\
0 \text { psig, } \\
40^{\circ} \mathrm{C}\end{array}$ & $\begin{array}{c}\text { Mixture data } \\
200 \mathrm{psig} \\
40^{\circ} \mathrm{C}\end{array}$ & $\begin{array}{c}\text { Pure gases } \\
50 \text { psig, } \\
23^{\circ} \mathrm{C}\end{array}$ \\
\hline $\mathrm{H}_{2} \mathrm{~S}$ & $8.0 \times 10^{-3}$ & $8.0 \times 10^{-3}$ & $2.5 \times 10^{-3}$ & $\mathrm{CO}_{2} / \mathrm{H}_{2}$ & 1.2 & 1.1 & 9.1 \\
\hline $\mathrm{CO}_{2}$ & $1.5 \times 10^{-3}$ & $2.0 \times 10^{-3}$ & $3.3 \times 10^{-4}$ & $\mathrm{H}_{2} \mathrm{~S} / \mathrm{H}_{2}$ & 6.1 & 4.2 & 69 \\
\hline $\mathrm{H}_{2}$ & $1.3 \times 10^{-3}$ & $1.9 \times 10^{-3}$ & $3.6 \times 10^{-5}$ & $\mathrm{H}_{2} \mathrm{~S} / \mathrm{CO}_{2}$ & 5.3 & 4.0 & 7.5 \\
\hline
\end{tabular}

D. Membrane Properties Used in Economic Evaluation

Based on the membrane testing and membrane module testing experiments described in this and the previous sections, determination was made of the permeation rate values to be used in the economic analysis, for both the polyetherimide membrane and the polyamide copolymer membrane .

\section{Polvetherimide Membrane}

The polyetherimide polymer used to produce the membrane has a thermal sof tening point of $219^{\circ} \mathrm{C}$ (General Electric Plastics, product literature). We have therefore assumed that a polyetherimide membrane can be used at temperatures up to $150^{\circ} \mathrm{C}$. Table 26 lists the properties of the polyetherimide membrane at $150^{\circ} \mathrm{C}$. As discussed in Section VI, the polyetherimide membrane performance is largely independent of feed pressure and feed gas composition. The permeation rates of hydrogen, carbon dioxide, carbon monoxide and nitrogen are obtained by extrapolating to $150^{\circ} \mathrm{C}$ the data given in Figures 9 and 11 . This extrapolation is accurate because the permeation rates closely follow Arrhenius law. No experimental permeation rate is available for hydrogen sulfide. However, an analysis of permeation data in the literature shows that the permeability of glassy polymers to carbon dioxide is 20 to $40 \%$ higher than the permeability to hydrogen sulfide. The value listed for hydrogen sulfide is thus an estimate based on the known permeation rate of carbon dioxide. 
Table 26. Polvetherimide Membrane Properties Used in Economic Evaluation (Temperature: $150^{\circ} \mathrm{C}$ )

\begin{tabular}{ll}
\hline Gas & $\begin{array}{c}\text { Normalized Permeation Rate } \\
\left(\mathrm{cm}^{3}(\mathrm{STP}) / \mathrm{cm}^{2} \cdot \mathrm{s} \cdot \mathrm{cmH}_{\mathrm{g}}\right)\end{array}$ \\
\hline $\mathrm{H}_{2}$ & $6.7 \times 10^{-4}$ \\
$\mathrm{CO}_{2}$ & $9.1 \times 10^{-6}$ \\
$\mathrm{H}_{2} \mathrm{~S}$ & $6.7 \times 10^{-6}$ \\
$\mathrm{CO}^{\mathrm{N}}$ & $1.3 \times 10^{-6}$ \\
$\mathrm{~N}_{2}$ & $9.9 \times 10^{-6}$ \\
\hline
\end{tabular}

\section{Polvamide Copolymer Membrane}

Temperature stability tests have shown that the polyamide copolymer membrane can be used at temperatures up to at least $80^{\circ} \mathrm{C}$ and perhaps to $100^{\circ} \mathrm{C}$. However, at the time the economic analysis was undertaken, only data obtained with gas mixtures at $25^{\circ} \mathrm{C}$ were available. The permeation rates used in the economic analysis are listed in Table 27. The hydrogen sulfide, carbon dioxide and hydrogen permeation rates are taken from Table 28. The nitrogen and carbon monoxide permeation rates are based on pure gas permeation experiments. Subsequent experiments have shown that the effective selectivities of the polyamide copolymer membrane decrease with increasing pressure and temperature. Using the data listed in Table 27, we have probably underestimated the costs of polyamide copolymer membrane systems. However, as will be clear in Section IX (Economic Evaluation of Membrane Systems for the Separation of Hydrogen from Synthesis Gas), even in this case, no systems employing the polyamide copolymer membrane appear economically attractive.

Table 27. Polvamide Copolvmer Membrane Properties Used in Economic Evaluation (Temperature: $25^{\circ} \mathrm{C}$ )

Gas

$$
\begin{gathered}
\text { Normalized Permeation Rate } \\
\left(\mathrm{cm}^{3}(\mathrm{STP}) / \mathrm{cm}^{2} \cdot \mathrm{s} \cdot \mathrm{cmH}_{\mathrm{g}}\right)
\end{gathered}
$$

$\begin{array}{ll}\mathrm{H}_{2} \mathrm{~S} & 8.0 \times 10^{-4} \\ \mathrm{CO}_{2} & 2.9 \times 10^{-4} \\ \mathrm{H}_{2} & 6.5 \times 10^{-6} \\ \mathrm{CO} & 1.0 \times 10^{-6} \\ \mathrm{~N}_{2} & 3.1 \times 10^{-6}\end{array}$




\section{MATHEMATICAL MODELING OF MEMBRANE GAS SEPARATION SYSTEMS}

One of the objectives of the present program was to perform an economic evaluation of membrane gas separation systems for the separation of hydrogen from synthesis gas. To allow prediction of the performance of membrane systems a mathematical model was developed to describe the permeation process in a membrane module. Two different gas flow patterns, cross flow and countercurrent flow, were considered. The model has been shown to accurately describe the performance of membrane modules.

\section{A. Mathematical Model}

The permeation of gases through polymer membranes is generally described by the solution-diffusion model. Thus, the basis for any mathematical model is Fick's law in the form of equation 5. The full set of equations describing both crossflow and countercurrent flow membrane modules are given in Appendix $A$. In deriving the equations of Appendix $A$, a number of assumptions were made which are listed in Table 28 . The equations were incorporated into computer simulations that calculate the performance of membrane systems as a function of the membrane properties and the operating conditions.

\section{Table 28. Assumptions Used in Crossflow and Countercurrent Membrane Module Models}

1. Transport of all species is by Fickian diffusion with constant diffusion coefficients, and constant solubilities, i.e., all permeabilities are independent of pressure and composition.

2. Diffusion inside the membrane along the length of the membrane is negligible.

3. There is no gas phase mass transfer resistance.

4. The gas is in plug flow on both sides of the membrane.

5. The system is at steady-state.

6. Pressure drops in feed, and permeate streams are negligible.

The difference in flow patterns between crossflow and countercurrent flow is illustrated in Figure 27. In the crossflow mode, the permeate composition at any given position in the module is independent of the permeate composition at other points. Thus, the separation achieved at each point depends only on the feed composition at that point, the pressures and the membrane properties. In contrast, in the countercurrent mode, the permeate composition at any given point in the module is affected by the permeate composition of the points upstream. This means that the separation achieved depends not only on the local feed concentration but also on the downstream feed concentrations. 


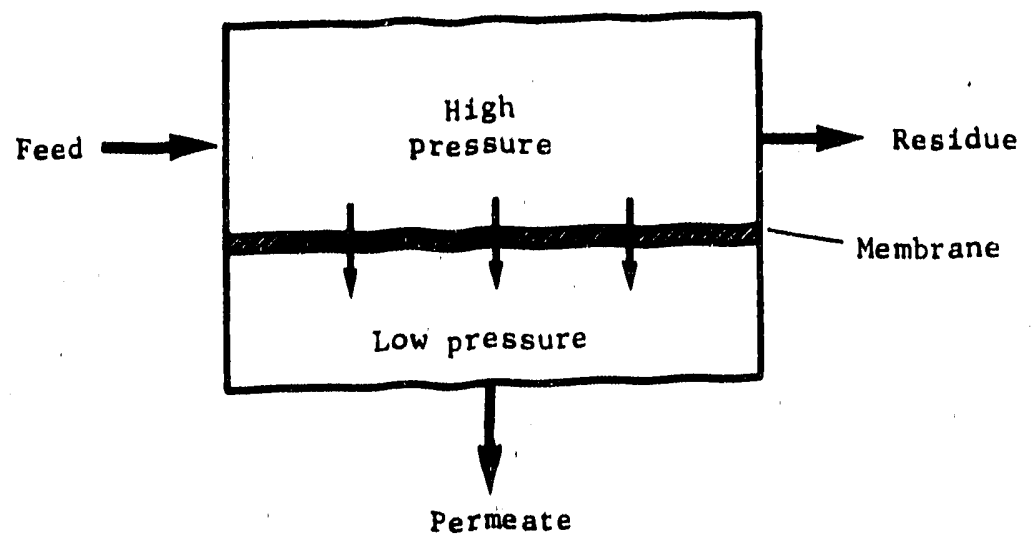

(a) Cross-flow membrane module

The local permeate composition is independent of the permeate composition at any other point in the module.

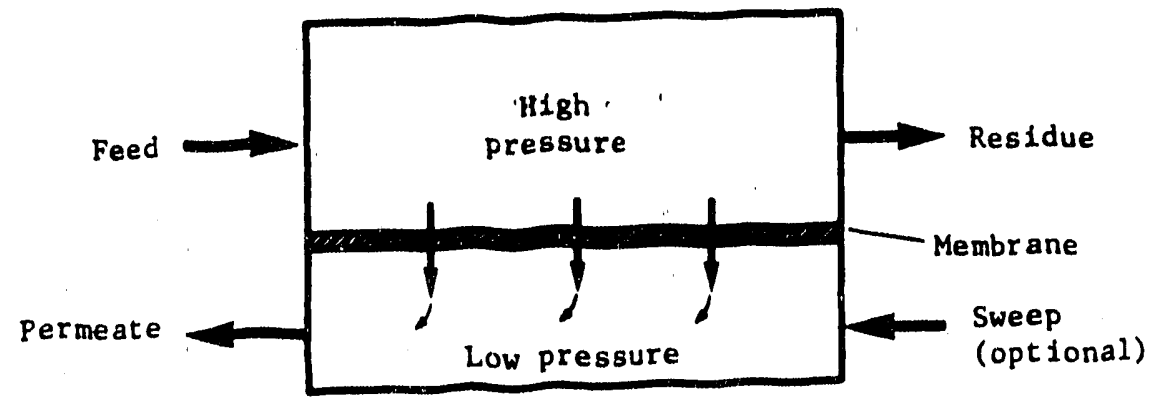

(b) Countercurrent membrane module

The local permeate composition is dependent upon the permeate composition directly upstream of that point.

Figure 27. Schematic of now pattern in (a) crossflow membrane model and (b) countercurrent membrane module. 
Although both crossflow and countercurrent flow models have been developed, only the crossflow model has been used in the membrane system analysis and economic evaluation. The reason for this is two-fold: (1) most membrane modules, including all spiral-wound modules, have a flow pattern that is most closely described by the crossflow model, and (2) it has been shown that for asymmetric membranes, the crossflow model best describes the module performance, even if the actual flow pattern is countercurrent. All commercial gas separation membranes have an asymmetric membrane structure, as have the membranes developed in this program. Thus, the crossflow model is the preferred model. Table 29 lists the most commonly used combinations of input and output parameters used during the computer calculations.

Table 29. List of Inout Parameter/Outbut Parameter Combinations for the Crossflow Module Computer Model

1. Membrane properties

2. Feed conceritrations

3. Feed pressure

4. Permeate pressure

5. Feed flow rate

6. One residue or permeate concentration
1. Residue concentrations

2. Permeate concentration

3. Residue flow rate

4. Permeate flow rate

5. Membrane area

\section{B. Comparison of Model and Experimental Results}

To test the accuracy of the model predictions, we compared the predictions with experimental results obtained using a spiral-wound module. The module performance tests using a mixed-gas feed for this project had only just begun at the time of writing of this report, so the experimental results used for evaluating the model were obtained from a previous MTR project. The experimental module was manufactured by MTR and contained $2,000 \mathrm{~cm}^{2}$ of a silicone rubber membrane. The feed mixture used in this test consisted of carbon dioxide, oxygen, and nitrogen. The pressure-zormalized fluxes, (permeability/membrane thickness), obtained using pure gases in the module are given in Table 30. 
Tavile 30. Pure Gas Membrane Properties

\begin{tabular}{ll}
\hline Gas & $\begin{array}{c}\text { Normalized } \\
\text { flux }\end{array}$ \\
\hline $\mathrm{CO}_{2}$ & $\left.\frac{\mathrm{cm}^{3}(\mathrm{STP})}{\mathrm{cm}^{2} \cdot \mathrm{s} \cdot \mathrm{cmH}}\right)$ \\
$\mathrm{O}_{2}$ & $2.3 \times 10^{-3}$ \\
$\mathrm{~N}_{2}$ & $0.48 \times 10^{-3}$ \\
& $0.25 \times 10^{-3}$ \\
\hline
\end{tabular}

The experiments were performed using two different feed mixtures (Case I: $0.3 \% \mathrm{CO}_{2}, 18.9 \%$ oxygen, $80.8 \%$ nitrogen; Case II: $10.4 \%$ carbon dioxide $16.6 \%$ oxygen, $73.0 \%$ nitrogen), each at various feed flow rates. The results (residue and permeate compositions and feed fraction permeated are summarized in Table 31. Because of experimental error in the residue and permeate compositions obtained during the experimunts, the material balance around the module does not close a full $100 \%$. The largest deviation in mass balance is $5 \%$. Since the computer model rigc ously conserves mass, the model can never exactly agree with these experimental results.

The model predictions were obtained by specifying that the predicted feed fraction permeated is equal to the reported value, and the pressure ratio used by the model is the experimentilly reported value. The model then predicts the residue and permeate composicions and the required membrane area. Predictions were obtained by varying the pressure-normalized fluxes to cause the predictions to fall within $2.5 \%$ of the experimental values. For each of the two cases, the experiment which had the lowest mass balance error was used for calculating the pressure-normalized flux values (experiment I.2 for Case I and II.1 for Case II). The calculated pressure-normalized flux are listed in Table 32 and are identical within a margin of $10 \%$. The calculated pressure-normalized flux values were then used to predict the experimental results obtained at the other feed flow rates. Agreement between experimental and calculated residue and permeate composition is within $5 \%$. The largest difference between the experimental and calculated membrane area was $8 \%$. In our opinion, these discrepancies are the result of experimer.sal error, not deficiencies in the mathematical model. 
Table 31. Experimental Results for Separation of a Gas Mixture With a Spiral-Wound Membrane Module

\begin{tabular}{|c|c|c|c|c|c|c|c|c|c|}
\hline \multirow[b]{2}{*}{ Case } & \multirow{2}{*}{$\begin{array}{l}\text { Experiment } \\
\text { Number }\end{array}$} & \multirow{2}{*}{$\begin{array}{l}\text { Feed Flow } \\
(\mathrm{L}(\mathrm{STP}) / \mathrm{min})\end{array}$} & \multirow{2}{*}{$\begin{array}{l}\text { Feed Fraction } \\
\text { Permeated }\end{array}$} & \multicolumn{3}{|c|}{$\begin{array}{c}\text { Residus } \\
\text { Composition (\%) }\end{array}$} & \multicolumn{3}{|c|}{$\begin{array}{c}\text { Permeate } \\
\text { Composition (\%) }\end{array}$} \\
\hline & & & & $\mathrm{CO}_{2}$ & $\mathrm{O}_{2}$ & $\mathbf{N}_{2}$ & $\mathrm{CO}_{2}$ & $\mathrm{O}_{2}$ & $\mathbf{N}_{2}$ \\
\hline I & I.1 & 11.2 & 0.197 & 0.17 & 16.7 & 83.1 & 0.90 & 29.2 & 69.9 \\
\hline I & 1.2 & 7.2 & 0.304 & 0.11 & 15.0 & 84.9 & 0.74 & 28.5 & 70.8 \\
\hline I & 1.3 & 3.4 & 0.639 & 0.02 & 9.6 & 90.4 & 0.46 & 24.7 & 74.9 \\
\hline II & 11.1 & 13.0 & 0.211 & 6.3 & 15.8 & 77.9 & 24.6 & 20.4 & 55.0 \\
\hline II & II. 2 & 8.3 & 0.333 & 4.2 & 14.9 & 80.9 & 21.9 & 20.5 & 57.6 \\
\hline II & Il. 3 & 5.3 & 0.523 & 1.8 & 13.1 & 85.1 & 17.6 & 20.4 & 62.0 \\
\hline
\end{tabular}

Table 32. Calculated Membrane Properties from Mixed Gas Experiments

\begin{tabular}{llc}
\hline Gas & $\begin{array}{l}\text { Pressure } \\
\text { normalized } \\
\text { flux }\end{array}$ & $\left(\begin{array}{c}\mathrm{cm}^{3}(\mathrm{STP}) \\
\mathrm{cm}^{2} \cdot \mathrm{s} \cdot \mathrm{cmHg}\end{array}\right)$ \\
\hline & Case I & Case II \\
$\mathrm{CO}_{2}$ & $1.06 \times 10^{-3}$ & $1.05 \times 10^{-3}$ \\
$\mathrm{O}_{2}$ & $0.43 \times 10^{-3}$ & $0.40 \times 10^{-3}$ \\
$\mathrm{~N}_{2}$ & $0.21 \times 10^{-3}$ & $0.23 \times 10^{-3}$ \\
\hline
\end{tabular}

That the predictions agree, not only with the experimental results from which the pressure-normalized fluxes were calculated, but also with the results at the other feed flow rates, implies that the model does accurately describe the process of mass transport across a membrane and that the caiculated values are true physical properties, not simply a set of arbitrary values that allow us to match an individual set of experimental results. The calculated pressurenormalized fluxes for the two different feed cases are very similar (the values are all within $8 \%$ of each other); this similarity in the calculated pressure-normalized fluxes indicates that one set of experimental data can be used to predict module performance over a significant range of operating conditions. 
As can be seen from Tables 31 and 32 , there is a discrepancy between the pure gas and fitted values for pressure-normalized flux (the fitted pressurenormalized flux of carbon dioxide is less than $50 \%$ of the pure gas values, and the fitted pressure-aormalized fluxes of oxygen and nitrogen are 80-90\% of their pure gas values). This illustrates the faet thaf pure gas permeation data are not always a sound basis for system design calculations, especially if the membrane is a rubbery polymer or a glassy polymer that can be plasticized by one of the feed gas components.

\section{The Effect of Pressure Ratio on Membrane System Performance}

The pressure ratio across the membrane is normally a process variable whose value is at the discretion of the process designer. Prastical constraints may intervene, however, such as when the feed pressure is fixed by an upstrean process, or when the permeate pressure must be above atmospheric to avoid the use of vacuum pumps.

The various constraints and guidelines for estimating the optimum pressure ratio have been presented in prior papers, 22,23 however, it is useful to present them again here. In membrane systems, a larger pressure ratio causes a poorer degree of separation for a given membrane. Thus, there is a value of the pressure ratio beyond which a desired purity cannot be obtained. This constraint is illustrated in Figure 28, where the maximum permeate mole fraction decreases toward the feed composition as the pressure ratio is increased toward 1.0. In this figure, the calculations are made for a feed rate so large that the feed-side concentration does not change and the fraction of feed permeated approaches zero. This configuration results in the maximum permeate mole fraction (for component 1) from this system.

Figure 28 also illustrates the fact that as the pressure ratio is reduced, a point is reached at which any further reduction has no significant effect on membrane performance. In addition, the point below which further reductions in pressure ratio have no effect is different for membranes of different selectivity; as the selectivity increases, this point takes on a smaller value. Thus, below a certain pressure ratio, the selectivity limits the degree of separation; at higher pressure ratios, the pressure ratio limits the degree of separation.

The feed composition is also controllinig factor in membrane performance, and like selectivity, can affect the point at which further reductions in the pressure ratio have no effect on membrane performance. This effect is illustrated in Figure 29, similar to Figure 28 except that instead of showing curves of different selectivities, it shows curves of different feed compositions. As the feed becomes more pure, the point below which pressure ratio has no effect gets closer to 1.0. Thus, for feeds of high purity nothing can be gained by using a small pressure ratio. Figures 28 and 29 show that, as a general rule, little can be gained by using a pressure ratio with a value more than one magnitude smaller than either (1) the feed mole fraction of the most permeable component or (2) the inverse of the selectivity. 


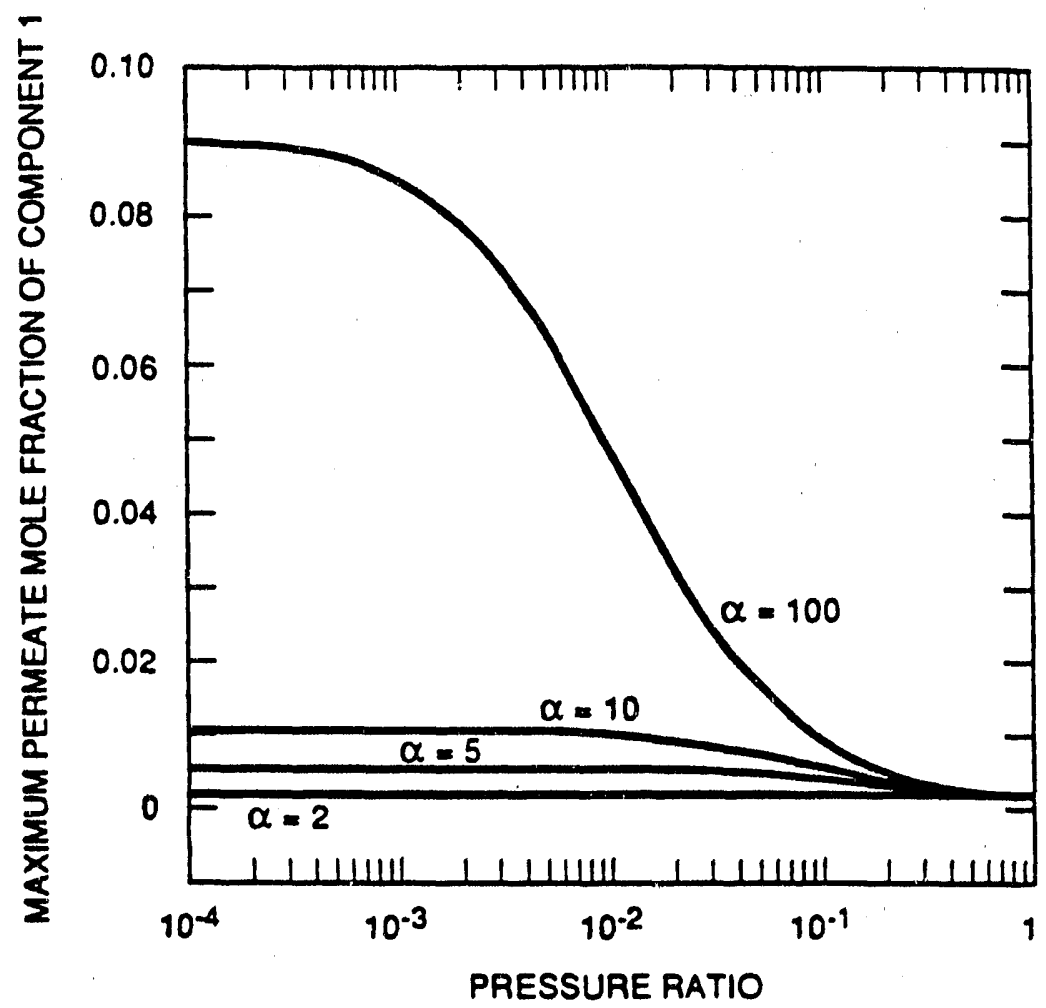

Figure 28. Effect of pressure ratio on the maximum permeate mole fraction with various selectivities. The calculations are made for a feed rate so large that the feed-side concentration does not change and the fraction of feed permeated approaches zero. 


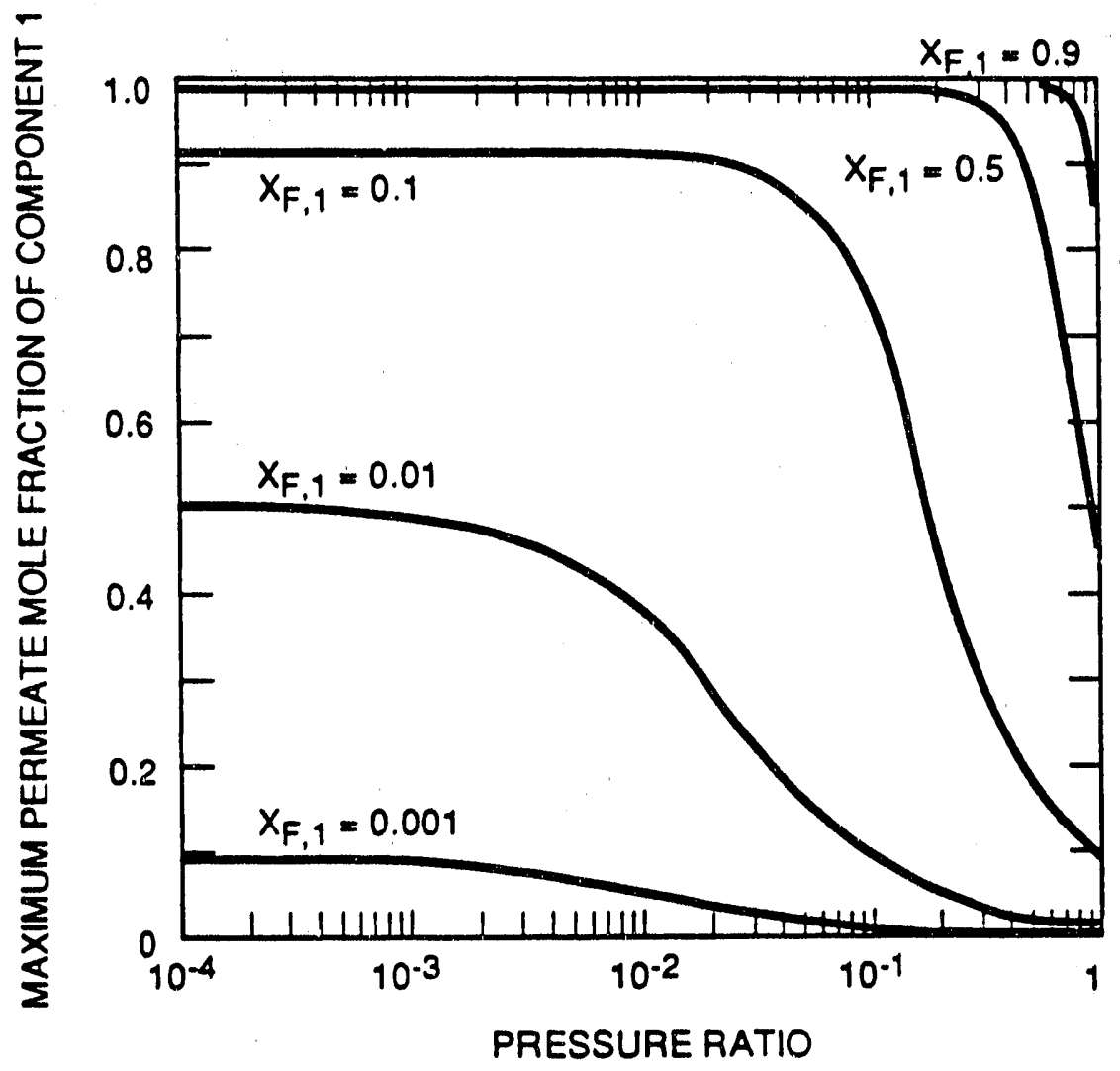

Figure 29. Effect of pressure ratio on the maximum permeate mole fraction with various feed purities. Selectivity is assumed to be 100 and the feed fraction permeated is zero. 
The membrane area required to perform a given separation is less when a smaller pressure ratio is used (up to a point, as discussed above), but the compression expenses are greater. By assigning a cost to membrane area and to compression requirements (capital and operating), an optimum pressure ratio can be determined resulting in the lowest total cost for a given separation.

\section{Ty. Ef ect of System Configuration on Membrane System Performance}

Orice the model for an individual membrane module is completed, it can be used as a building block to describe the performance of an arrangement of modules. A large number of possible arrangements could be used, including recycle streams, multiple stages, and variations in compressor positions. At this point it is useful to make a distinction between the tet mis "module" and "stage". A single membrane module has only one inlet stream (feed) and two outlet streams leaving the module (permeate and residue). A multimodule system may contain any number of modules and more than two outlet streams (multiple permeate, residue, and recycle streams). The number of stages is defined as the number of membranes separating the feed and overall permeate streams. A stage may contain any number of membrane modules. This study will include three basic configurations: (1) single-stage, (2) series, and (3) cascade.

\section{Single-Stage Configurations}

The basic single-stage configuration (SS) is shown in Figure 30a. This basic gas separation configuration is described by the crossflow model previously developed. When the permeate purity requirement is fixed, reducing the pressure ratio increases the fraction of the most permeable component, which is recovered in the permeate stream. Reducing the pressure ratio also increases the permeate purity that can be obtained with the membrane.

If part of the permeate stream is recycled back to the feed, the membrane feed will be more concentrated, and a more concentrated permeate can be obtained than is possible without recycle. The single-stage with recycle configuration (SSR) is shown in Figure 30b. A drawback of the recycle configuration, however, is that the total flow through the modules is increased by the recycle stream, which results in an increase in both the membrane area and compressor size. Both of these configurations, and the remaining configurations to be discussed, assume that the feed is available at pressure and that the product streams must also be at the feed pressure. 


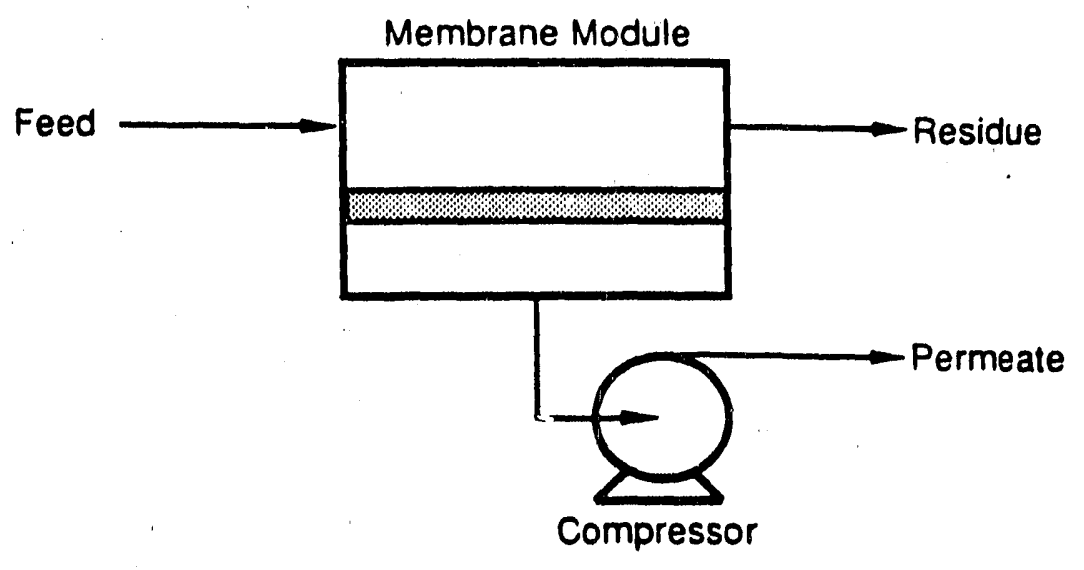

(a) Single-stage (SS)

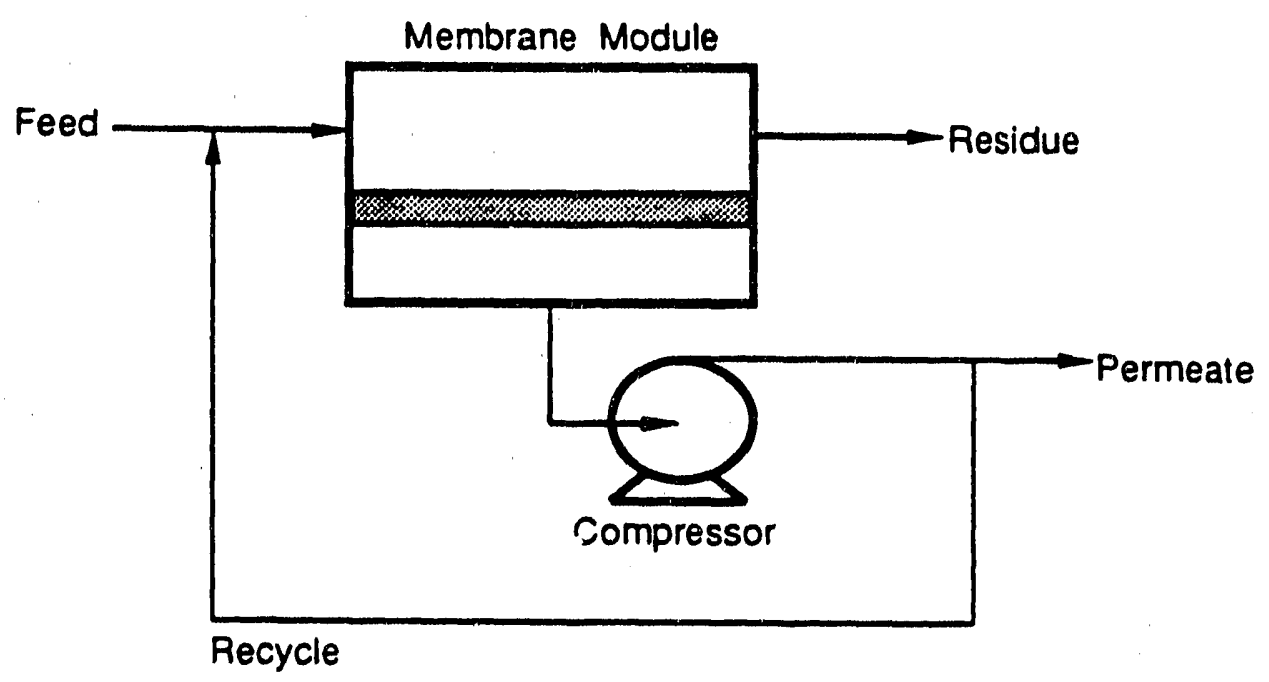

(b) Single-stage with recycle (SSR)

Figure 30. Single-stage module configurations for gas separation. 


\section{Series Configuration}

To increase the degree of separation obtainable by the membrane system, we can add additional modules, using either the first-stage residue or permeate as the feed for the additional modules. When the residue from the first module is used as the feed to the second module, we use the term series configuration (SER) (Figure 31). In a membrane module, the most concentrated permeate is produced by the initial part of the membrane, where the feed-side concentration is highest. Thus, in this configuration, the permeate from the first module is the most concentrated and is the product stream. Because the residue from the first module may still contain a significant fraction of the component to be recovered, a second module is used to recover the remaining product, although at purities too low for use as product. This stream is therefore recycled back to the first module. To increase the fractional recovery of a component using this configuration, the recycle stream flow rate is increased. Reducing the permeate stream flow rate or increasing the recycle stream flow rate will improve the degree of separation, but will also increase the per unit product cost.

\section{Cascade Configuration}

In the cascade configuration (CAS), shown in Figure 32, the first module permeate is used as the feed to the second module. The concentrated stream from the first module is reconcentrated in the second module, and a more concentrated product can be obtained than with any of the previously described configurations. Because the feed and permeate are separated by two membranes, each module is a stage and the configuration is a two-stage configuration.

In a cascade configuration, there are several possible locations for the compressors, depending on various factors: the pressure at which the feed is available; whether or not the second stage residue is to be recycled; and the pressures at which the permeate and residue streams must be delivered. For this analysis, we use an interstage compression arrangement in which the permeate is delivered at the feed pressure.

Use of the CAS configurations results in very different membrane system performance than use of the SER configuration. In the series configuration, the feed and permeate streams are separated by only one stage, whereas two stages separate them in the cascade configuration. Thus, the cascade configuration provides a greater degree of separation but at the cost of a greater compression requirement.

\section{E. Example of Membrane System Analysis}

To demonstrate the performance characteristics of different configurations, calculations were done for the configurations discussed in the previous section. As mentioned earlier, the pressure ratio is a variable whose value is specified by the process designer. Within the constraints on the "alue of the pressure ratio, the designer must determine the optimum pressure ratio that results in the lowest overall cost to perform the desired separation. 


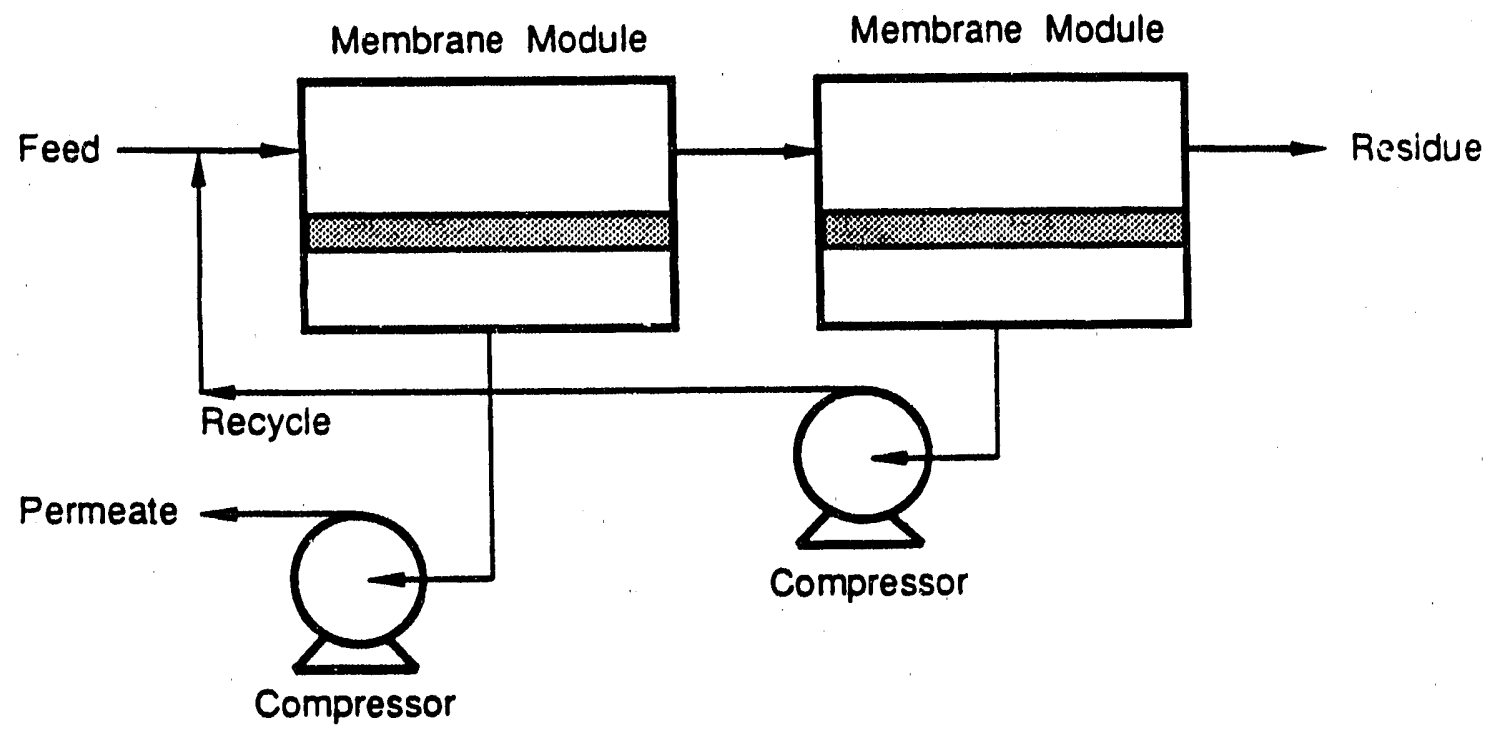

Figure 31. Series configuration (SER) for gas separation. 


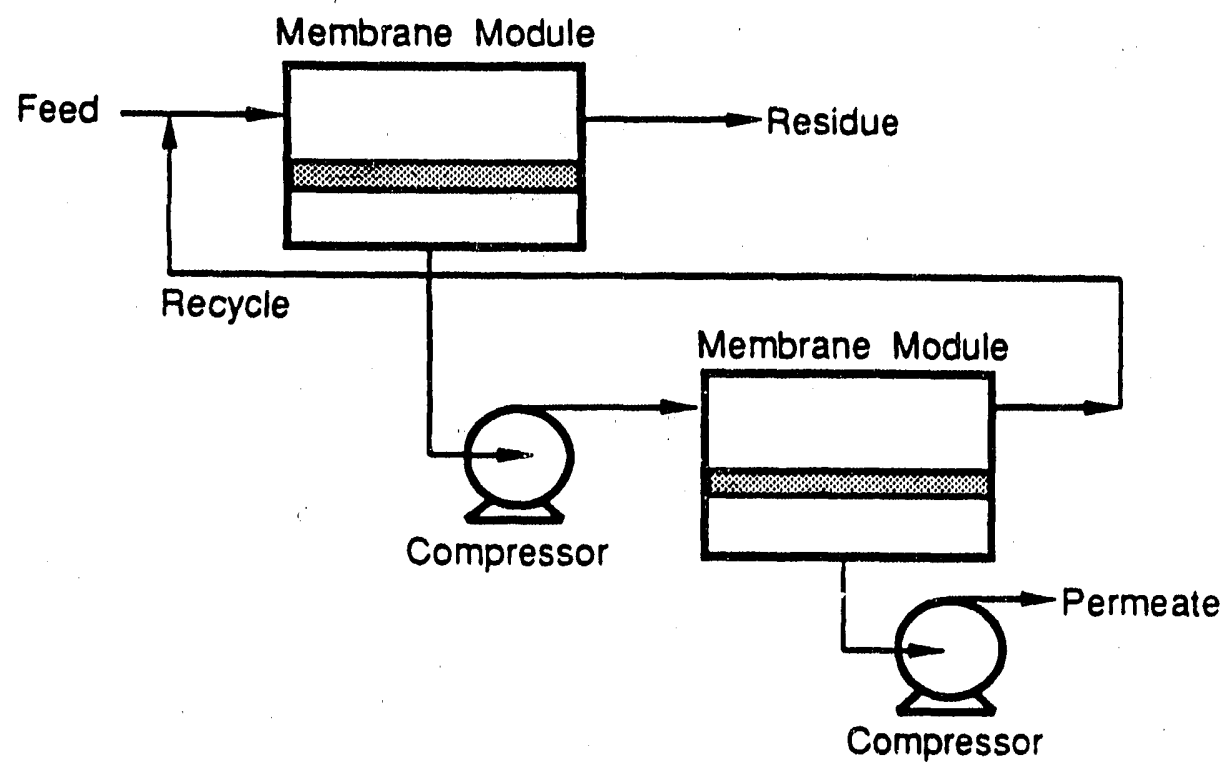

Figure 32. A two-stage cascade configurations (CAS) for gas separations. 
For cach process considered in this section, the optimum pressure ratio was determined and the processing cost at this pressure ratio was calculated. The processing cost is the value that must be recovered per unit of product to pay for capital and operating expenses of the separation system and give a $15 \%$ return on capital investment. The separation systems evaluated in this section consist of membrane modules and compressors. Membrane costs were assigned an installed cost of $\$ 24 / \mathrm{ft}^{2}$ and a replacement cost of $\$ 10 / \mathrm{ft}^{2}$. A membrane lifetime of 5 years was used. Compressor expenses were obtained through the standard equation used by SRI's Process Economic Program.

\section{Example Application}

The application for which the configuration comparisons are given is the separation of a mixture of two components, hydrogen and nitrogen, where nitrogen is the product to be concentrated in the permeate stream. The feed conditions and membrane properties are given in Table 22 . The feed conditions and membrane properties are given in Table 33. The feed conditions are similar to those obtained in an air-blown coal gasification process, after carbon monoxide to hydrogen shift and acid gas removal. (The conditions in the real process would be slightly different due to the presence of impurities such as hydrogen sulfide, carbon monoxide and carbon dioxide.) The membrane properties are those of the polyetherimide, PEI, membrane developed by MTR for this project. We assume that the use of vacuum pumps is to be avoided; thus, the permeate pressure can never be less than atmospheric. Since the feed pressure is 300 psia, the minimum allowed valued for the pressure ratio is 0.05 .

\section{Table 33. Feed Conditions and Membrane Properties for Example Aoplication}

Feed conditions:

mole fraction of $\mathrm{H}_{2}\left(\mathrm{X}_{\mathrm{FH}}\right)$ :

mole fraction of $\mathrm{N}_{2}\left(\mathrm{X}_{\mathrm{rN}}\right)$ :

temperature $\left({ }^{\circ} \mathrm{C}\right)$ :

150

pressure (psia):

300

flow rate (scfm)

10,000

Pressure normalized flux of polyetherimide membrane:

$\mathrm{H}_{2}$

$\mathrm{N}_{2}$
$6.7 \times 10^{-4} \mathrm{~cm}^{3}(\mathrm{STP}) / \mathrm{cm}^{2} \cdot \mathrm{s} \cdot \mathrm{cmHg}$

$9.9 \times 10^{-6} \mathrm{~cm}^{3}(\mathrm{STP}) / \mathrm{cm}^{2} \cdot \mathrm{s} \cdot \mathrm{cmHg}$

To compare the different configurations, we established two criteria for the product stream: in all cases, $95 \%$ of the hydrogen contained in the feedstream must be recovered in the permeate stream; and the product purity must be the same for all processes to be compared. Since we did not expect the same configuration to be best for all product purities, the performance calculations were made over a range of product purities fr $3 \mathrm{~m} 80 \% \mathrm{H}_{2}$ to $29.8 \% \mathrm{H}_{2}$. 
Four configurations were examined: single-stage (SS, Figure 30a); singlestage with recycle (SSR, Figure 30b); series (SER, Figure 31); and cascade with interstage compression (CAS, Figure 32). For simplicity, the abbreviations SS, SSR, SER and CAS will be used in the discussions that follow.

\section{Performance Calculation Results}

The processing costs for configurations SM, SMR, SER and CAS are shown in Figure 33. With the single module configuration, the maximum obtainable permeate purity at $95 \%$ recovery of the hydrogen, is $86.2 \%$ hydrogen. To obtain higher purities, one of the other configurations must be used. For low product purities (less than approximately $86 \%$ hydrogen), the processing costs for configurations SM, SMR, and SER are the same. Examination of the optimized process conditions at these low product purities showed that the recycle rate was zero in SMR, and the second-stage membrane area was reduced to essentially zero for SER; thus, the optimum SMR and SER configurations reduce to SM when the product purity is less than approximately $86 \%$.

The CAS configuration does not reduce to the SM case at low purities because two stages separate the product from the feedstream. In the other configurations, the product and feedstreams are separated by only one stage, and all can be reduced to the SM configuration by setting the flow rates of certain streams to zero.

For purities above those obtainable with SM, SER always has a lower processing cost than does SMR. The processing cost with SER begins to increase sharply near a product purity of $96 \%$, and above this purity CAS has the lowest processing cost of all configurations.

In Figure 33, a shallow minimum occurs in the processing cost curves for both SS (which includes the optimized SSR and SER configurations) and CAS. For product purities lower than approximately $83 \%$ for SS and approximately $97 \%$ for CAS, the processing cost increases with decreasing product purity. This behavior is unexpected. In most separation processes, decrease in product purity corresponds to a decrease in processing cost. This behavior is the result of the different process conditions that apply when producing different purity permeates. To lower the product purity in this example, the pressure ratio (the only variable which is not fixed) must be increased. The increased pressure ratio reduces the driving force for mass transfer across the membrane, and the membrane area must be increased to maintain $95 \%$ recovery of hydrogen. Although the large pressure ratio reduces the compression costs, these savings are more than offset by the increased membrane expenses, and the net result is increased processing cost. The product purity value at which this minimum occurs is determined by the process and economic conditions of each application.

If a membrane system produces a product with a higher purity than necessary and at less cost than it could produce the desired, lower purity product, then it would be sensible to produce the high-purity product and dilute it with untreated feed to the desired purity. This flow scheme is shown in Figure 34 , in which only part of the feed is treated by the membrane system and then is mixed with the remaining untreated feed. This process is called partial feed bypass. The overall product that can be produced with partial feed bypass was calculated by mass balance. 


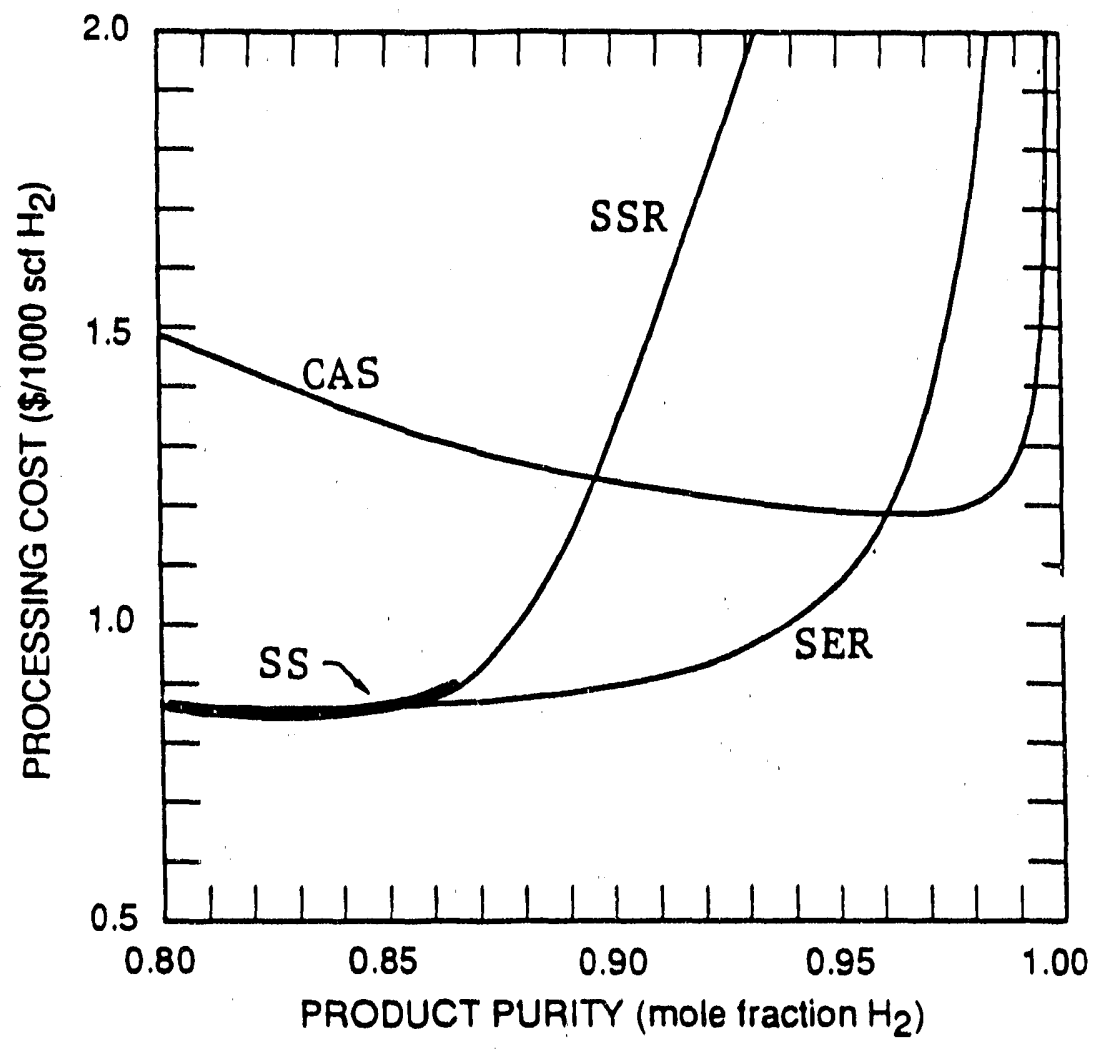

Figure 33. Processing cost as a function of product purity for four membrane system configurations. In all cases $95 \%$ of hydrogen is removed. 


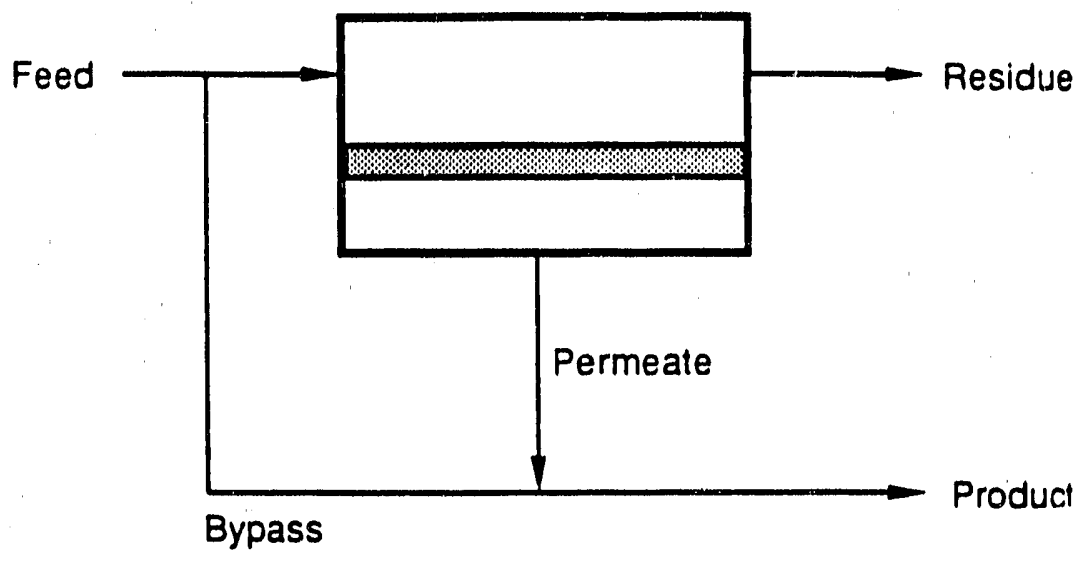

Figure 34. Partial feed bypass scheme. Only a portion of the feed must be processed by the membrane system. 
The concept of partial feed bypass was applied to each of the four configurations included in Figure 33 . Figure 35 shows the reduced processing costs possible when partial feed bypass is used in the single-module and cascade configurations. The dashed lines represent the purity regions where partial feed bypass would be used. The solid lines represent the cases in which all the feed should be treated by the membrane system. In the specific example calculated here and illustrated in Figure 35, the use of partial feed bypass does not change the economic cross-over points for the four system configurations. This is, above $96 \%$ purity, CAS is still the lowest cost configuration, and in the approximate range of $86-96 \%$, SER has the lowest cost. However, as will be demonstrated in the calculations for other separations in Section IX, there are instances when the use of partial feed bypass would influence the choice of configuration.

In this section, we have discussed methods for determining the optimum membrane system configuration for a given application. For this particular separation problem, CAS appears more economical than either SER or the single stage configurations for obtaining higher purity products, and SER is best for lower purity products. Because of its simplicity, SS may replace SER when low product purities are required, even though the predicted costs are slightly lower with SER; single-stage with recycle, however, is never the best configuration.

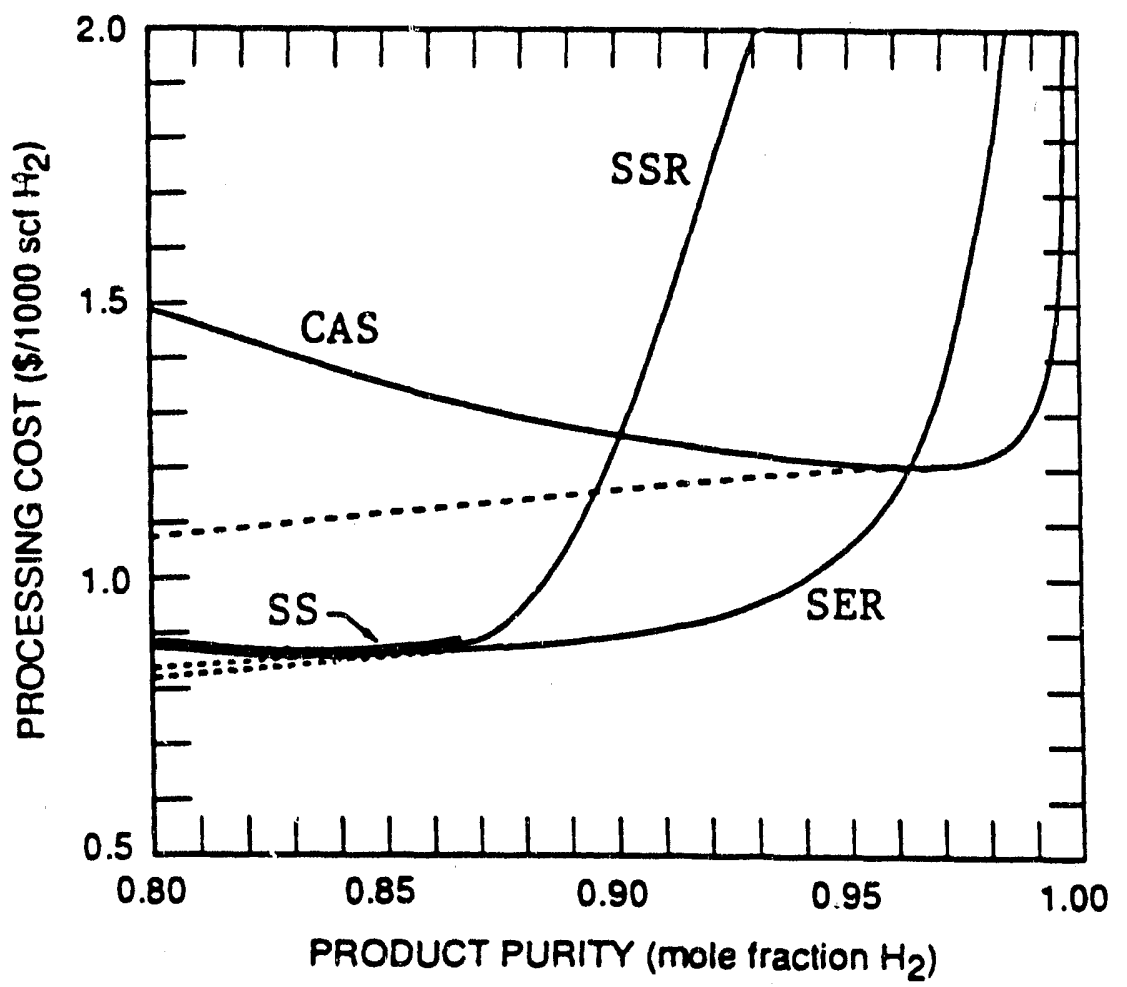

Figure 35. Processing costs for the four different conigurauums with partial feed bypass. The dashed lines represent the costs when partial feed bypass is used. 


\section{ECONOMIC EVALUATION OF MEMBRANE GAS SEPARATION SYSTEMS FOR THE SEPARATION OF HYDROGEN FROM SYNTHESIS GAS}

\section{A. Introduction and Overview}

For membranes to be included as a unit operation in the separation of hydrogen from synthesis gas, they must not only be technically adequate, but must also be economically favorable compared with competing purification technologies. The goal of this section is to determine the membrane system which results in the lowest overall cost for purification of hydrogen. As discussed in Section III, there are three main locations where membranes can be used in the hydrogen purification scheme: (1) final separation of hydrogen/nitrogen mixtures exiting the acid gas removal unit (air-blown only); (2) reduction in AGR cost; and (3) reduction in shift reactor costs. At each of these three locations, there are several different membrane configurations which could be used. The hydrogen cost is an economic result which will be used to determine which configuration and which location results in the lowest hydrogen purification cost.

The approach we used to determine the membrane system resulting in the lowest hydrogen purification cost is given by the following procedure:

1. Determine procedure for computing the hydrogen cost to be used in the economic analysis to compare different purification systems;

2. Choose likely configurations for membrane systems to be used at each of the three locations;

3. Optimize system configuration and operating conditions to give lowest hydrogen cost; and

4. Determine the membrane system with the lowest hydrogen cost, and compare with conventional technology.

The discussion that follows will outline the procedure for determining hydrogen cost, define the Base Case system for a conventional gasifier, and evaluate and optimize the chosen configurations for each of the three possible membrane locations. Although the majority of the evaluations are aimed at production of high-purity hydrogen $(>98 \%)$, there may be applications where a lower hydrogen purity is acceptable. Membrane systems for production of lowpurity hydrogen are also described.

A list of purification systems evaluated is given in Table 34 . The systems are classified by membrane system iocation and by whether the gasifier oxygen source is pure oxygen or air. Of these systems, the lowest hydrogen cost was obtained with an oxygen-blown gasifier using a single-stage polyetherimide membrane to concentrate the hydrogen stream prior to final purification by AGR, thereby reducing the AGR cost (this system is referred to as AGR/OX-SS(PEI) in 
Table 34). For production of $98 \%$ pure hydrogen (with $95 \%$ hydrogen recovery), this configuration has $7 \%$ lower costs than the Base Case system with no membrane. Thus, membranes do present an opportunity to lower the costs for purification of hydrogen in coal gasification processes.

Table 34. Purification Systems Examined for Hydrosen Purification

$\begin{array}{lccc}\begin{array}{l}\text { Membrane } \\ \text { Location }\end{array} & \begin{array}{c}\text { Gasifier } \\ \text { Oxygen Source }\end{array} & \begin{array}{c}\text { Configuration } \\ \text { Description } \\ \text { (membrane material) }\end{array} & \begin{array}{c}\text { Abbreviated } \\ \text { System Name }\end{array}\end{array}$

\begin{tabular}{|c|c|c|c|}
\hline No membrane & Oxygen & Single-stage & Base Case \\
\hline $\begin{array}{l}\text { Final } \\
\text { separation }\end{array}$ & Air & $\begin{array}{l}\text { Single-stage } \\
\text { Single-stage } w / \text { recycle } \\
\text { Series } \\
\text { Cascade }\end{array}$ & $\begin{array}{l}\text { FS/ARI-SS } \\
\text { FS/AIR-SSR } \\
\text { FS/AIR-SER } \\
\text { FS/AIR-CAS }\end{array}$ \\
\hline \multirow[t]{2}{*}{$\begin{array}{l}\text { AGR cost } \\
\text { reduction }\end{array}$} & Oxygen & $\begin{array}{l}\text { Single-stage (PA) } \\
\text { Single-stage (PEI) } \\
\text { Cascade } \\
\text { Series }\end{array}$ & $\begin{array}{l}\text { AGR/OX-SS(PA) } \\
\text { AGR/OX-SS(PEI) } \\
\text { AGR/OX-CAS } \\
\text { AGR/OX-SER }\end{array}$ \\
\hline & Air & $\begin{array}{l}\text { Membrane/AGR hybrid } \\
\text { Cascade (PEI) } \\
\text { Cascade (PA) }\end{array}$ & $\begin{array}{l}\text { AGR/AIR-HYB } \\
\text { AGR/AIR-CAS(PEI) } \\
\text { AGR/AIR-CAS(PA) }\end{array}$ \\
\hline \multirow[t]{2}{*}{$\begin{array}{l}\text { Shift } \\
\text { cost reduction }\end{array}$} & Oxygen & $\begin{array}{l}\text { Bypass shift reactor } \\
\text { Reject } \mathrm{CO}_{2} \text { before shift }\end{array}$ & $\begin{array}{l}\text { SHIFT/OX-BYP } \\
\text { SHIFT/OX-REJ }\end{array}$ \\
\hline & Air & $\begin{array}{l}\text { Bypass shift reactor (PEI) } \\
\text { Bypass shift reactor (PA) } \\
\text { Bypass shift reactor (PA/PEI) } \\
\text { Bypass shift reactor (PEI/PA) }\end{array}$ & $\begin{array}{l}\text { SHIFT/AIR-BYP(PEI) } \\
\text { SHIFT/AIR-BYP(PA) } \\
\text { SHIFT-BYP(PA/PEI) } \\
\text { SHIFT/AIR-BYP(PA) }\end{array}$ \\
\hline
\end{tabular}

B. Procedure for Economic Evaluations

For the purpose of determining the best purification system, a quantity representing the cost of hydrogen purification is needed upon which comparisons can be based; this quantity is called the hydrogen cost. The procedure for calculating hydrogen cost is illustrated by the flow diagram shown in Figure 36. 


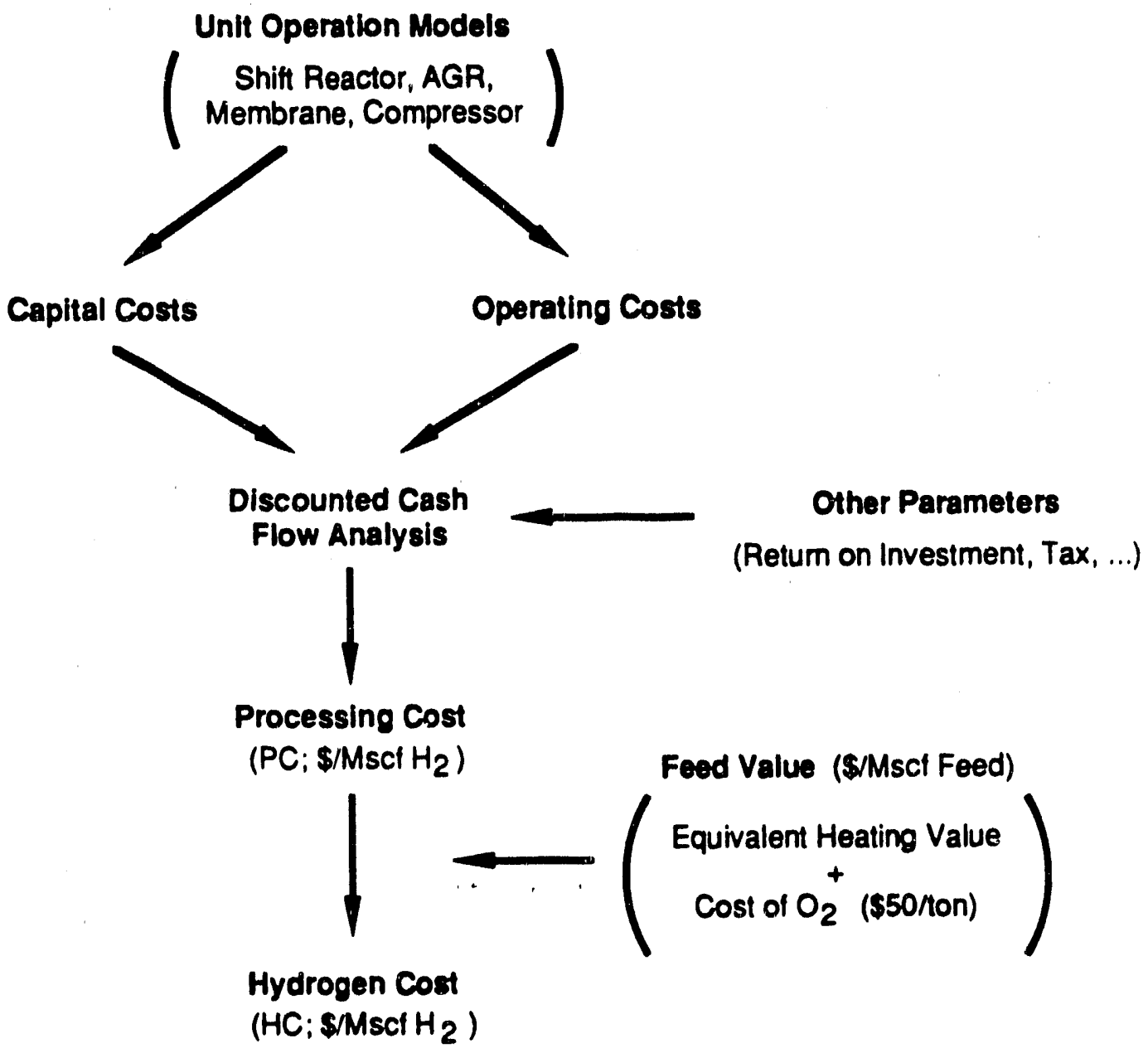

Figure 36. Flow diagram showing procedure for calculating hydrogen cest. 
First, models which estimate the capital and operating costs for a given set of process conditions are developed for each unit operation. The capital and operating costs determined for each unit operation are included in a discounted cash flow analysis along with other parameters such as tax rates and return on capital investment, which result in the hydrogen processing cost in S/Mscf hydrogen. Because different hydrogen purification systems recover slightly different amounts of hydrogen, the value of the feedstream entering the purification system must be included to penalize systems for unrecovered hydrogen. The value of this feedstream (which is produced in the gasifier) is estimated to be the value of a natural gas stream of equivalent heating value. If the gasifier is blown with oxygen rather than air, the cost of oxygen fed to the gasifier is also included in the feed value. The feed value and the processing costs are combined to give the hydrogen cost in $\mathbf{S} /$ Mscf hydrogen. The hydrogen cost parameter is used as the basis for comparing all purification systems. Details of the procedure for calculating are described in the following sections.

\section{Unit Operation Models}

The unit operations for which models have been developed are the shift reactor, the acid gas removal unit, and the membrane system including the and compressor. The models are based on physical and chemical fundamentals, and include empirical cost models. Although unit operation models for the gasifier and air-separation plant are not included, the hydrogen cost, do take the costs of these units into account through the feed value adjustment.

Shift Reactor. In a shift reactor, the carbon monoxide produced during gasification is reacted with water to produce hydrogen and carbon dioxide. The shift reactor exit stream composition was assumed to be that resulting from $98 \%$ of the equilibrium conversion of the carbon monoxide to hydrogen. The reaction rate was assumed to follow pseudo-first-order kinetics. Rate constants and physical properties of Girdler catalyst were used to estimate the reaction rate. ${ }^{24}$ Reaction temperature was assumed to be $300^{\circ} \mathrm{C}$. Knowing the reaction rate, the size of the reactor can be determined. Finally, reactor capital costs (shell, catalyst, support trays, i tallation) and operating costs (repiacement catalyst, operating labor) were estitidated.

Acid Gas Removal Unit. The AGR removes carbon dioxide and hydrogen sulfide using a diethanolamine-based absorber/scrubber system. The acid gas free stream leaving the AGR is assumed to contain 0.01 vol\% carbon dioxide and no hydrogen sulfide. We have also assumed that no hydrogen, nitrogen or carbon monoxide is lost with the acid gases. Capital cosis (columns, pumps, initial absorbent charge, installation) and operating costs (electricity, steam, chemicals, operating labor) were obtained from the Process Economics Program at SRI International.

Membrane Modules. Membrane areas were calculated using the model described in the previous chapters. Capital costs were assumed to be $\$ 24 / \mathrm{ft}^{2}$ (which includes installation) and $\$ 10 / \mathrm{ft}^{2}$ for membrane replacement. A membrane lifetime of five years was used. No operating costs were associated with the membrane modules. 
Compressors. Compressor costs are calculated assuming centrifugal multistage compressors with a compressor efficiency of 0.85 and a motor efficiency of 0.90 . Capital costs include compressor, motor, and installation; operating costs include electricity and operating labor.

\section{Discounted Cash Flow Analysis}

The capital and operating costs are incorporated into a discounted cash flow analysis assuming 20-year plant life. Other parameters used in the discounted cash flow analysis are listed in Table 35. All costs are in January 1987 dollars. The discounted cash flow analysis yields the hydrogen processing cost, in S/Mscf hydrogen.

\section{Table 35. Economic Parameters Used in Discounted Cash Flow Calculations}

Yearly operation

Return on investment

Plant life

Depreciation life

General service facilities

Operating labor

Maintenance labor

Labor overhead

Maintenance material

Federal income tax

Property tax and insurance

General administration expenses

Organization and start-up expenses

Construction time

Land cost

Electricity cost

Steam cost
7884 hours/year (90\% on-stream)

$15 \%$

20 years

15 years (sum of years' digits method)

$15 \%$ of capital costs

$\$ 12 / \mathrm{h}$

$2.5 \%$ of capital costs

$62 \%$ of labor cost

$2 \%$ of capital costs

$50 \%$

$2.5 \%$ of capital costs

$2 \%$ of capital costs

5\% of capital costs

1 year

$\$ 10,000$

S0.05/kWh

$\$ 5 / 1,050 \mathrm{lb}$ 
Because not all purification systems recover the same quantity of hydrogen, the systems recovering less hydrogen must be penalized for the comparison to be meaningful. The true value of the feed is a combination of all the costs required to produce this feed, including gasifier and air separation plant capital and operating costs, and the cost of coal used in the gasifier. Determining these costs requires models of the unit operations which are beyond the scope of this project. Instead, we assigned the purification system feed (produced by the gasifier) a value equal to the value of a quantity of natural gas with equivalent heating value. If the gasifier is oxygen-fed, the value of the oxygen used is also added to the feed cost based on the commercial selling price of oxygen, i.e., $\$ 50 /$ ton. If oxygen-enriched air, is used to feed the gasifier we assumed it is produced by mixing pure oxygen with air to produce the desired concentration of oxygen. The following equations were used to calculate the feed value, $V_{\ell}$ :

$$
\begin{gathered}
\mathrm{V}_{\mathrm{f}}=\mathrm{V}_{\mathrm{H}}+\mathrm{V}_{\mathrm{O}_{2}} \\
\mathrm{~V}_{\mathrm{H}}=\mathrm{V}_{\mathrm{NG}}\left(\mathrm{X}_{\mathrm{H}_{2}} \cdot \Delta \mathrm{H}_{\mathrm{H}_{2}}+\mathrm{X}_{\mathrm{CO}} \cdot \Delta \mathrm{H}_{\mathrm{CO}}\right) \\
\mathrm{V}_{\mathrm{O}_{2}}=\mathrm{F}_{\mathrm{O}_{2}} \cdot \mathrm{C}_{\mathrm{O}_{2}}
\end{gathered}
$$

where:

$\begin{array}{ll}\mathrm{V}_{1} & =\text { total feed value, } \mathrm{S} / \mathrm{Mscf} \\ \mathrm{V}_{\mathrm{H}} & =\text { feed value due to heat content, } \mathbf{S} / \mathrm{Mscf} \\ \mathrm{V}_{\mathrm{O}_{2}} & =\text { feed value due to oxygen, } \mathrm{S} / \mathrm{Mscf} \\ \mathrm{V}_{\mathrm{NG}} & =\text { value of natural gas }=\$ 2 / \mathrm{MMbtu} \\ \mathrm{X}_{\mathrm{H}_{2}} & =\text { mole fraction of } \mathrm{H}_{2} \text { in feed } \\ \mathrm{X}_{\mathrm{CO}} & =\text { mole fraction of } \mathrm{CO} \text { in feed } \\ \Delta \mathrm{H}_{\mathrm{H}_{2}} & =\text { heat of combustion of } \mathrm{H}_{2}=0.339 \mathrm{MMbtu} / \mathrm{Mscf} \\ \Delta \mathrm{H}_{\mathrm{CO}} & =\text { heat of combustion of } \mathrm{CO}=0.290 \mathrm{MMbtu} / \mathrm{Mscf} \\ \mathrm{F}_{\mathrm{O}_{2}} & =\text { quantity of pure } \mathrm{O}_{2} \text { needs for gasification, Mscf } \\ \mathrm{C}_{\mathrm{O}_{2}} & =\text { cost of pure } \mathrm{O}_{2}=\$ 2.23 / \mathrm{Mscf}=\$ 50 / \text { ton }\end{array}$

The feed value and hydrogen processing cost are combined to give the hydrogen cost according to the following equation

$$
H C=P C+V_{f}\left(\frac{M_{l}}{M_{p}}\right)
$$

where

$$
\begin{aligned}
& H C=\text { hydrogen cost } \\
& P C=\text { hydrogen processing cost } \\
& M_{t}=\text { total flowrate in feed, Mscfm feed } \\
& M_{p}=\text { hydrogen flowrate in product stream, Mscfm hydrogen }
\end{aligned}
$$


The hydrogen cost parameter is used to compare different purification systems. For the comparison to be meaningful, the hydrogen product resulting from the various systems must be equivalent, i.e., the product purity and hydrogen recovery must meet minimum criteria. In the evaluations, we have specified that all systems must recover at least $95 \%$ of the hydrogen exiting the shift reactor and that the product purity must be at least $98 \%$ hydrogen.

\section{Base Case Calculations}

The Base Case, with which all other purification systems will be compared, is shown in Figure 37 and represents a purification system based on current, conventional technology. The gas exiting the air-blown gasifier goes through shift conversion which is followed by the acid gas removal unit. However, the resulting gas stream has a hydrogen purity of only $95 \%$, primarily due to unconverted carbon monoxide. To increase the product purity above the minimum 98\% level, a second pair of shift reactor and AGR units are added in series to the first pair. This configuration produces a product purity of $98.5 \%$ hydrogen and, because no hydrogen is lost, has $100 \%$ hydrogen recovery. The hydrogen cost associated with the Base Case system is $\$ 4.72 /$ Mscf hydrogen. The second converter and second $A G R$ represent only $5 \%$ of the total hydrogen cost.

In 1987, pipeline hydrogen was priced at $\$ 2.50$ to $\$ 4.00 /$ Mscf. Hydrogen produced by coal gasification should be more expensive than that produced by steam reforming of natural gas (current, commercial hydrogen production process), and therefore, the calculated hydrogen cost value for Base Case is reasonable with respect to 1987 commercial hydrogen prices.

\section{Final Separation of Hydrogen from Nitrogen}

The objective of a membrane separation system downstream from the acid gas removal unit is to separate hydrogen from nitrogen in an air-blown or oxygenenriched-air-blown gasification process. Oxygen-blown gasifiers are not considered in this section. The gas stream exiting the AGR contains $32.2 \%$ hydrogen, $66.1 \%$ nitrogen and $1.6 \%$ carbon monoxide. Four membrane configurations have been examined for the production of $98 \%$ hydrogen: singlestage, single-stage with recycle, series, and cascade. These configurations have were introduced in Section VIII. The results, listed in Table 36, show that the cascade configuration (FS/AIR-CAS) is the most economical with a hydrogen cost of $\$ 5.26 /$ Mscf hydrogen compared to $\$ 4.62 / \mathrm{Mscf}$ hydrogen for the Base Case. Feeding the gasifier with oxygen-enriched air rather than air reduces the hydrogen cost, but no configuration has hydrogen cost under $\$ 4.62 /$ Mscf hydrogen. It is thus concluded that it is cheaper to produce oxygen from air by standard cryogenic methods than to separate hydrogen from nitrogen by membrane separation. 


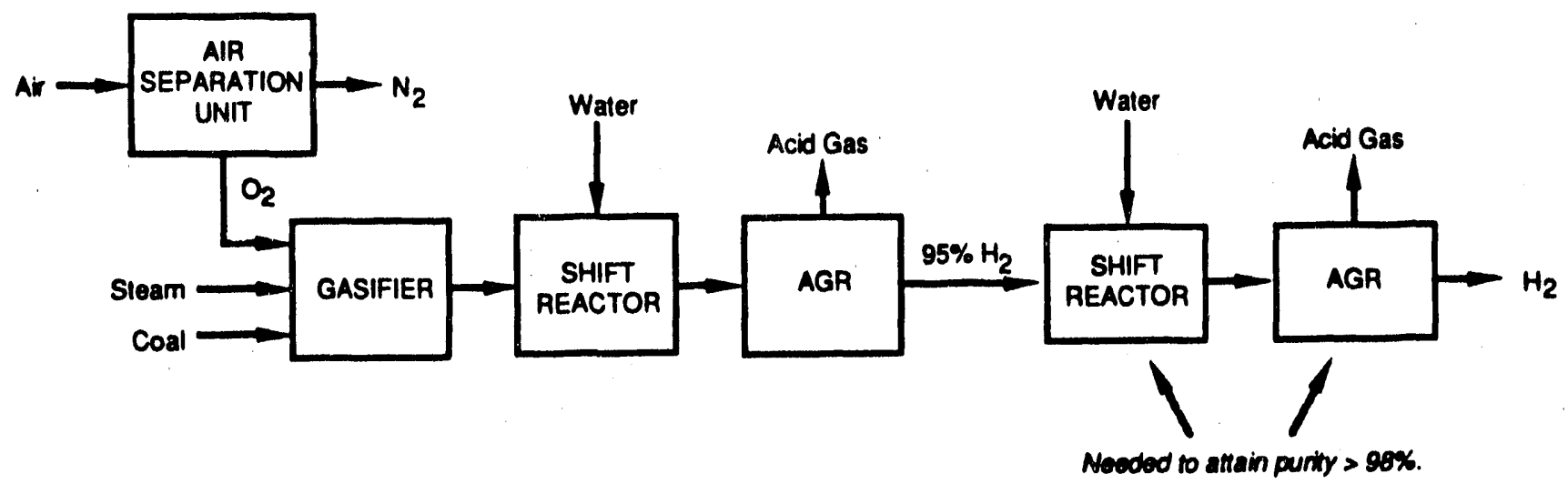

Figure 37. Base Case (non-membrane) purification system (oxygen-blown gasification). 
Table 36. Final Separation - Air-Blown Results

Configuration

Hydrogen Cost (SMscf $\mathbf{H}_{2}$ )

Base Case

Single stage

(FS/AIR-SS)

Single stage with recycle

(FS/AIR-SSR)

Series

(FS/AIR-SER)

Cascade

(FS/AIR-CAS)
4.62

Maximum purity $=86 \%$

12.5

A discussion of the various system configuration for an air-blown gasification process follows. A subsequent section will deal with oxygen-enriched-air-blown gasifiers.

\section{Single-Stage (FS/AIR-SS)}

The single-stage configuration shown in Figure 38a is the more common configuration used in industry tuday. A concentrated hydrogen stream is obtained after a portion of the feed passes through a membrane system; the non-permeate (residue stream) contains most of the feed nitrogen and carbon dioxide. The product hydrogen is recompressed to 300 psi since in all purification system evaluations a hydrogen product pressure of $300 \mathrm{psi}$ is specified. At a feed gas pressure of 300 psi and a permeate pressure of $15 \mathrm{psi}$, the use of vacuum pumps is avoided. The single-stage cannot meet the hydrogen recovery and purity requirements. At $95 \%$ recovery, the maximum hydrogen purity is only $86 \%$.

\section{Single-Stage with Recycle (FS/AIR-SSR)}

This configuration is identical to the single-atsge with the exception that a portion of the hydrogen product is recycled to the feed, as shown in Figure 38b. The advantage of this configuration is that the feed to the membrane has a higher hydrogen content due to the recycled product stream. Therefore, a more pure product can be produced. However, recycling increases the flow rate through the membrane system, which increases both membrane area and compressor requirements. 


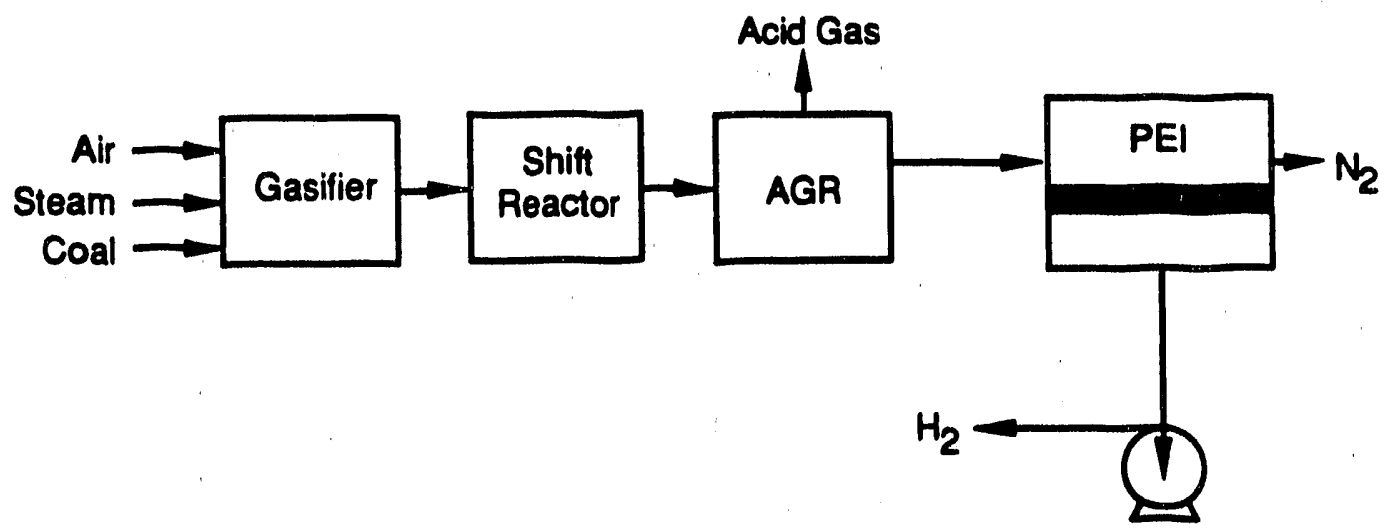

(a) FSIAIR - SS

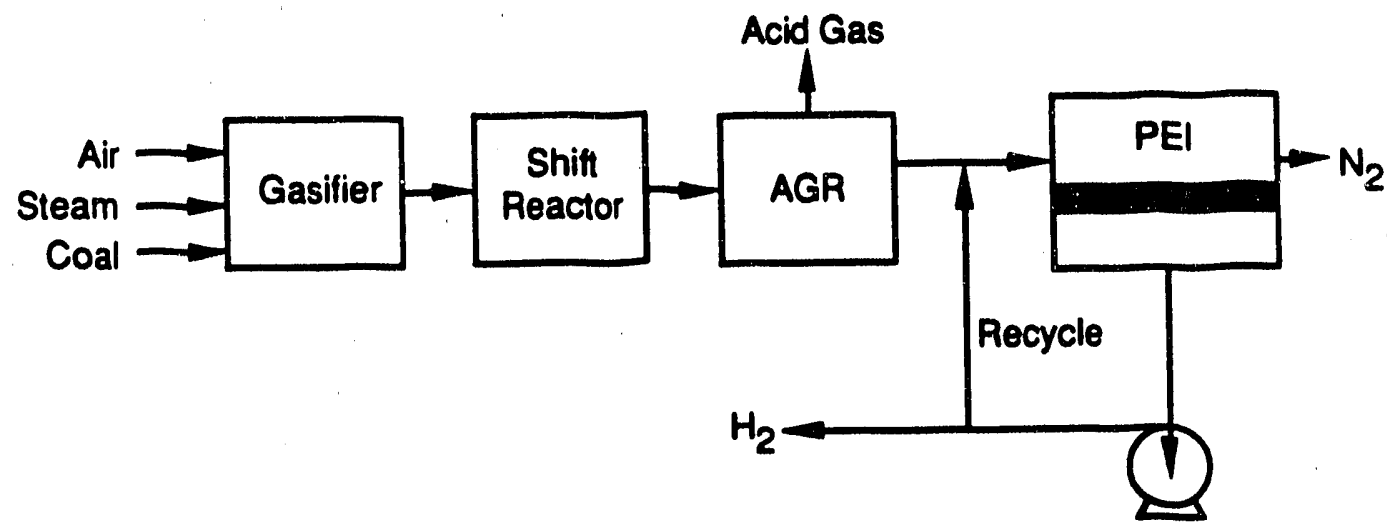

(b) FSIAIR - SSR

Figure 38. Single-stage membrane systems for final separation of hydrogen from nitrogen with an air-blown gasifier. (a) single-stage, (b) single-stage with recycle. The systems are calculated on the basis of the polyetherimide (PEI) membrane data. Membrane feed gas pressure is 300 psi. 
Compared with a simple single-stage system, the single-stage with recycle system has an additional operating parameter that can be freely chosen: the recycle ratio, i.e., the ratio of recycle stream to total permeate stream. By manipulating this ratio, a wide range of hydrogen recoveries and hydrogen purities can be simultaneously achieved. The single-stage with recycle system produces 98\% hydrogen at $95 \%$ recovery if the recycle ratio is 0.92 . This is a very large recycle ratio, one being the maximum, and, as a consequence, the membrane system is very large. The hydrogen costs are therefore very high, \$12.50/Mscf hydrogen.

\section{Series (FS/AIR-SER)}

In a single-stage membrane system, the hydrogen composition in the feed decreases from the feed inlet to the residue outlet. Since a higher hydrogen concentration is obtained from a higher feed concentration, the local permeate purity also continuously decreases as you move from the feed inlet towards the residue outlet. Thus, if the membrane system is cut into two sections, the section closest to the feed inlet will produce the highest permeate purity. As shown in Figure 39a, the series configuration can be thought of as a single-stage membrane system cut into two sections; the permeate stream from the first section is a high purity hydrogen product. The residue leaving the first section still contains a significant amount of hydrogen. The permeate from the second section is too low in purity for use as a product. However, by recycling this permeate back to the feed inlet of the first membrane section, the second section can improve the overall hydrogen recovery of the system.

Because there are two separate membrane sections, there are two pressure ratios (pressure ratio - permeate pressure divided by feed pressure) that can be manipulated to yield the desired hydrogen purity and recovery. The two pressure ratios were varied until the lowest hydrogen cost was obtained. The optimum pressure ratios for the cascade configuration are 0.08 (24 psi permeate pressure) and 0.06 (20 psi permeate pressure) for the first and second stages, respectively. The recycle stream, i.e., the second permeate stream, accounts for $36 \%$ of the total flow enturing ihe first membrane section. The hydrogen cost achieved with

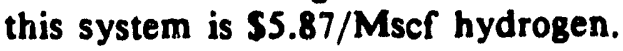

\section{Cascade (FS/AIR-CAS)}

In the cascade configuration shown in Figure $39 \mathrm{~b}$, the permeate stream from the first stage is the feed to the second stage. The second stage permeate is the desired hydrogen product and the residue is recycled to the first-stage feed. The fact that the product hydrogen passes through two membranes (as compared with one in the previous configurations) is significant; high product purities can be obtained but compression and membrane area requirements are greatly increased.

The optimum pressure ratios for the cascade configurations are 0.08 (24 psi permeate pressure) and 0.33 (100 psi permeate pressure) for the first and second membrane stages, respectively. The higher permeate pressure of the second stage reflects the high hydrogen feed concentration for that stage. The cascade configuration results in a hydrogen cost equal to $\$ 5.26 /$ Msci hydrogen. This is the lowest cost so far, but still higher than the Base Case hydrogen cost of \$4.62/Mscf hydrogen. 


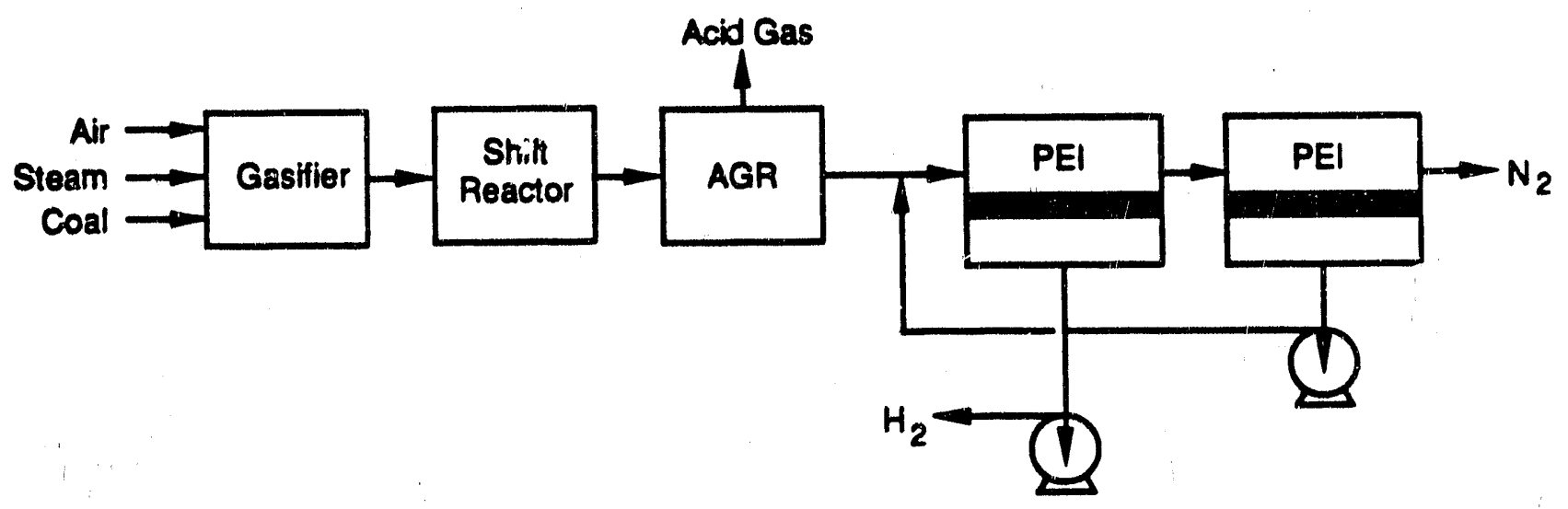

(a) FSIAIR - SER

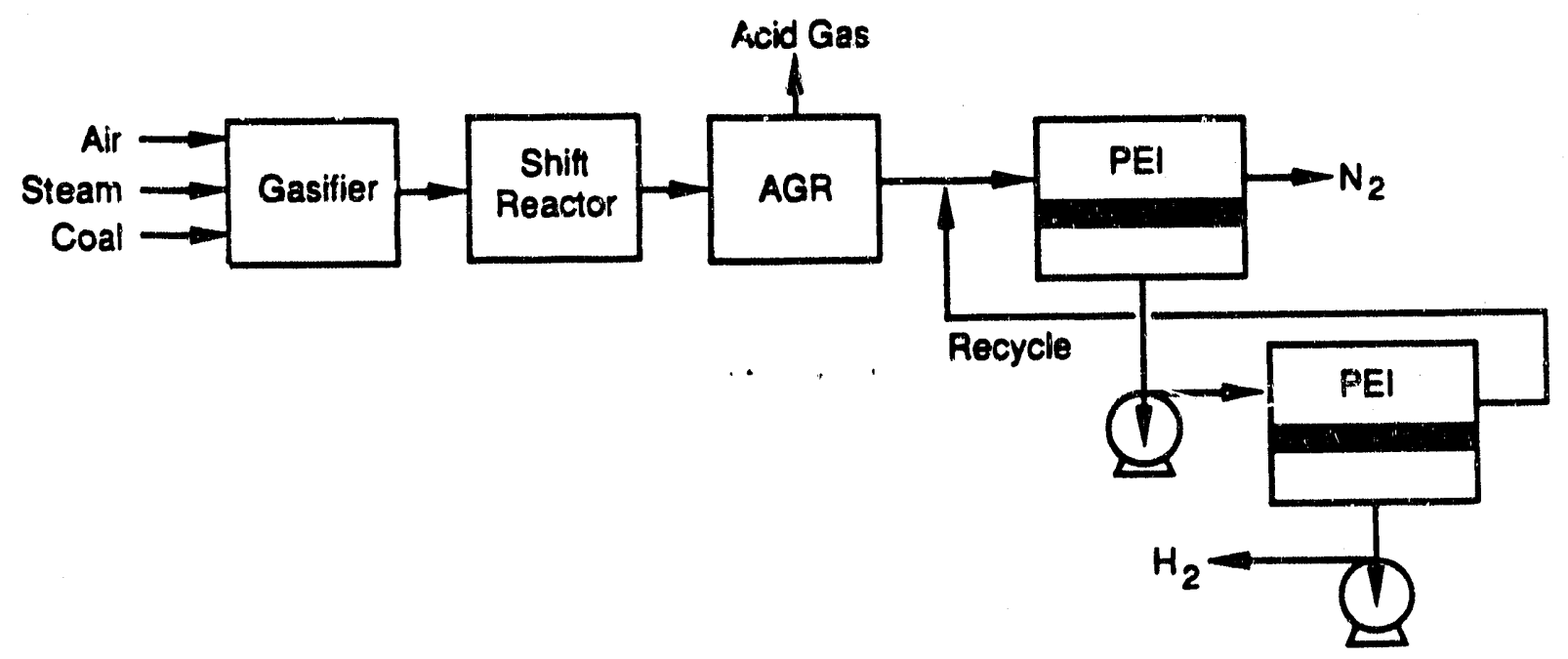

(b) FSIAIR - CAS

Figure 39. Two-stage membrane systems for final separation of hydrogen from nitrogen with an air-blown gasifier: (a) series configuration, (b) cassade configuration. 


\section{Effect of Usine Oxypen-Enriched-Air}

Although the evaluations so far rule out the use of membranes for final hydrogen separation in an air-blown gasifier, it may be that lower hydrogen costs can be obtained by feeding the gasifier with oxygen-enriched air. Using oxygen-enriched air will reduce the amount of nitrogen in the hydrogen product stream exiting the AGR and will thus reduce the size and costs of the membrane system separating the hydrogen and nitrogen. On the other hand, the cost of crygen used to produce the oxygen-enriched air has to be taken into account To evgluate systems using oxygen-enriched air, the composition and flow rate of the gas exiting an oxygen-enriched air-blown gasifier must be known for a given oxygen content. The composition and flow rate were determined by correcting the known exit gas composition and flow rate of an air-blown gasifier for the varying nitrogen content. In an actual gasification process, varying the oxygen concentration will result in slightly different operating conditions, and therefore, slightly different flow rates and comnositions than those calculated by the mass balance approach. However, these differences are negligible.

The calculated hydrogen costs listed in Table 36 show that the cascade configuration is the most economical for producing $98 \%$ hydrogen with an airblown gasification process, followed by the series configuration. These two configurations were also evaluated for oxygen-enriched air-blown gasification processes and the results are shown in Figure 40 . The figure shows that the hydrogen cost does not significantly depend on the oxygen content of the gasifier feed gas if the cascade configuration is used. This means that, as the oxygen content increases, the reduction in membrane system costs is exactly offset by the increase in oxygen cost. For the series configuration, even though the hydrogen cost decreases somewhat with increasing oxygen content in the gasifier feed, the Base Case system (an oxygen-blown gasifier) is still cheaper than any system incorporating a membrane unit for the final separation of hydrogen from nitrogen.

The results shown in Figure 40 are, of course, dependent on the cost of oxygen used in the economic calcuiations. If oxygen becomes more expensive, the option of an air-blown gasification process which includes a membrane system will become more attractive. Our calculations show that at an oxygen cost of $\$ 80 /$ ton and higher the membrane-based option is indeed more economical than the Base Case oxygen-blown gasifier. However, a $60 \%$ increase in the cost of oxygen is very unlikely.

\section{Summary}

Gasification processes which include membrane systems for the final separation of hydrogen from nitrogen were evaluated. Although a variety of membrane configurations were considered for both air- and oxygen-enriched airfed gasifiers, no niche was found where the membrane-based systems resulted in a lower hyd:ogen cost than that obtained for the Base Case system. 


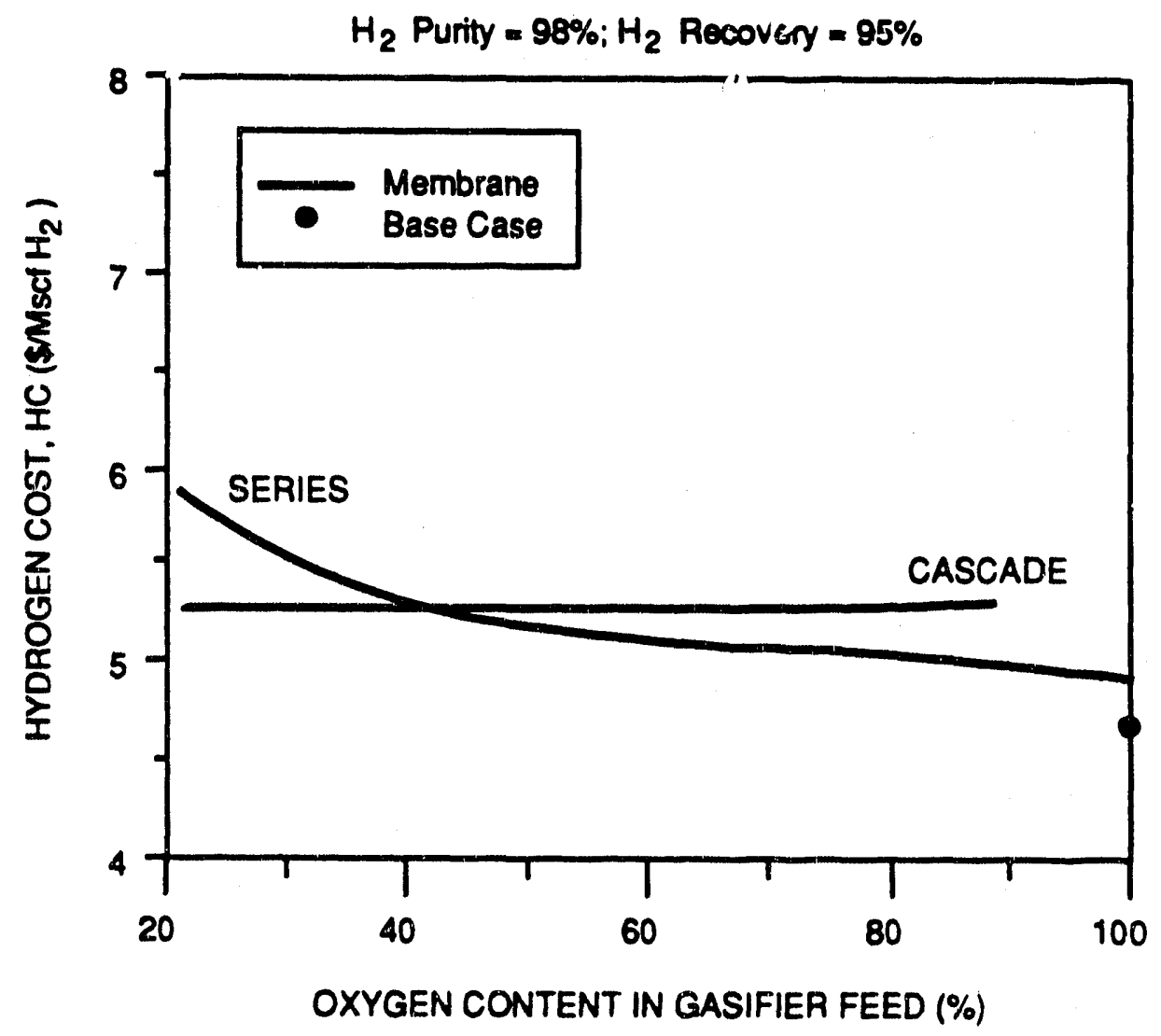

Figure 40. Effect of gasifier feed oxygen content on hydrogen cost for both the series and cascade configurations used in the membrane system separating hydrogen and nitrogen (final separation). 


\section{E. Acid Gas Removal Cost Reduction}

The acid gas removal dnit represents a signiricant portion of the total cost of producing hydrogen by coal gasification. Using membrane gas separation systems to reduce the size of, or completely eliminate, the AGR may result in reduced hydrogen cost as compared to the Base Case. We evaluated a number of different membrane configurations for both oxygen-blown and air-blown gasifiers. These configurations use the polyetherimide membrane or the polyamide copolymer membrane, or combine both membranes.

The results of the economic evaluations for use of a membrane system to reduce the AGR cost are given in Tables 37 and 38 for oxygen-blown and airblown gasification systems, respectively. A discussion of the configurations that were considered follows. For oxygen-blown gasification, the use of a polyetherimide membrane to preconcentrate the hydrogen before final purification in the AGR results in a hydrogen cost of $\$ 4.28 / \mathrm{N}$.scf hydrogen, lower than the Base Case hydrogen cost.

Table 37. AGR Cost Reduction - Oxyeen-Blown Results

Configuration Hydrogen Cost $\left(\right.$ S/Mscf $\left.\mathrm{H}_{2}\right)$

Base Case

Single-stage (PA)

(AGR/OX-SS(PA)

Single-stage (PEI)

(AGR/OX-SS (PA)

Cascade

(AGR/OX-CAS)

Series

(AGR/OX-SER) $4.41^{\circ}$

Cannot meet criteria

- Membrane properties were measured at room temperature; using membrane properties obtained at the higher temperatures of an actual gasifier would result in an hydrogen cost close to that of the Base Case. 
Table 38. AGR Cost Reduction - Air-Blown Results

Configuration

Hydrogen Cost (S/Mscf $\left.\mathbf{H}_{2}\right)$

Base Case

Hybrid

(AGR/AIR-HYB)

Cascade (PEI)

Cannot meet criteria

(AGR/AIR-CAS (PEI)

Cannot meet criteria

Cascade (PA)

(AGR/AIR-CAS (PA)

Cascade

(FS/AIR-CAS)

\section{Oxvgen-Blown Gasification Process}

Four different membrane system configurations for the oxygen-blown process have been examined. Single-stage membrane systems using either the polyetherimide or polyamide copolymer membrane can be used to reduce the size of the AGR. Complete elimination of the AGR unit can be achieved by using eithes a cascade or a series configuration, equipped with a combination of polyetherimide and the polyamide copolymer membranes modules.

\section{Single-Stage (AGR/OX-SS)}

One way of reducing the carbon dioxide and hydrogen sulfide content of the stream entering the AGR is to use polyamide copolymer membrane to remove the acid gases prior to the $A G R$ as shown in Figure 4la. Since the calculations are based on $95 \%$ hydrogen recovery, the amount of carbon dioxide which can he rejected is limited by the amount of hydrogen lost with the rejected carbon dioxide. As with the Base Case, a second shift reactor and AGR unit are needed to meet the product purity specification. The membrane permeate stream in this case is considered waste, and is simply exhausted to the atmosphere.

The hydrogen cost calculated for the AGR/OX-SS(PA) configuration is $\$ 4.41 /$ Mscf hydrogen which is slightly cheaper than the Base Case hydrogea cost. However, as discussed in Section VIII, calculations involving the polyamide copolymer membrane are based on room temperature membrane properties while the actual separation would be carried out at a higher temperature of at least $100^{\circ} \mathrm{C}$. The observed decrease in membrane selectivity with increasing temperature reduces the separation efficiency and increases the hydrogen cost. It is therefore unlikely that the AGR/OX-SS(PA) configuration in practice will of fer an opportunity for savings in the production of hydrogen. 


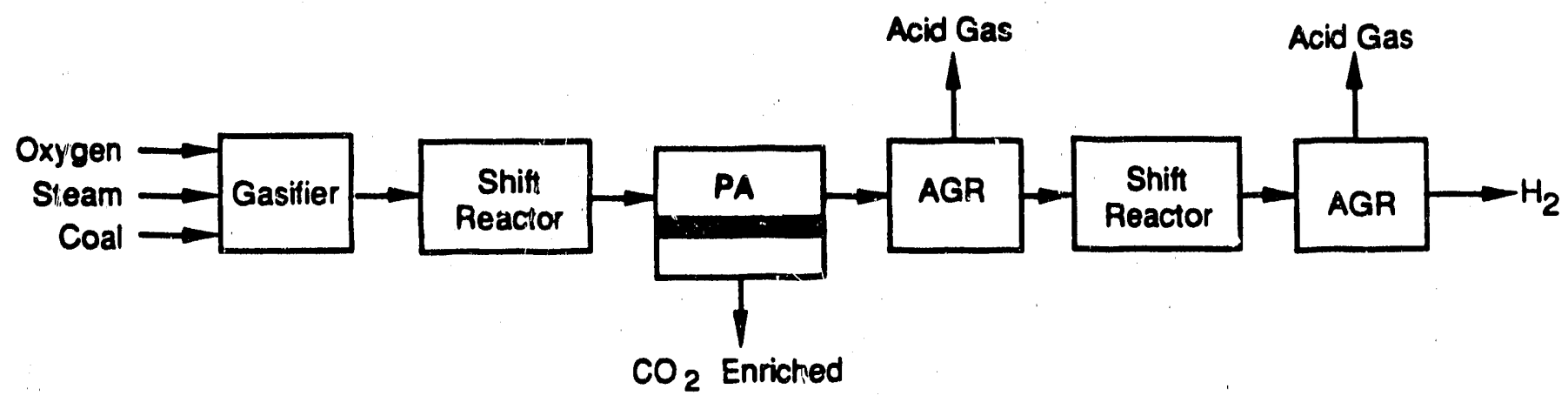

(a) AGR/OX - SS [ PA]

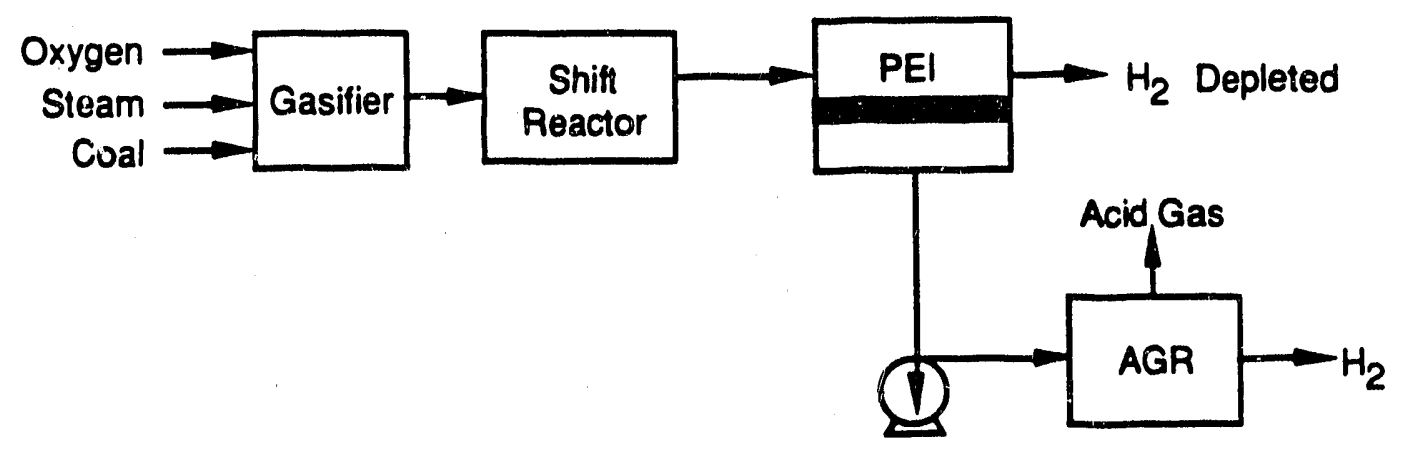

(b) AGR/OX - SS [PEI]

Figure 41. Single-step membrane systems for reduction of AGR costs with an oxygen-blown gasifier. 


\section{Single-Stare Polvetherimide Membrane (AGR/OX-SSIPEII)}

In this configuration shown in Figure $41 \mathrm{~b}$, single-stage polyetherimide membrane is used to preconcentrate the hydrogen before it enters the $A G R$ unit. Because hydrogen preferentially permeates the membrane, the residue stream contains the unwanted species carbon dioxide with small amounts of hydrogen sulfide, carbon monoxide and nitrogen. To meet the hydrogen recovery specifications, $95 \%$ of the hydrogen must permeate the membrane. Some hydrogen sulfide and carbon dioxide also permeate the membrane and must be removed by an AGR unit. Because the small amounts of carbon monoxide and nitrogen present in the system are removed by the membrane, a second shift reactor and AGR unit are not necessary.

The hydrogen cost calculated for the AGR/OX-SS(PEI) configuration is \$4.28/Mscf hydrogen which is lower than the Base Case cost (\$4.26/Mscf hydrogen) and the lowest of all configurations considered in this program. The polyetherimide membrane properties used in the calculation are valid for $150^{\circ} \mathrm{C}$ and thus represent membrane performance in an actual system. We therefore conclude that using a polyetherimide membrane prior to AGR represents a realistic opportunity for cost saving in the production of hydrogen.

Since the AGR/OX-SS(PEI) configuration is promising, it is of interest to determine the sensitivity of the calculated hydrogen cost to membrane performance. Figure 42 gives the hydrogen cost as a function of hydrogen/carbon dioxide selectivity for three different hydrogen permeation rates. It is clear from Figure 42 that improving the membrane permeation rates at constant selectivity does not significantly reduce the hydrogen cost. This shows that the membrane capital and replacement costs are only a minor contributor to the overall hydrogen cost. However, improving the membrane's selectivity would be very beneficial. Doubling the selectivity, even at a modest reduction in membrane permeation rate, will lower the hydrogen cost to under $\$ 4.00 / \mathrm{Mscf}$ hydrogen.

\section{Cascade (AGR/OX-CAS)}

Figure 43a shows a configuration where the AGR is completely replaced by a cascade membrane configuration. In the first stage, a polyetherimide membrane is used to concentrate the hydrogen stream. The first-stage residue contains mostly carbon dioxide with small amounts of carbon monoxide, nitrogen and hydrogen and is exhausted to the atmosphere. The concentrated hydrogen permeate is recompressed and sent to a second-stage membrane unit containing the polyamide copolymer membrane where carbon dioxide and hydrogen sulfide (the minor components) are removed in the pert acate. The second-stage residue stream is the hydrogen product stream and the permeate, which still contains a significant amount of hydrogen is recycled to the first-stage feed. The AGR/OX-CAS configuration is capable of producing $98 \%$ hydrogen at $95 \%$ recovery. However, the hydrogen cost is high (\$5.72/Mscf hydrogen). 


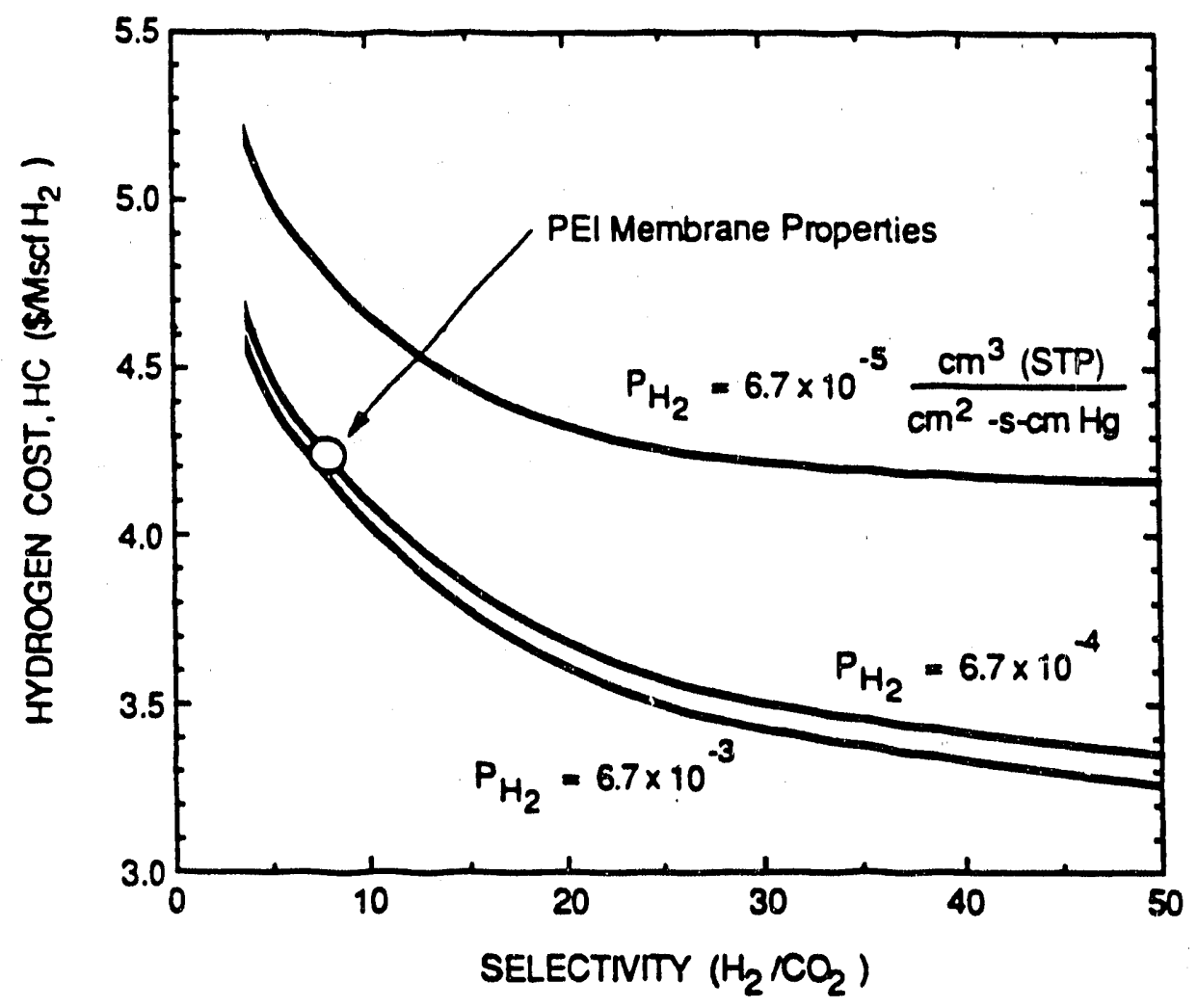

Figure 42. Effect of membrane selectivity and permeability on hydrogen cost for AGR/OX-SS(PEI). 


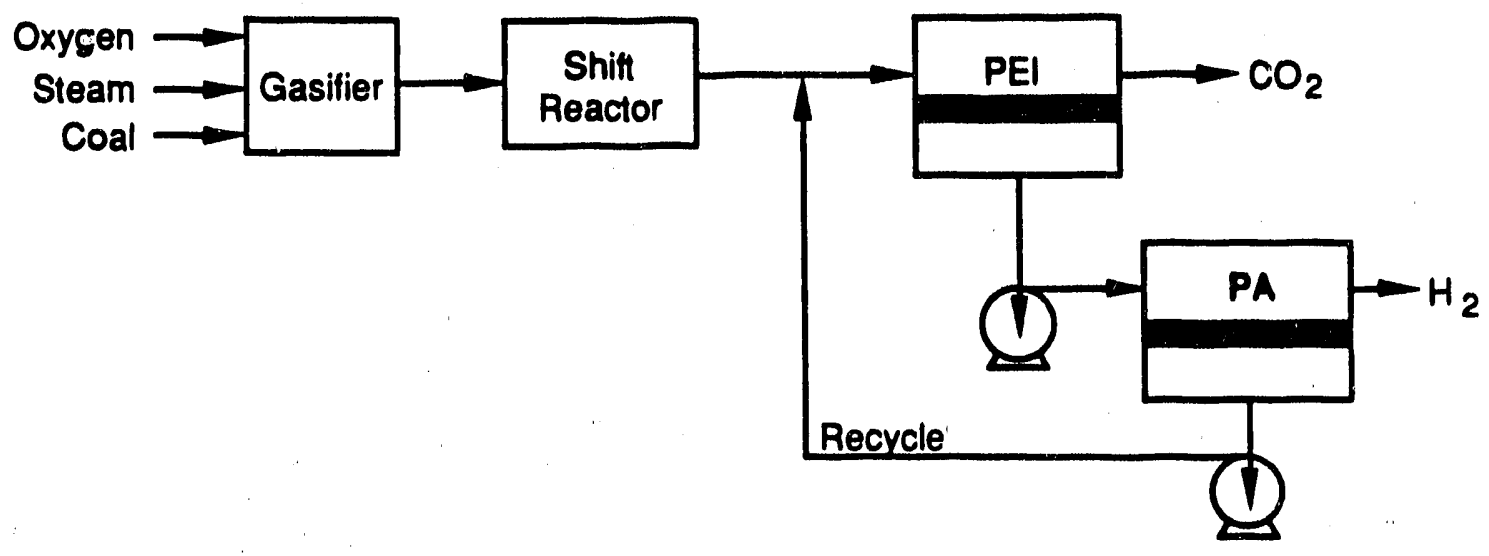

(a) AGR/OX-CAS

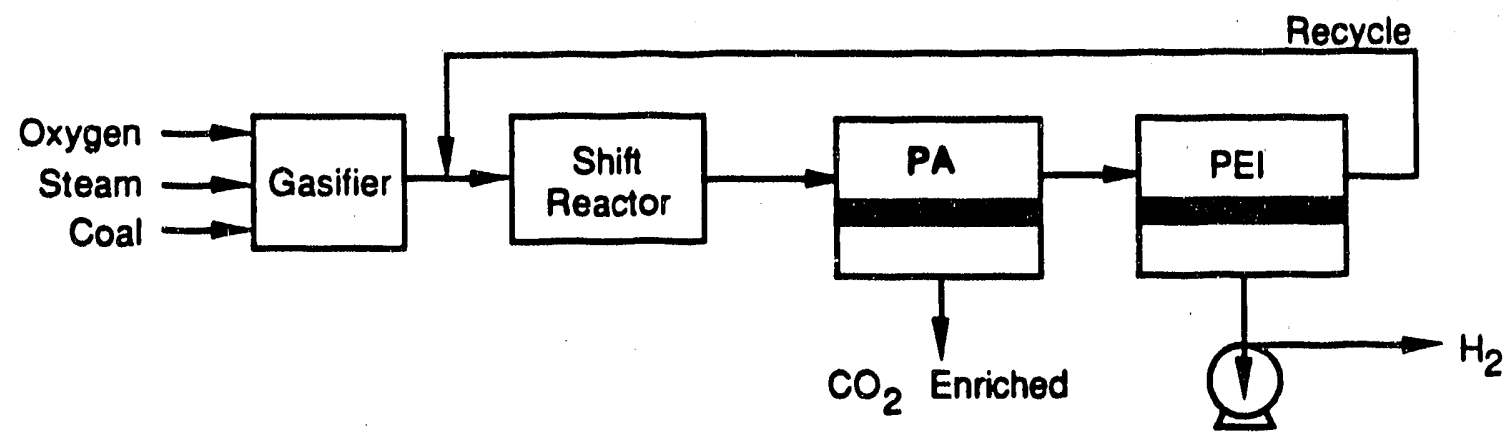

(b) AGR/OX - SER

Figure 43. Membrane systems for reduction of AGR costs with an oxygen-blown gasifier. 


\section{Series (AGR/OX-SER)}

In this configuration, shown in Figure 43b, the stream leaving the shift reactor first enters a polyamide copolymer membrane where carbon dioxide and hydrogen sulfide are removed as the permeate. The hydrogen-enriched residue from the polyamide copolymer membrane passes to a polyetherimide membrane where hydrogen is produced as the permeate stream. The polyetherimide membrane residue, which contains a significant amount of hydrogen, is recycled to improve the hydrogen recovery. The recycle stream also contains carbon monoxide.

The calculations performed show that the AGR/OX-SER configuration is not capable of producing $98 \%$ hydrogen at $95 \%$ recovery. This configuration is thus not a feasible option for hydrogen production by coal gasification.

\section{Air-Blown Gasification Process}

Three different membrane configurations for the air-blown gasification process have been evaluated with the objective of reducing or eliminating the AGR unit. Because the gasifier is fed with air, the membrane systems have to remove nitrogen as well. The three configurations are discussed below.

\section{Hubrid (AGR/AIR-HYB)}

This configuration is shown in Figure 44. A polyamide copolymer membrane is used to remove carbon dioxide and hydrogen sulfide from the shift converter exit gas. The residue of the polyamide copolymer membrane system consists mainly of nitrogen and hydrogen and is fed into a cascade membrane system to separate the hydrogen from the nitrogen by means of polyetherimide membranes. The permeate of the polyamide copolymer membrane system is fed into an AGR unit where the acid gases are removed. The AGR unit exit gas, containing hydrogen and nitrogen, is directed to the polyetherimide system.

The AGR/AIR-HYB configuration results in a hydrogen cost of $\$ 6.23 / \mathrm{Mscf}$ hydrogen which is higher than the Base Case cost of $\$ 4.62 /$ Mscf hydrogen and even higher than the FS/AIR-CAS configuration which is essentially the identical configuration without the polyamide copolymer membrane system.

\section{Cascade Polvetherimide Membrane (AGR/AIR-CAS(PEI))}

This configuration, as shown in Figure 45a, is identical to the FS/AIR-CAS configuration (Figure 39b) with the exception that the AGR unit is completely eliminated and that the polyetherimide membrane system has to separate hydrogen from not only nitrogen, but from carbon dioxide and hydrogen sulfide as well.

The calculations performed show that the AGR/AIR-CAS(PEI) configuration is not capable of meeting the hydrogen purity (98\%) and recovery (95\%) requirements. The reason is that the gas stream entering the membrane system has a low hydrogen concentration because of the presence of the acid gases, and because membrane separation efficiency is much lower for hydrogen from acid gases than for hydrogen from nitrogen. 


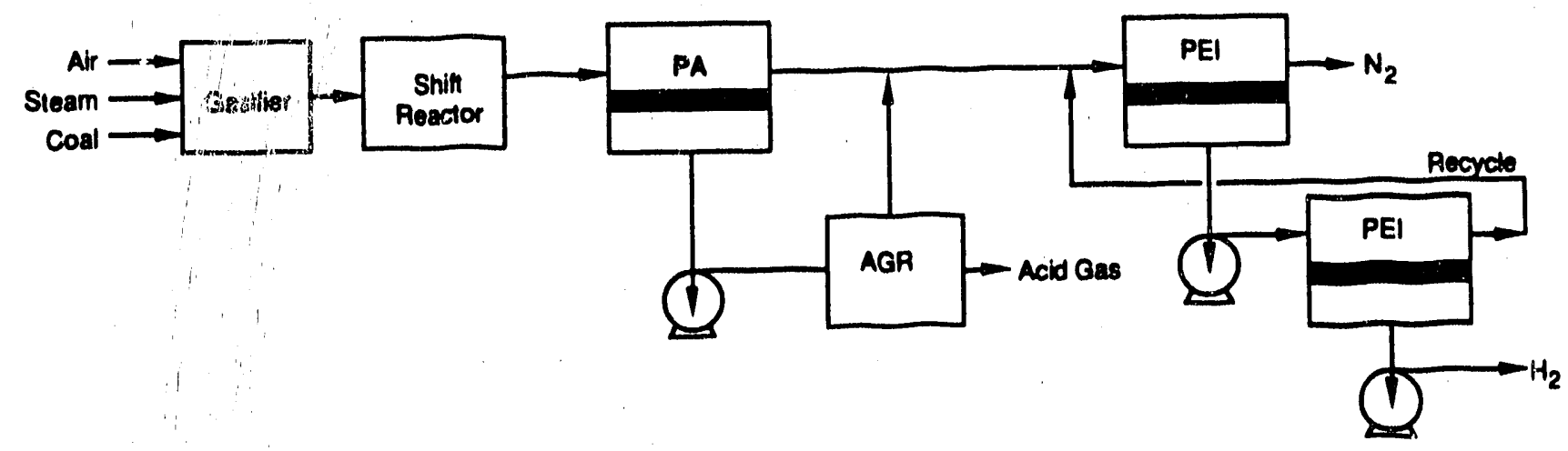

Figure 44. Membrane/AGR hybrid system (AGR/AIR-HYB; for reduction of AGR costs with an air-blown gasifier. 

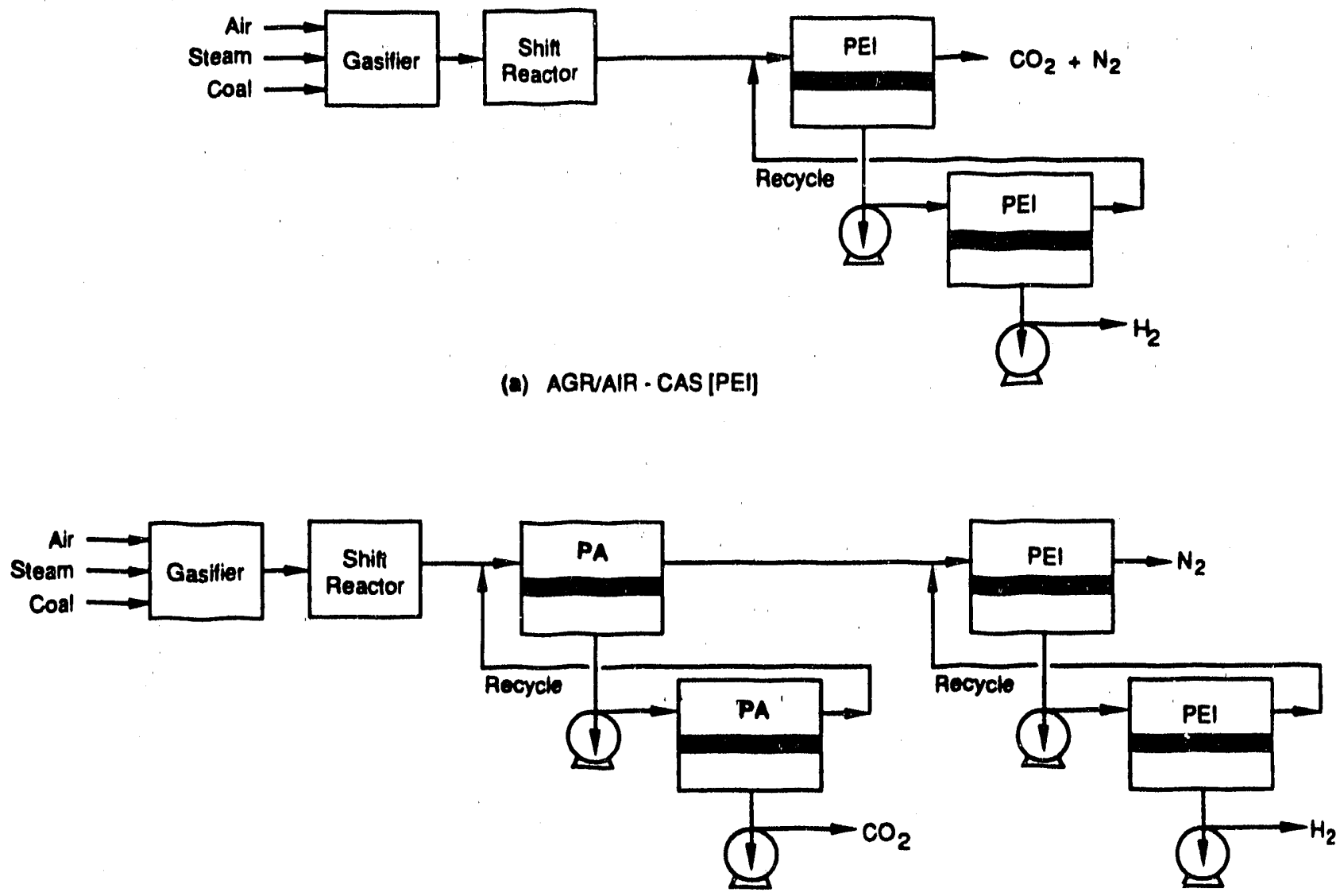

(b) AGR/AIR - CAS|PA]

Figure 45. Membrane cascade systems for reduction of AGR costs with an air-blown gasifier. 


\section{Cascade (AGR/AIR-CAS)}

This configuration, shown in Figure 45b, consists of two cascade membrane systems in series. The first cascade system uses the polyamide copolymer membrane and serves to remove the carbon dioxide and hydrogen sulfide from the shift converter exit gas. The residue stream from the first cascade contains mainly hydrogen and nitrogen and is fed into the second cascade system which separates the hydrogen and nitrogen with polyetherimide membranes.

As is the case with the AGR/AIR-CAS configuration, the AGR/AIR-CAS(PA) configuration is not capable of producing $98 \%$ hydrogen at $95 \%$ recovery. It thus appears to be much more difficult for membranes to compete with a AGR unit in an air-blown gasification process than in a oxygen-blown gasification process.

\section{F. Shift Reactor Cost Reduction}

\section{Oxygen-Blown Gasifier Systems}

Two membrane configurations for shift reactor cost reduction were evaluated for use in oxygen-blown systems. In the first configuration, a portion of the carbon dioxide and hydrogen is bypassed around the shift reactor, while in the second, a portion of the carbon dioxide is removed prior to shift conversion and vented to the atmosphere.

\section{Bypass (SHIFT/OX-BYP)}

In the configuration shown in Figure $46 \mathrm{a}$, a polyetherimide membrane is used to remove hydrogen and carbon dioxide from the shift reactor feed gas. The hydrogen/carbon dioxide permeate stream is recompressed and recycled to the shift reactor exit stream to avoid wasting the hydrogen. The economic evaluation shows that bypassing the shift reactor increnses the hydrogen cost. In other words, the costs associated with the polyetherimide membrane system are larger than the savings obtained by reducing the reactor size. The optimized system, therefore, is characterized by zero membrane area and is identical to the Base Case system.

The shift reactor converts carbon monoxide and water into hydrogen and carbon dioxide by means of an equilibrium reaction. Removing hydrogen and/or carbon dioxide from the reactor feed gas will improve the reaction rate which reduces the size of the shift reactor, and will also result in more hydrogen produced. The objective of a membrane gas separation system prior to the shift reactor is thus to influence the equilibrium reaction in the shift converter.

The results for oxygen air-blown and air-blown gasification systems are given in Tables 39 and 40 , respectively. It appears that no memurane system configuration offers an improvement over the Base Case system.

\section{Carbon_Dioxide Reiection (SHIFT/OX-REJ)}

In this configuration (Figure $46 \mathrm{~b}$ ), a polyamide copolymer membrane is used to remove carbon dioxide prior to the shift reactor. 


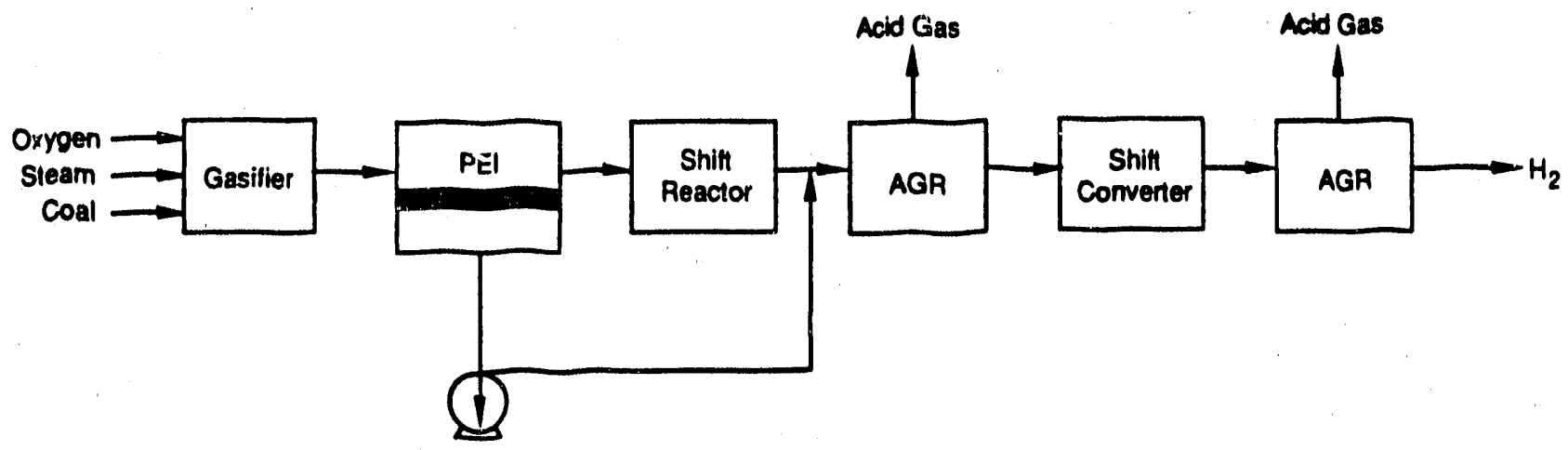

(a) SHIFT/OX - BXP

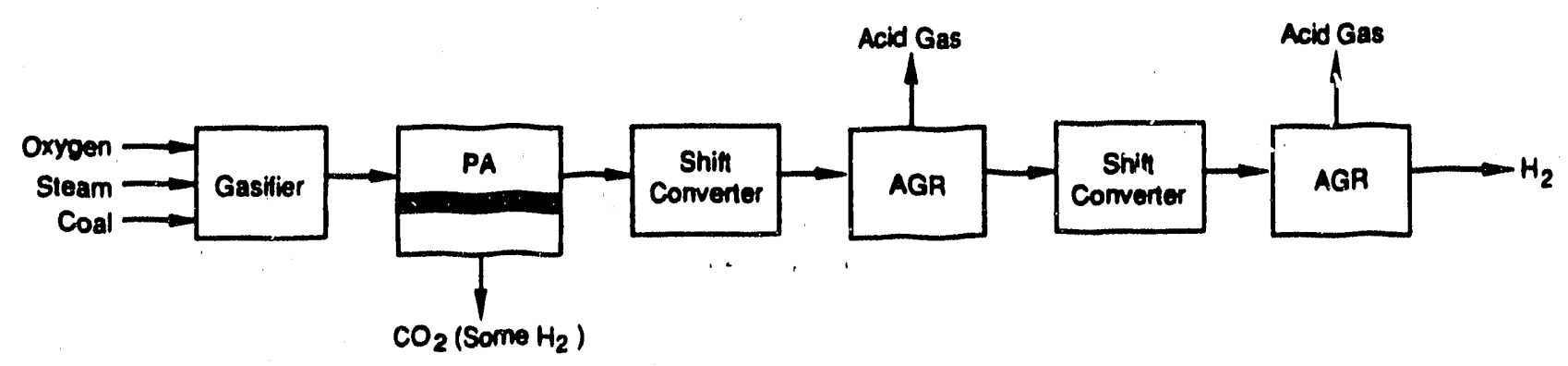

(b) SHIFTOX - REJ

Figure 46. Membrane systems for reduction of shift reactor costs with an oxygen-blown gasifier. 
Table 39. Shift Reactor Cost Reduction - Oxyeen-Blown Results

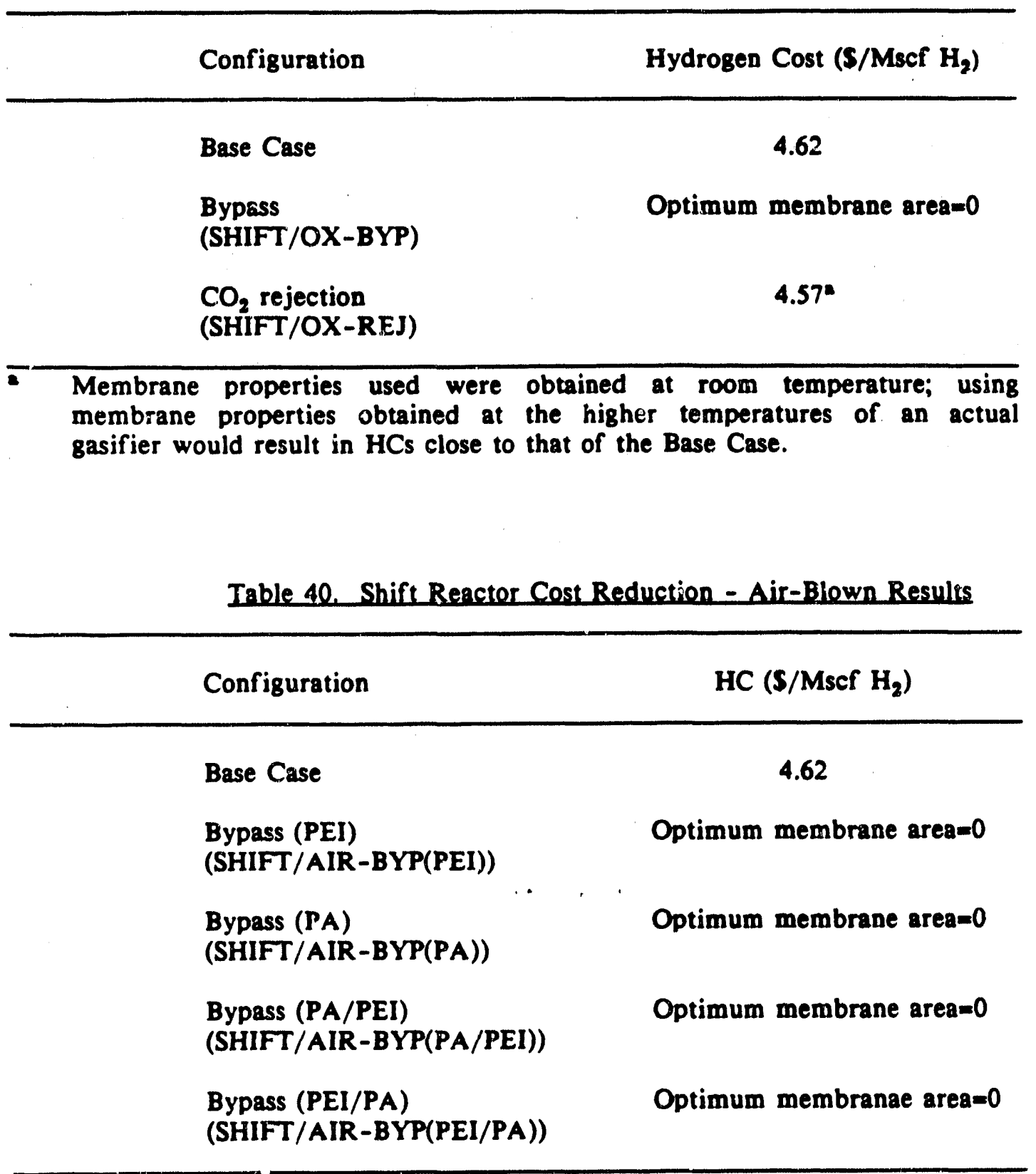

Since the polyamide copolymer membrane is selective for carbon dioxide over hydrogen in contrast to the polyetherimide membrane, the permeate stream contains relatively little hydrogen. The permeate stream, thus, can be vented which eliminates a recompression step. In this case, the total amount vented is limited by the amount of hydrogen lost due to the hydrogen recovery requirement. 
The economic evaluation shows that the SHIFT/OX-REJ configuration results in a hydrogen cost of $54.57 / \mathrm{Mscf}$ hydrogen, nearly the same as the Base Case cost of $\$ 4.62 /$ Mscf hydrogen. Taking into account that the polyamide copolymer membrane properties used in the evaluation where taken from room temperature data, and that under actual conditions the membrane will be less selective, we conclude that the SHIFT/OX-REJ configuration does not offer any savings in the production of hydrogen from coal.

\section{Air-Blown Gasification Systems}

Four configurations were evaluated for use with an air-blown gasifier. All four are variations on the bypass configuration described in the previous section, and a two-stage polyetherimide membrane cascade is added at the end to separate hydrogen from nitrogen. No configuration analogous to the carbon dioxide rejection configuration for oxygen-blown gasifiers has been evaluated here because the presence of nitrogen increases the amount of hydrogen lost in the permeate, making the system less attractive.

\section{Sinsle-Membrane Material Confieurations}

(SHIFT/AIR-BYP[PA] and SHIFT/AIR-BYP[PEI])

In the two configurations considered here, a membrane system is used to remove a portion of the carbon dioxide and hydrogen prior to the shift reactor; the permeate is then recompressed and mixed with the stream exiting the reactor. Because both carbon dioxide and hydrogen are to be removed, either the polyamide copolymer or the polyetherimide membrane can be used; high selectivity for both carbon dioxide and hydrogen over carbon monoxide, and a high permeability being the desirable membrane characteristics. Figure 47 shows the two single-membrane configurations, one using the polyetherimide membrane and the other using the polyamide copolymer. As was the case with the SHIFT/OX-BYP configuration, the economic evaluation shows that the bypass configurations increase the hydrogen cost. Consequently, the optimum systems have zero membrane area.

Double-Membrane Material Confiesurations (SHIFT/AIR-BYPIPA/PEI] and SHIFT/AIR-BYP[PEI/PA])

Since either the polyetherimide or the polyamide copolymer membrane can be used to remove carbon dioxide and hydrogen, it may be advantageous to use both types in a single system. A polyetherimide membrane can be used fin to remove primarily hydrogen but also significent amount of carbon dioxide. The polyetherimide membrane is followed by a polyamide copolymer membrane which primarily removes carbon dioxide. Conversely, the polyamide copolymer membrane can be used first followed by the polyetherimide membrane. Both of these configurations are shown in Figure 48. However, the economic analysis shows that neither of these configurations offer any economic advantage. 

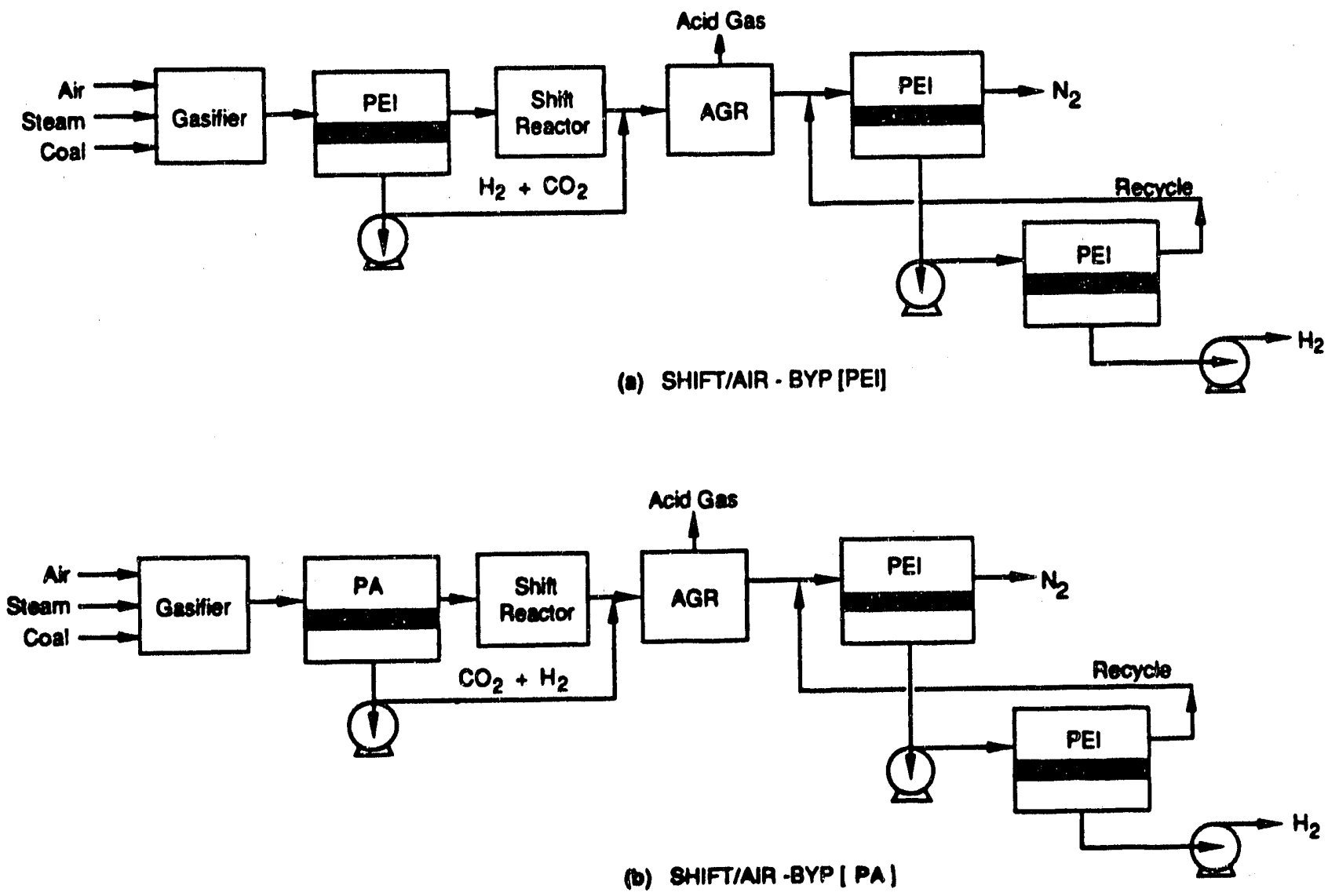

Figure 47. Single-step membrane systems for reduction of shift reactor costs with an air-blown gasifier. 

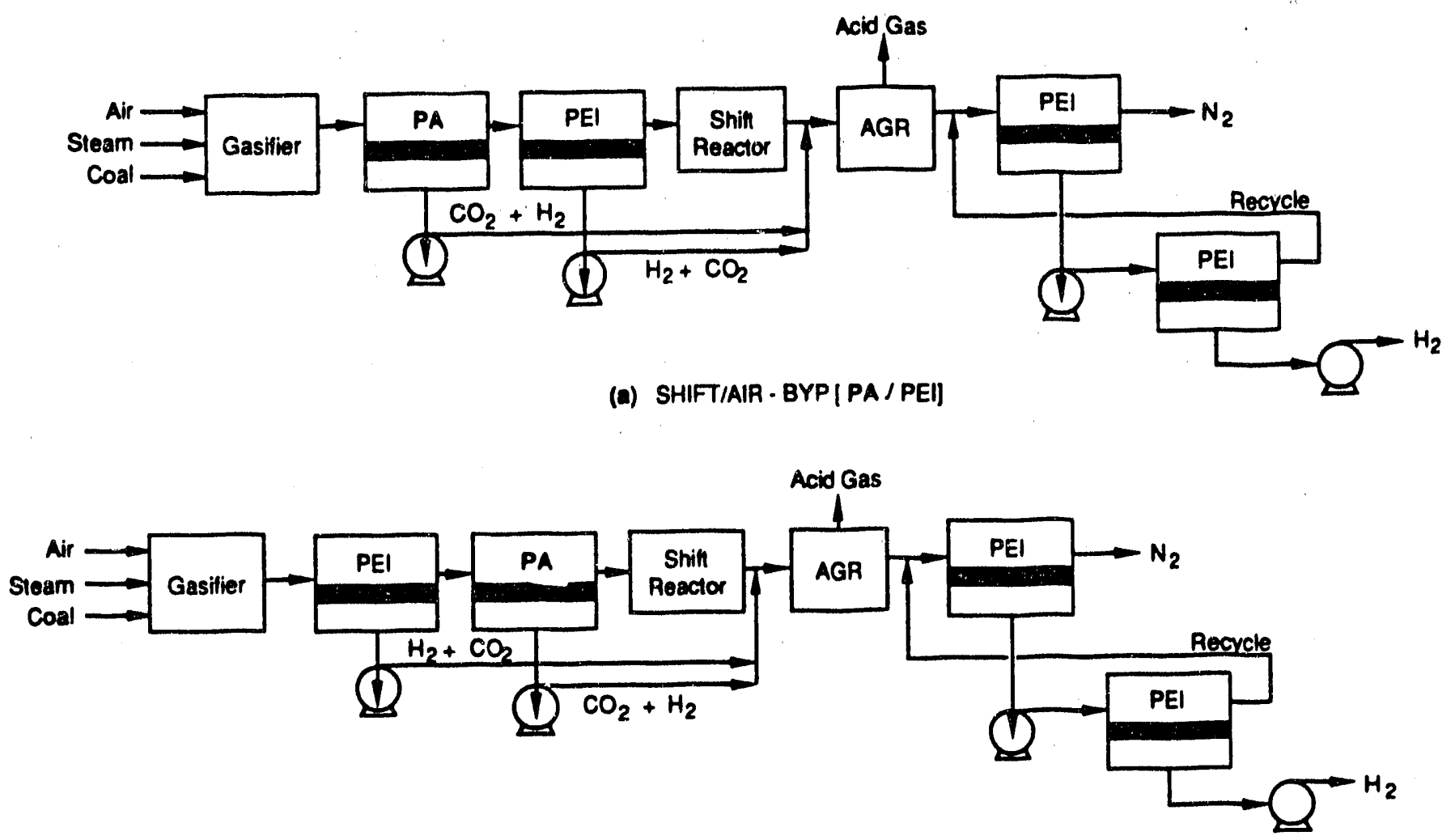

(B) SHIFT/AIR -BYP [PEV PA]

Figure 48. Membrane systems employing two membrane materials for reduction of shift reactor costs with an air-blown gasifier. 


\section{G. Summary of Economic Analysis}

Using a conventional oxygen-blown gasifier as the Base Case system, a wide variety of process designs incorporating membrane systems were evaluated for the production of $98 \%$ hydrogen. The membrane configurations were evaluated for both oxygen-blown and air-blown gasifiers.

Only one configuration resulted in lower hydrogen cost than the Base Case system. In this configuration, a polyetherimide membrane unit is used to reduce the size of the acid gas removal unit in an oxygen-blown gasification process. The corresponding hydrogen cost is $\$ 4.28 /$ Mscf hydrogen compared to $\$ 4.62$ Mscf hydrogen for the Base Case system. Reducing the size of the acid gas removal unit is an attractive option because the acid gas removal unit represents about one-third of the total "coal-to-hydrogen" costs.

Using membranes to separate hydrogen from nitrogen in an air-blown gasification process is more expensive than the Base Case system. Thus, the membrane system is more expensive than the oxygen plant needed for an oxygenblown gasifier, even though the polyetherimide membranes is an excellent hydrogen-separating membrane.

Membranes can be used to influence the equilibrium reaction in the shift reactor, thereby reducing the size of the reactor. However, for both air-blown and oxygen-blown gasifiers, the membrane system costs more than offset the reduced reactor costs. The main reason for this is that the shift reactor represents only a small cost in the total gasification system.

\section{H. Production of Low-Purity Hydrogen}

Generally speaking, membrane separation systems are not favored for production of high-purity products because the capital and operating costs increase sharply with increasing product purity. The previous sections indicate that the use of membranes can result in reduced costs for the production of $98 \%$ hydrogen. If a hydrogen product of lower purity is acceptable, there may be an even greater incentive to use membranes.

Depending on the application for which the hydrogen is produced, the nature of the impurities will be of importance. We have therefore considered two separate kind of hydrogen-producing systems: 1) systems producing hydrogen with nitrogen as the major impurity, and 2) systems producing hydrogen with carbon dioxide and hydrogen sulfide as the major impurities.

The economic evaluation shows that producing low-purity hydrogen with nitrogen as the impurity is best achieved by feeding the gasifier with oxygenenriched air and not using membranes at all. The amount of nitrogen present in the gasifier feed stream determines the amount of nitrogen present in the hydrogen product stream. The hydrogen costs range from $\$ 3.80 /$ Mscf hydrogen at $32 \%$ hydrogen purity to $\$ 4.62 /$ Mscf hydrogen at $98 \%$ hydrogen purity (Base Case). 
Producing low-purity hydrogen with carbon dioxide and hydrogen sulfide as the impurities results in significant reduction in hydrogen cost because the removal of the acid gas is a significant cost factor. As was shown previously, $98 \%$ purity hydrogen is most economically produced by using a hybrid membrane/AGR configuration to remove the carbon dioxide and hydrogen sulfide (the AGR/SS configurstion). Lower purity hydrogen is best produced by a variation on this configuration where part of the hydrogen-containing stream bypasses the AGR unit. The hydrogen cost drops as low as \$2.05/Mscf hydrogen for $53 \%$ purity hydrogen.

A more detailed discussion of the configurations for producing low-purity hydrogen follows.

\section{Production of Low-Purity Hudrogen: Nitrogen Impurity}

Four different coal gasification systems have been considered for the production of low-purity hydrogen.

1. An air-blown gasifier using a polyetherimide membrane separation system to produce hydrogen of a certain desired purity, see Figure 49.

2. An oxygen-enriched air-blown gasifier (38.2\% oxygen) using a polyetherimide membrane separation system to produce hydrogen of a certain desired purity.

3. An oxygen-enriched air-blown gasifier which is fed with such an axygen concentration that hyourogen of a certain desired purity is produced without using a membrane separation system.

The hydrogen cost associated with each system has been calculated and the results are given in Figure 50. In optimizing the membrane system, both the cascade and the series configuration have been considered as well as the partial feed bypass option discussed previously.

Figure 50 clearly shows that the most economic way to produce low-purity hydrogen with nitrogen as the impurity is to feed the gasifier with oxygenenriched air of the proper composition and to avoid the use of a membrane separation system. Thus, it is cheaper to produce oxygen-enriched air (or pure oxygen) to feed the gasifier than to separate the hydrogen from nitrogen with membranes in a final purification step.

\section{Production of Low-Purity Hydrosen: Carbon Dioxide and Hydrogen Sulfide Impurities}

Two process configurations have been considered for the production of lowpurity hydrogen with acid gases as the impurities. Both configurations are chown in Figure 51 and both are based on the AGK/OX-SS configuration (see Figure 41) in which a hybrid membrane/AGR system is used to remove carbon dioxide and hydrogen sulfide. The AGR/OX-SS configuration was shown to be the most economic method for producing $98 \%$ purity hydrogen. In order to produce lower purity hydrogen, the membrane system and/or the AGR unit can be partially bypassed as shown in Figures $51 \mathrm{a}$ and $b$. 


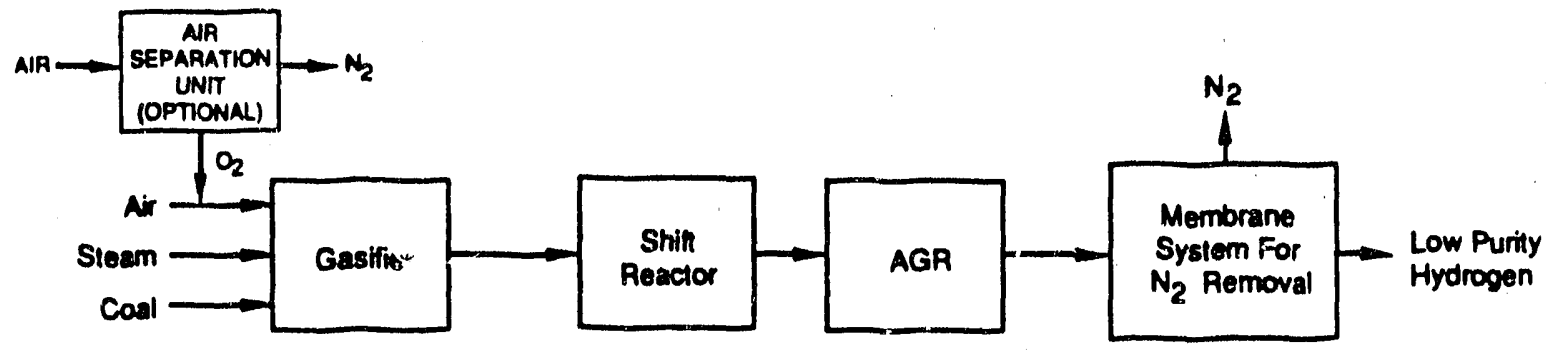

Figure 49. Air-blown gasification system for production of low-purity hydrogen with nitrogen impurities. 


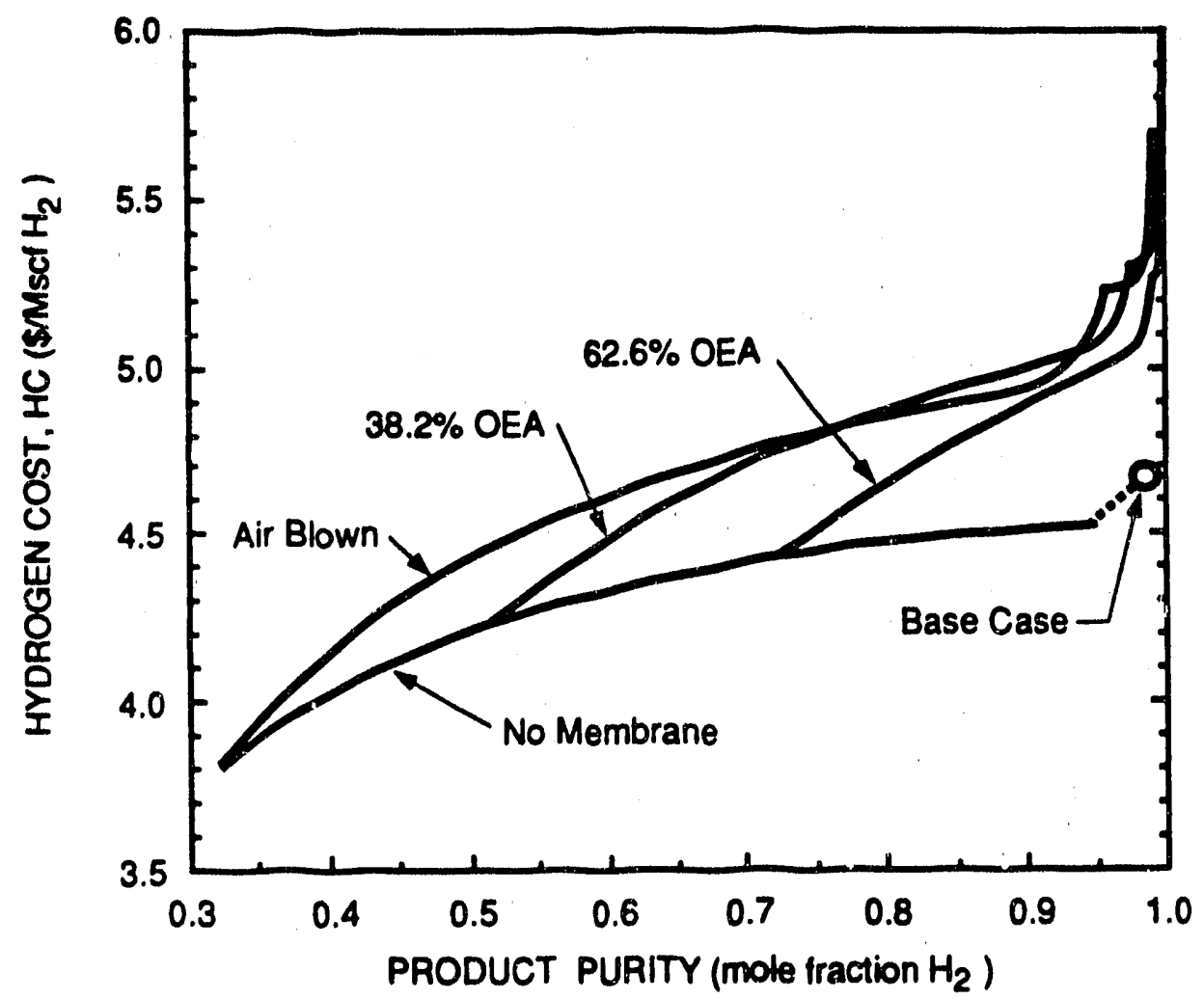

Figure 50. Hydrogen costs for various product purities resulting from membrane and non-membrane purification systems. Airblown and oxygen-enriched air (OEA) blown systems are shown. 


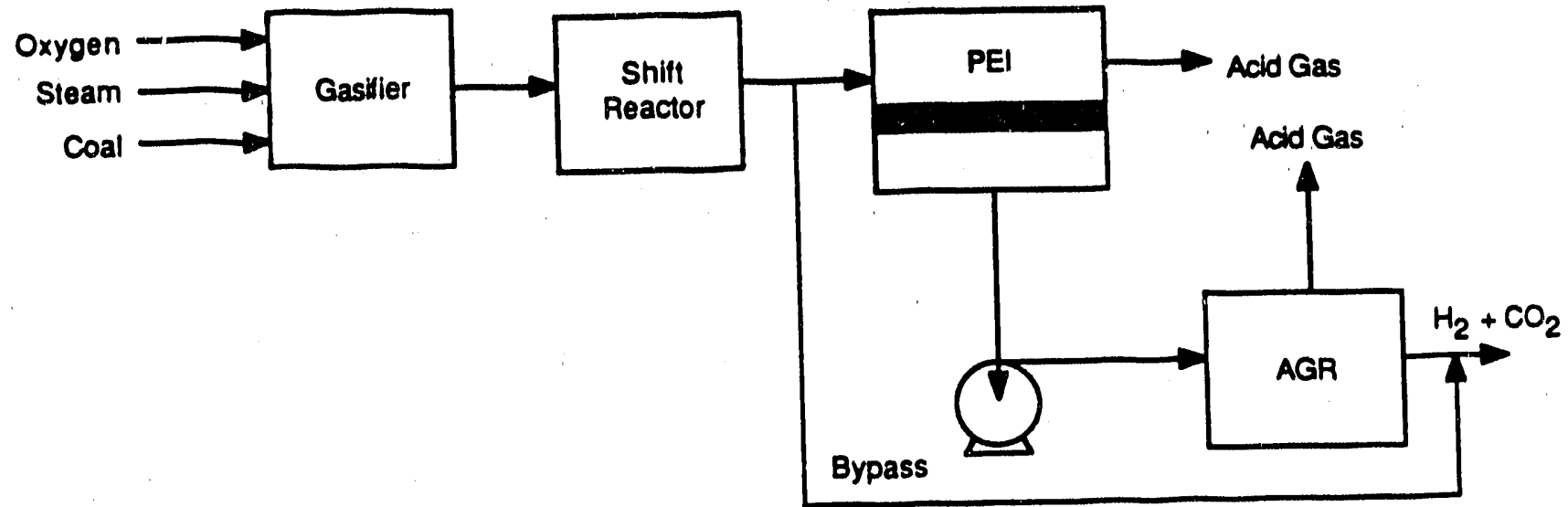

(a) Total Bypass

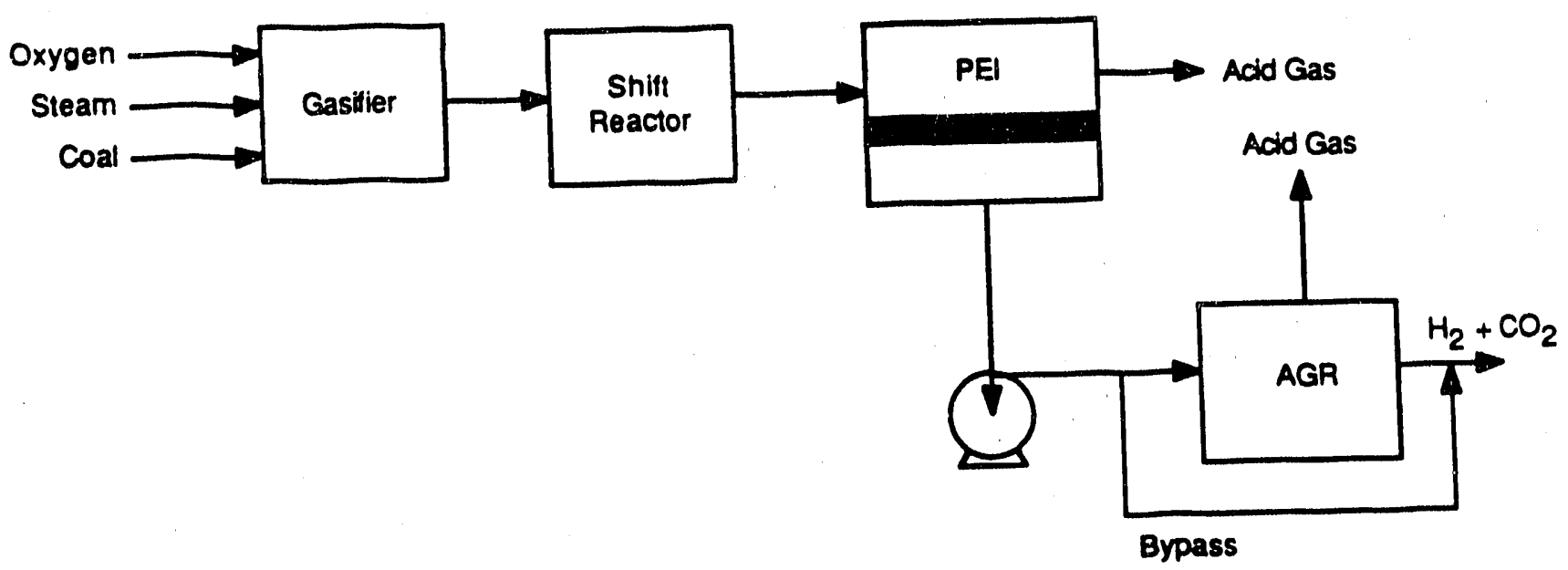

(b) AGR Bypass

Figure 51. Membrane systems for producing low-purity hydrogen with carbon dioxide impurities. 
The total bypass configuration (Figure $5 / \mathrm{a}$ ) produces hydrogen ranging in purity from 53-98\% hydrogen. The hydrogen cost is a strong function of purity and varies from \$2.05/Mscf hydrogen to \$4.62/Mscf hydrogen (Base Case), as shown in Figure 52. The AGR bypass configuration (Figure 51b) is somewhat cheaper than the total bypass configuration, but only produces hydrogen in the 70-98\% purity range. In case of $70 \%$ purity hydrogen, the AGR unit is completely eliminated and only the membrane system removes acid gases from the hydrogen product stream. Hydrogen in the 53-70\% purity range is thus most economically produced by a membrane bypass configuration and not by the total bypass configuration. This is illustrated in Figure 52.

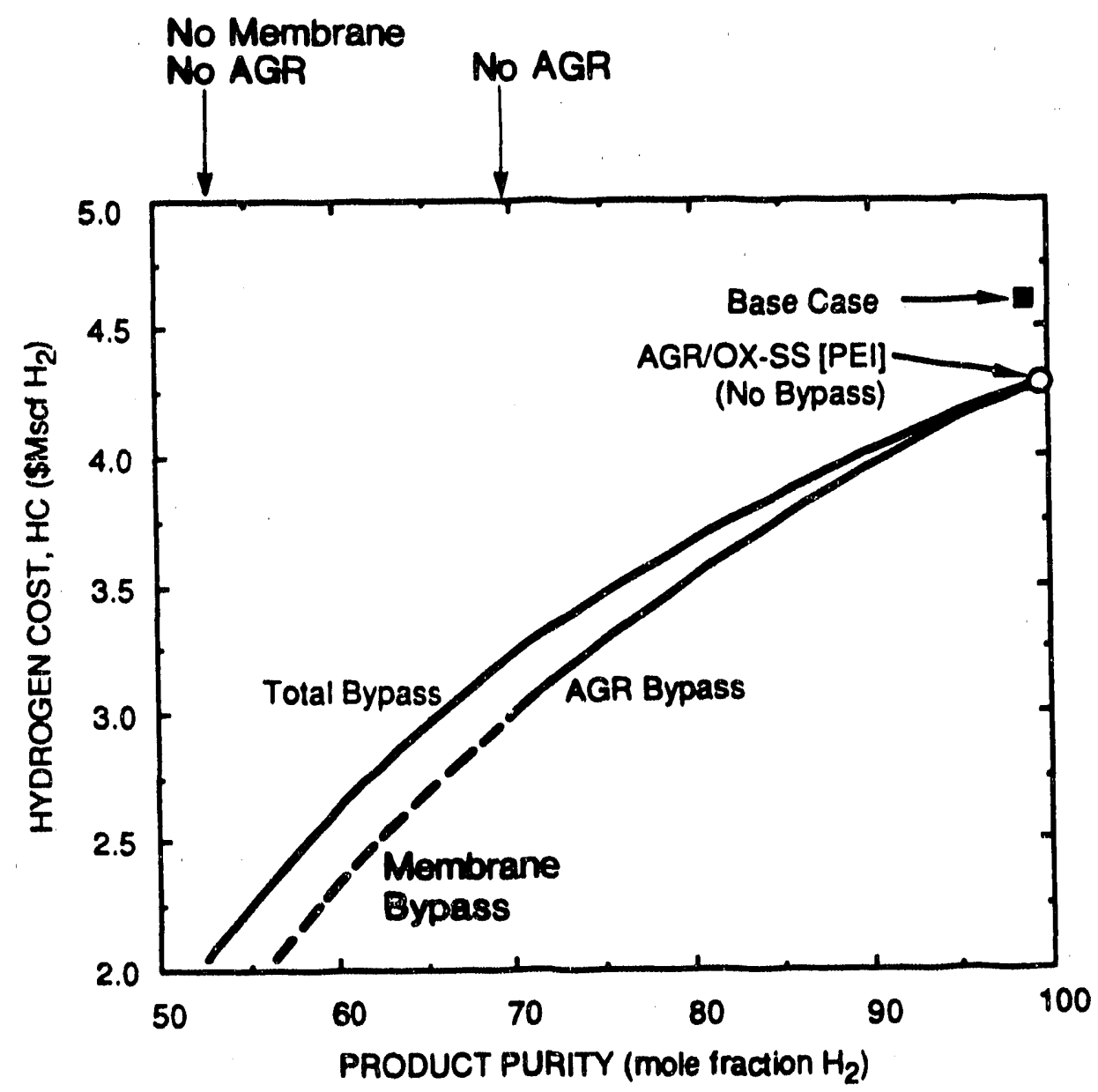

Figure 52. Hydrogen costs as a function of hydrogen purity. Impurities are carbon dioxide and hydrogen sulfide. 


\section{ALTERNATIVE SEPARATION TECHNIQUES}

A. Introduction

In the previous section, various membrane separation configurations have were evaluated for the production of hydrogen from synthesis gas. Membrane systems were used to separate hydrogen from nitrogen and/or to separate hydrogen from carbon dioxide and hydrogen sulfide. The initial objective of this section was to perform a preliminary evaluation of two alternative separation techniques: 1) cryogenic distillation and 2) pressure-swing adsorption. A short description of the two processes follows.

\section{Cryosenic Distillation}

In distillation processes, the liquid-to-vapor phase transition is used to separate mixtures. For gas mixtures, this means that the separation has to be performed at low temperatures and the process is called cryogenic distillation. Cryogenic distillation is an established unit operation for the production of nitrogen and oxygen from air. However, to our knowledge, no industrial experience is available on the distillative separation of hydrogen from nitrogen or of hydrogen from carbon dioxide and hydrogen sulfide. The latter separation is very complicated because carbon dioxide does not liquify, but will freeze onto the heat exchangers. The evaluation of the feasibility of such a distillation process is beyond the scope of this program, and therefore, we did not consider cryogenic distillation as an alternative separation technique.

\section{Pressure-Swing Adsorotion}

Separation by pressure-swing-adsorption (PSA) is based on the selective adsorption of various components on an adsorbent material. A gas mixture under pressure is contacted with the adsorbent and one or more components of the gas mixture are adsorbed. After the adsorbent is surrounded, the remaining gases are removed and the adsorbent is subsequently regenerated by reducing the pressure.

Pressure-swing adsorption is a well-established technique for gas separation and, among other applications, is used to separate hydrogen from carbon dioxide in the steam reforming of methane. We will, therefore, consider pressure-swing adsorption for the separation of hydrogen from carbon dioxide and hydrogen sulfide. No information has been found on the separation of hydrogen from nitrogen by pressure-swing adsorption and this separation will not be evaluated. 


\section{B. Description of Pressure-Swing Adsorption}

As the name indicates, pressure-swing adsorption is a cyclic, non-steadystate process and, therefore, a number of adsorption beds are needed to allow continuous separation of a gas mixture. The feed gas enters the adsorbent bed at high pressure, carbon dioxide and hydrogen sulfide are adsorbed, and high-purity hydrogen exit the bed until the maximum capacity of the bed has been reached. At this point, feed and product flows are stopped and the bed is regenerated by lowering the bed pressure and exhausting the desorbed carbon dioxide and hydrogen sulfide to the atmosphere. This two-step process is a simplified version of the commercial PSA process. Because the carbon dioxide and hydrogen sulfide exhaust also contains hydrogen (due to co-adsorption of hydrogen, and to hydrogen contained in the bed void space), and to improve energy efficiencies during pressure reduction in the regeneration phase, five-step process is typically used..$^{26-28}$ These steps are described below and illustrated in Figure 53.

1. Adsorption. High-pressure feed gas enters the bed, while purified hydrogen product (still pressurized) exits the bed.

2. Co-Current Depressurization. Feed and product flows are stopped and pressure is reduced allowing void gas to exit the bed. Because the void gas contains mostly hydrogen, this gas can be used to repressurize a regenerated bed, thereby increasing hydrogen recovery. The greater the number of beds in a system, the greater the amount of void gas that can be used for recompression, and hydrogen recovery is increased.

3. Counter-Current Blowdown. The bed pressure is reduced to its final value. Blowdown gas exits through the feed end of the bed and contains most of the impurities adsorbed by the bed. Blowdown gas is vented to the atmosphere.

4. Purge. Bed is fully regenerated by sweeping counter-currently with gas leaving another bed undergoing the last stage of co-current depressurization. The gas exiting the bed during the purge stream can be used as fuel.

5. Repressurization. The regenerated bed is initially repressurized by equalization with the vessel providing the purge. The bed is further pressurized by equalization with the bed undergoing the first phase of co-current depressurization. The bed is fully pressurized with product hydrogen.

Pressure-swing adsorption systems are currently used for separating carbon dioxide and hydrogen. The gas to be separated in a coal gasification process contains hydrogen sulfide as well. Hydrogen sulfide can reduce the efficiency of pressure-swing adsorption because it tends to interact strongly with the sorbent and is difficult to desorb. 


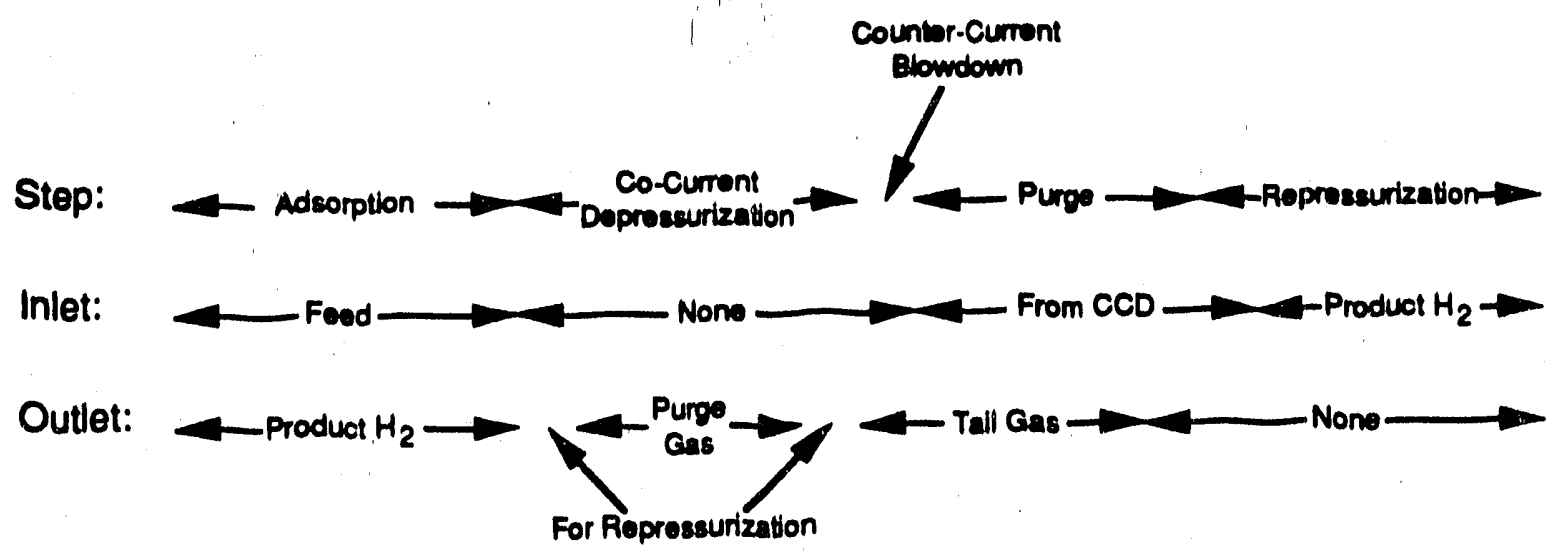

BED A

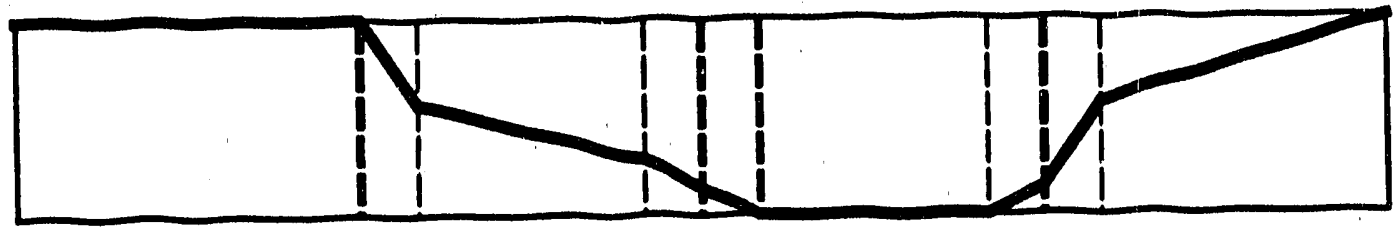

$\mid$

BED B

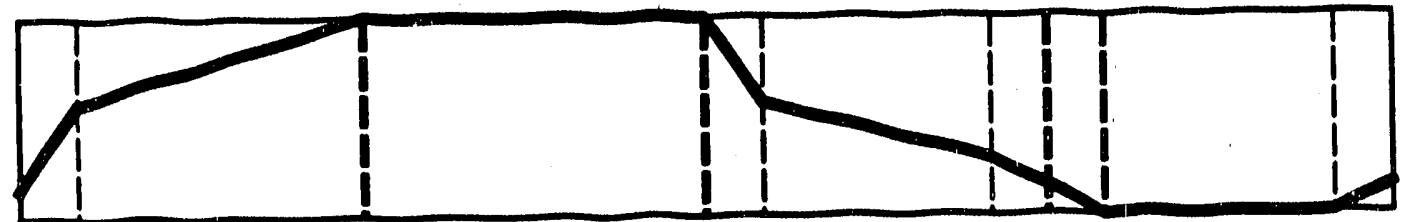

BED C

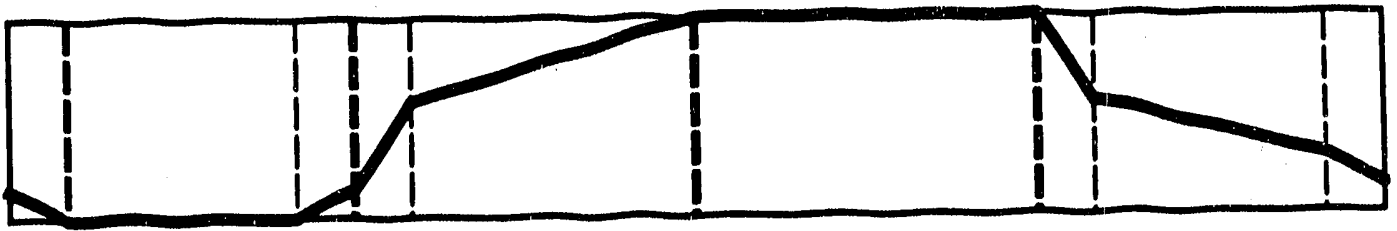

BED D

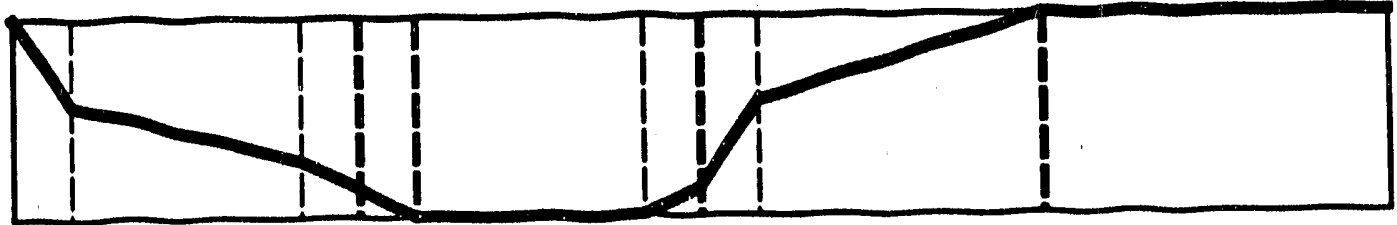

TIME

Figure 53. Pressure history for a four-bed PSA system. 


\section{Economic Evaluation of Pressure-Swing Adsorption}

The PSA system configuration used in the economic calculations is shown in Figure 54. The gases produced by an oxygen-blown gasifier are passed to the shift reactor to convert the remaining carbon monoxide into hydrogen. The gas stream leaving the shift reactor contains mainly hydrogen, carbon dioxide and hydrogen sulfide, and instead of a conventional ethanolamine acid gas removal unit, a pressure-swing adsorption system is used to purify the hydrogen.

Two identical PSA manufacturers were contacted to obtain cost estimates for a PSA system designed to treat the gas leaving the shift reactor. One manufacturer did not provide an estimate because the amount of hydrogen sulfide in the feed gas was judged to be too high. The other manufacturer did provide rough estimates for capital and operating costs for a PSA system capable of producing $99 \%$ purity hydrogen at $82 \%$ hydrogen recovery.

Based on the capital and operating costs for the PSA system, the hydrogen cost was calculated using the same procedure used in Section IX. The fact that the PSA system has a lower hydrogen recovery than the acid gas removal unit or the membrane separation unit, is at least partially accounted for through the feed value adjustment which is part of the calculation procedure. The hydrogen cost calculated for the process configuration shown in Figure 54 is $\$ 2.66 /$ Mscf hydrogen, which is substantially lower than both the Base Case costs (\$4.62/Mscf hydrogen) and the cost calculated for the hybrid membrane/AGR configuration (\$4.28/Mscf hydrogen). The large difference is mainly due to the very low capital cost estimate provided for PSA compared to the ethanolamine acid gas removal unit and the membrane system.

We are hesitant to base any economic conclusions on a single manufacturer's estimate for a hypothetical installation. In addition, interviews with industry experts led us to believe that the economic difference between PSA and ethanolamine absorption is not as great as calculated in this report. Although PSA seems to hold an economic edge in the most closely related commercial application (hydrogen production by steam reforming of natural gas), there are cases where absorption has comparable or superior economics. Characteristics which make the process economics of a specific application favorable for adsorption include large capacities ( $>20$ million scfd hydrogen) and lower product purity requirements $(>99 \%)$. Both these characteristics apply to the coal gasification application being considered in this report.

Therefore, more reliable cost estimates have to be developed for the use of PSA in the coal gasification process before it can be considered an economically competitive alternative to ethanolamine absorption and processes incorporating membrane gas separation. 


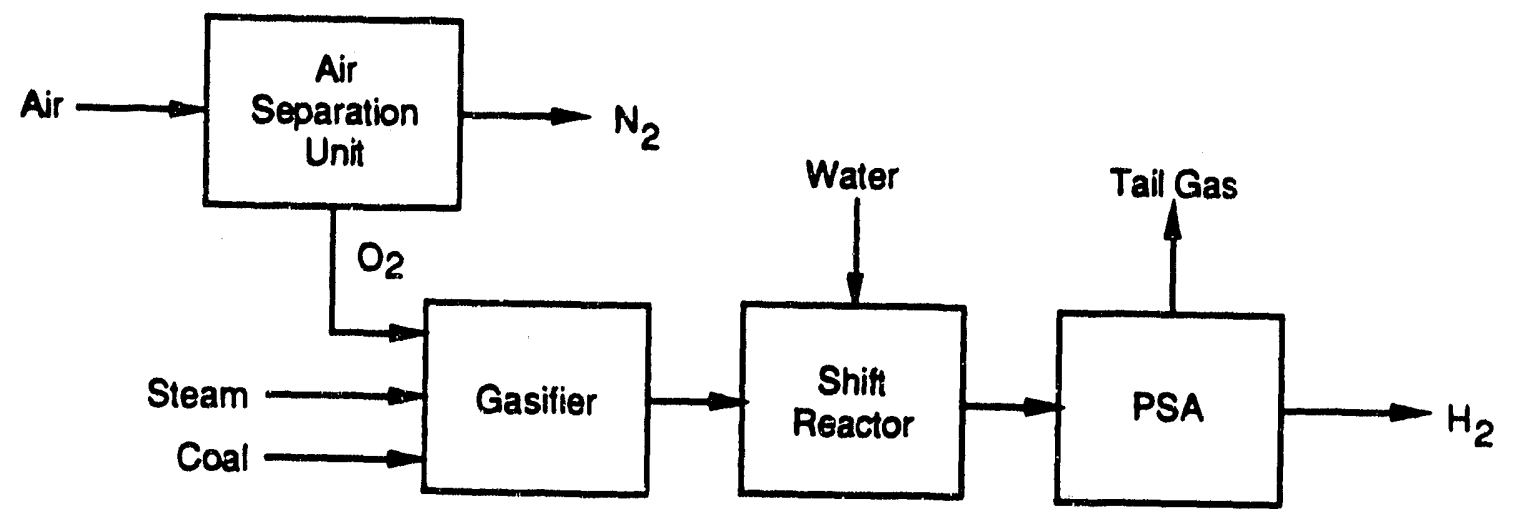

Figure 54. Pressure-swing adsorption purification system. 


\section{REFERENCES}

1. T.R. Roszkowski and N.W. Snyder, "Present and Emerging Hydrogen Production Technology," in Hydrogen Energy Progress Vl. Vol. 1. T.N. Veziroglu (Ed.), Pergamon Press, New York (1982).

2. R.A. Meyers, Handbook of Synfuels Technology. McGraw-Hill, New York (i980).

3. H.D. Schilling, B. Bonn, and U. Krauss, Coal Gasification: Existine Process and New Developments., Graham and Trotman Limited, London, England (1979).

4. E.C. Mangold et al., Coal Liauification and Gasification Technolosies, Ann Arbor Science Publishers, Michigan (1982).

5. The Synfuels Manual: A Guide For Concerned Citizens, J. Lash and L. King (Eds.), Natural Resources Defense Council, New York (1983).

6. Coal Gasification Environmental Baseline Studies, a report (\#AP-22215) prepared by Texaco, Inc. for Electric Power Research Institute (1982).

7. R.E. Billings, Hydrosen from Coal: A Cost Estimation Guidebook, Pennwell Books, Tulsa, Oklahoma (1983).

8. D. Fleming, "Gasification of Itnermediate Streams in Coal Gasification," in Papers Clean Fuels from Coal Symposium II, Institute of Gas Technology (1975).

9. G.J. Van Amerongen, "Influence of Structure of Elastomers on their Permeability to Gases," L.Appl. Polv. Sci. 5, 307 (1950).

10. R.M. Barrer, "Permeability in Relation to Viscosity and Structure of Rubber," Trans. Far. Soc. 38, 322 (1942).

11. P. Meares, "The Diffusion of Gases through Polyvinyl Acetate," I Am. Chem. Soc. 76, (1954).

12. V. Stannett, M. Szwarc, R.L. Bhargave, J.A. Meyer, A.W. Myers, and C.E. Rogers, "Permenbility of Plastic Films and Coated Paper to Gases and Vapors," Tappi Monoeraph Series. No._23 (1962).

13. V.T. Stannett, W.J. Koros, D.R. Paul, H.K. Lonsdale and R.W. Baker, "Recent Advances in Membrane Science and Technology," Adv. Polym. Sci. 32, 71 (1979).

14. S.L. Matson, J. Lopez and J.A. Quinn, "Separation of Gases with Synthetic Membranes," Chem. Ene._Sci.38, 503 (1983).

15. S.A. Stern and H.L. Frisch, The Selective Permeation of Gases Through Polymers," Ann. Rev, Mater. Sci. 11, 523 (1981). 
16. J.M.S. Henis, M.K. Tripodi, "Multicomponent Membranes for Gas Separation," U.S. Patent 4,230,463 (1980).

17. J. van't Hoff, "Wet Spinning of Asymmetric Hollow Fibre Membranes for Gas Separation," Doctoral dissertation, Enschede, The Netherlands (1988).

18. Peinemann, K.-V. and I. Pinnau, U.S. Patent 4,746,333 (1988).

19. R.J. Peterson, J.E. Cadotte, E.J. Conway, R.H. Forester, and M.J. Steuck, "Research and Development on Membrane Processes for Removal of Acid Gases During Coal Gasification," Final report prepared for Energy Research and Development Administration under Contract No. E(49-18)-2008.

20. K.-V. Peinemann, "Method for Producing an Integral Asymmetric Membrane and the Resultant Membrane," U.S. Patent 4,673,418 (1987).

21. J.G. Wijmans, R.W. Baker, J. Louie and P.H. Pfromm, "Purification of Hydrogen Gas Streams," Final report prepared for the department of the Army under Contract DAAK 70-85-C-0083.

22. C.Y. Pan and H.W. Habgood, "An Analysis of the Single-Stage Gaseous Permeation Process," Ind. Ene. Chem. Fund. 134, 323-31 (1974).

23. K.V. Peinemann, J.M. Mohr and R.W. Baker, "The Separation of Organic Vapors from Air," AlChE Symoosium Series No.250, Vol. 82, 19 (1986).

24. D.M. Ruthven, "The Activity of Commercial Water Gas Shift Catalysts," Canadian J. of Chem. Ens. 47, 327-331 (1969).

25. W.C. Kratz, D.L. Rarig and J.M. Pietrantonio, "Hydrogen and Carbon Dioxide Coproduction for SMR Offgas by Pressure Swing Adsorption," AIChE National Meeting, New York, November (1987).

26. G.Q. Miller and J. Stoecker, "Selection of a Hydrogen Separation Process," 1989 NPRA Annual Meetins, San Francisco, March (1989).

27. A.M. Watson, "Use Pressure Swing Adsorption for Lowest Cost Hydrogen," Hydrocarbon Processine, 91-95, March (1983).

28. R.T. Yang, Gas Separation by Adsorption Processes, Butterworths, Boston (1987). 

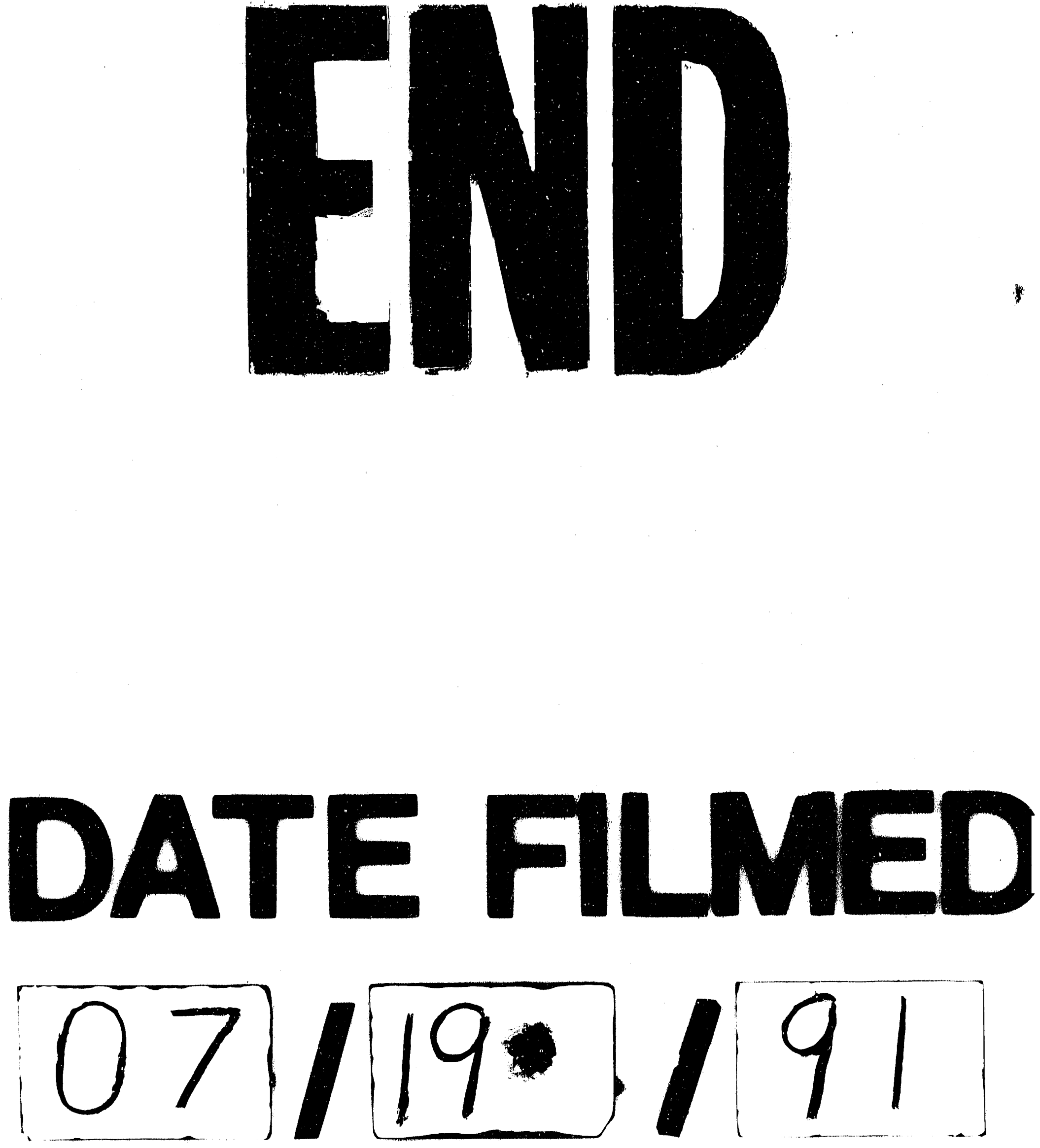
